Portland State University

PDXScholar

$1-1-1983$

\title{
The placement information base: its utility and meaning for nursing home placement decisions
}

Darlene Schroedl McKenzie

Portland State University

Follow this and additional works at: https://pdxscholar.library.pdx.edu/open_access_etds Let us know how access to this document benefits you.

\section{Recommended Citation}

McKenzie, Darlene Schroedl, "The placement information base: its utility and meaning for nursing home placement decisions" (1983). Dissertations and Theses. Paper 412.

https://doi.org/10.15760/etd.412

This Dissertation is brought to you for free and open access. It has been accepted for inclusion in Dissertations and Theses by an authorized administrator of PDXScholar. Please contact us if we can make this document more accessible: pdxscholar@pdx.edu. 
THE PLACEMENT INFORMATION BASE: ITS UTILITY AND MEANING FOR NURSING HOME PLACEMENT DECISIONS

by

DARLENE SCHROEDL MCKENZIE

A dissertation submitted in partial fulfillment of the requirements for the degree of

DOCTOR OF PHILOSOPHY

in

URBAN STUDIES

Portland State University

(C) 1983 Darlene SchroedI McKenzie 
TO THE OFFICE OF GRADUATE STUDIES AND RESEARCH

The members of the Committee approve the dissertation of Darlene Schroedl McKenzie presented July 13, 1983.

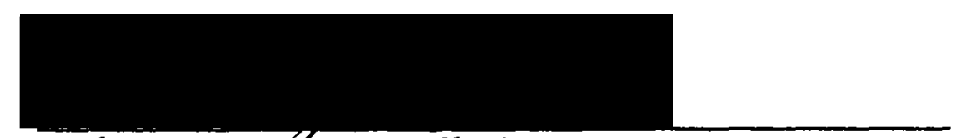
Barbara J. Sffewart, Chairman

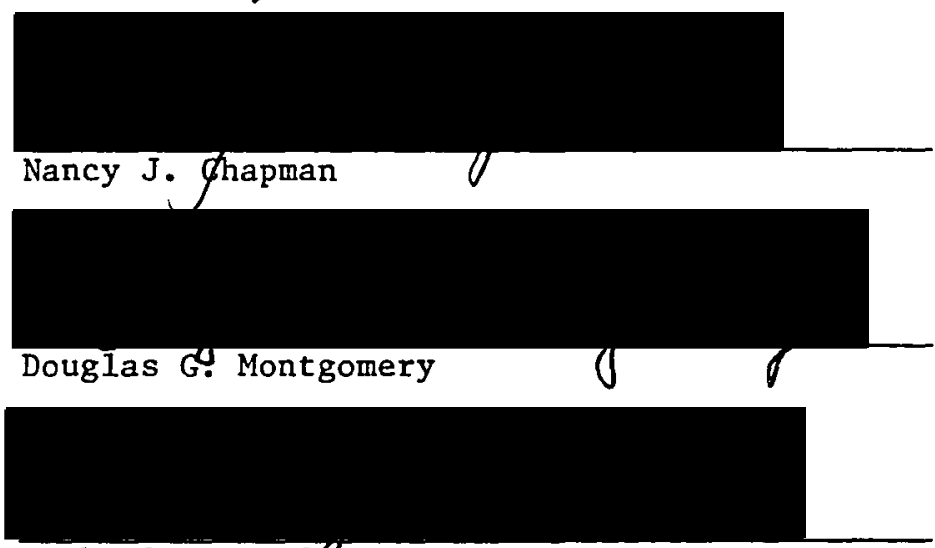

Michael G. Sas16w

APPROVED.

Kenneth J. Dueker, Assistant Dean, School of Urban and Public Affairs

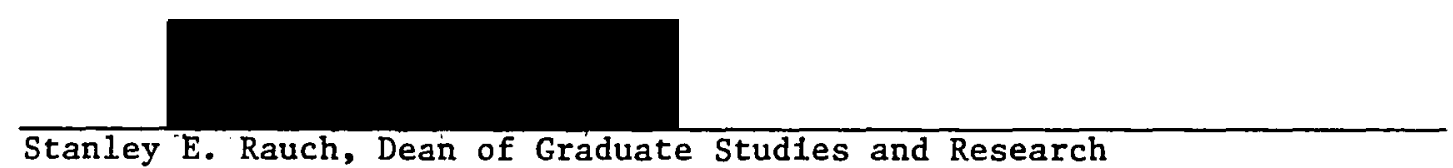

Stanley E. Rauch, Dean of Graduate Studies and Research 
AN ABSTRACT OF THE DISSERTATION of Darlene Schroed1 McKenzie for the Doctor of Philosophy in Urban Studies presented July 13, 1983.

Title: The Placement Information Base: Its Utility and Meaning for Nursing Home Placement Decisions

APPROVED BY MEMBERS OF THE DISSERTATION COMMITTEE:

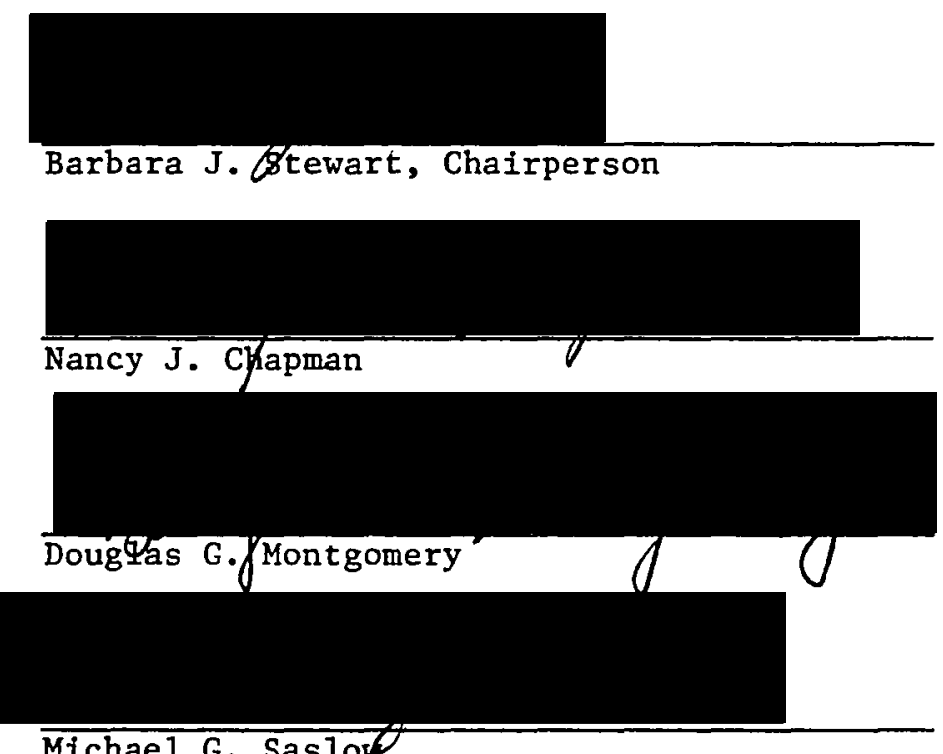

Michael G. Saslow

The State of Oregon is using the Placement Information Base, PIB, as part of an assessment process to determine the type of placement needed by Medicaid clients. While used for functional assessment, PIB has not been empirically studied for its use as a screening or predictive instrument to differentiate between the need for nursing home care and community care.

This dissertation addresses the question of whether PIB is suitable for use as a screening instrument for nursing home placement 
decisions. Both PIB's measurement and predictive capabilities are examined. Using secondary PIB data on 2287 elderly Department of Human Resources clients, four highly reliable scales were developed. Alpha coefficients range from .75 to .90 . These scales were found to measure the theoretically important dimensions of Activities of Daily Living (ADL), Instrumental Activitles of Daily Living (IADL), Social functioning and Mental functioning.

Ten discriminant function equations, using PIB items and scales as predictors, were developed and cross-validated to compare those elderly currently residing in the comminity and those currently residing in rursing homes $(n=1772)$. For each of the functions the predictive accuracy was at least 79 percent with the derivation sample and even higher with the cross-validation sample. Functions containing only single items predicted as well or better than those containing scales.

A comparison between the discriminant function equations and three a priori decision rules accompanying the PIB indicate that each of the discriminant function equations is predictively equivalent to one of the a priori decision rules and superior to the other two. The findings of this dissertation suggest that any one of the discriminant functions or the very high probability a priort decision rule could be used as an equitable and economically feasible screening instrument for nursing home placement. The choice of a particular function or the decision rule should be guided by practical and theoretical considerations. Policy Implications and suggestions for future research are discussed. 


\section{ACKNOWLEDGMENTS}

I wish to express my appreciation to all of the people who helped and encouraged my doctoral studies at Portland State University. In particular I'd like to thank my dissertation comittee chairman, Barbara J. Stewart, and comittee members Nancy J. Chapman, Douglas G. Montgomery, and Michael G. Saslow.

The data for this dissertation were made available by the State of Oregon Department of Human Resources Senior Services Division through the coordination of Daisy Reed. 
TABLE OF CONTENTS

Page

ACKNOWLEDGMENTS . . . . . . . . . . . . . . . . ili

LIST OF TABLES. ................... vi11

LIST OF FIGURES . . . . . . . . . . . . . . . . . $\mathrm{x}$

CHAPTER

I INTRODUCTION. ................ 1

Pre-Admission Screening. . . . . . . . . 3

Purpose of This Dissertation . . . . . . . 5

Placement Information Base........... 8

Benefits of This Dissertation. . . . . . . 9

Findings of the Proposed Dissertation. . . . . 12

II REVIEW OF LITERATURE. . . . . . . . . . . 13

Desirable Psychometric Characteristics of

Instruments Used for Nursing Home Placement . . . 13

Reliability

Validity

Quantification of Data

Summary

Psychometric Characteristics of a Selected Number of Instruments Used for Nursing

Home Placement............ 23

Instruments Commonly Associated with Geriatric Assessment

Instruments Developed Specifically for

Level of Care Decisions

Instruments Used by Other States

Granted a Federal Waiver 
Psychometric Characteristics of the Placement

Information Base (PIB). . . . . . . . . . .

Design for a Geriatric Population

Measure Along a Functional Continuum

Measurement of Physical, Mental and Social Content

Acceptable Inter-Rater Reliability

Criterion Validity Related to Nursing Home Placement

Quantification of Data

Summary

Selected Factors Related to Nursing

Home Placement. . . . . . . . . . . .

Age

Sex

Social and Economic Characteristics

Functional Limitations

Availability of Nursing Home Beds

Summary

Conceptual Framework . . . . . . . . . . .

Content Validity

Construct Validity

Criterion-Related Validity

Reliability

Summary

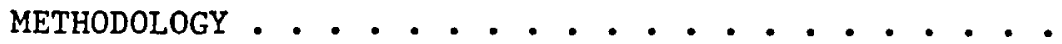

Subjects

Study Instrument . . . . . . . . . . . .

Procedure. . . . . . . . . . . . . . .

Design and Analysis for the First

Research Question ...............

Research Question 1

Content Validity

Internal-Consistency Reliability

Construct Validity 
Destgn and Analysis for the Second

Research Question...........

Research Question 2

Design and Analysis for the Third

Research Question ............

IV FINDINGS AND DISCUSSION OF FINDINGS . . . . . . . 104

Research Question I. ........... 104

Content Validity

Internal Consistency Reliability

Research Question Two. ............

A Priori Decision Rule

Mathematically Derived Decision Rule

Research Question Three.............

Findings on Research Question One

Expected Characteristics Based on the Literature

Functional Similarity Across Location

Summary of Important Results . . . . . . . .

Policy Recommendations . . . . . . . . . .

The Desirability of Using PIB as a Nursing Home Screening Instrument

Which Combination of PIB Items and Scales Should be Used for the Screening Instrument?

Natural Support and Nursing Home Placement

Suggestions for Future Research. . . . . . . .

Pilot Study

Measurement Concerns

Post Script. . . . . . . . . . . . . 
BIBLIOGRAPHY. . . . . . . . . . . . . . 166 APPENDICES

A INTERVIEW SCHEDULE AND INSTRUMENTS CITED IN THE LITERATURE . . . . . . . . . . . . 178

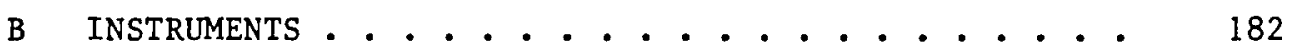

C NORMATIVE DATA ON PIB ITEMS AND SCALES. . . . . . 192 


\section{LIST OF TABLES}

TABLE

$\underline{\text { Page }}$

I Psychometric Characteristics of Instruments

Commonly Associated with Geriatric Assessment . . . . . 34

II Psychometric Characteristics of Instruments

Developed Specifically for Level of Care Decisions. . . 44

III Psychometric Characteristics of Instruments Used

by Other States Granted a Federal Waiver. . . . . . . 49

IV Selected Demographic Characteristics of the

Total Sample of Elderly Clients . . . . . . . . 89

$V$ Descriptive Statistics for Scores on the

Twenty-five PIB Items ... . . . . . . 106

VI Item Correlations with the Seven Dimensions

Listed on the Current PIB Instrument. . . . . . . . 109

VII Item Correlations Within the Seven A priori

Dimensions Identified by the Researcher........ . 111

VIII Rotated Factor Loadings of the PIB Items for

the Five Factors Extracted. . . . . . . . . . 113

IX Item Correlations Within the Five Factors

Extracted by Varimax Rotation . . . . . . . . . . 114

X Item Analysis for PIB Scales. . . . . . . . 116

XI Distribution of Scores on Scales. . . . . . . . 120

XII Internal-Consistency Reliability of PIB Scales. . . . 121

XIII Inter-Correlation Matrix of Single-Item and

Multi-Item Scales.............. 123

XIV Correlation Coefficients of Items Within

Scales and Across Scales. . . . . . . . . . . 124

XV A Comparison of Elderly Community Clients and

Elderly Nursing Home Clients on Selected

Demographic Characteristics . . . . . . . . 128 
XVI Percentage of Accurately Predicted Placement for Communtty and Nursing Home Clients Using Three A priori Decision Rules, Three Modified A priori Decision Rules, and Combinations of the Decision Rules . . . . . . . . . . . . . 133

XVII Summary of the Significance of Predictors Entered into Each of the Ten Discriminant Functions . . . 135

XVIII Percent of Accurately Predicted Placement for Derivation and Cross-Validation Groups by Function and Type of Placement. . . . . . . . . . 139

XIX A Breakdown of the Percent of Accurately Predicted Placement of the Cross-Validation Group by Age, by Sex, and by Source of Evaluation . . . . . . 142

$\mathrm{XX} \quad$ Percent of Elderly Clients Needing Post PIB Screening Assessment by Type of Placement, by Level of Placement Accuracy, and by Function. . . . . 160

XXI Relationship Between Levels of Functioning and Probability that Nursing Home Placement is Necessary . . . . . . . . . . . . 185 


\section{LIST OF FIGURES}

1 Variables selected from boxes included on the State of Oregon Department of Human Resources

Service Activity Report, DHR-280, revised in $2 / 80$. . . . 94

2 Relative Frequency Polygons of Scores on PIB

Scales for Total Elderly Population . . . . . . . . 118

3 Relative Frequency Polygons Illustratirg Discriminant Function Scores for Elderly Community and Nursing Home Clients. . . . . . . . . . . . . . 140

A List of the Full Title and Abbreviations of Instruments Referred to in Table I. . . . . . . . . 179

5 A List of the Abbreviations and Full Titles of Instruments Referred to in Table II . . . . . . . . 180

6 Open-Ended Interview Schedule Used to Obtain Information on Pre-Admission Screening Instruments Used by States with a Federal Medicaid Waiver . . . . . 181

That Portion of the DHR-280 Service Activity Report Which was Used to Record Secondary Data Employed in This Study. . . . . . . . . . . 183

8 Selected Service Activity Codes for DHR-280 Service Activity Report . . . . . . . . . . . . . 184

9 An Explanation of the Key to the Levels of Functioning Which Appears in Table XXI. . . . . . . . 187

The Placement Information Base. . . . . . . . . . 188

11 Relative Frequency Polygons Comparing PIB Item Scores of Elderly Nursing Home Clients with PIB Item Scores of Elderly Community Clients. . . . . . . . 193

12 Relative Frequency Polygons Comparing PIB Scale Scores of Elderly Nursing Home Clients with PIB Scale Scores of Elderly Community Clients . . . . . 200 
13 Ten Discriminant Function Equations Derfved from

PIB Items and Scales. . . . . . . . . . . 202

14 Relative Frequency Polygons, Illustrating the Relationship of Two Sets of Thresholds to

Levels of Predictive Accuracy . . . . . . . . 203 


\section{CHAPTER I}

\section{INTRODUCTION}

Converging financial and demographic trends are threatening our nation's ability to provide nursing home care for the elderly. Federal matching funds will soon be capped or lowered due to changing priorities and decreasing revenues. Economic recession and high unemployment are reducing state general funds while the cost of providing nursing home care continues to increase more rapidly than the consumer price index (Ladd 1981).

Concurrent with the reduction in the nation's ability to finance nursing home care, the demand for such care and the proportion of those needing government assistance is increasing. In 1977 an estimated 1.8 million elderly were in nursing homes at an annual cost of over 12.5 billion dollars (Kane et a1. 1981). Between 1977 and 1981 the demand for nursing home care increased 72.7 percent nationally (Saslow 1981) and it is estimated that public sector payments exceed 70 percent of the total nursing expenditures (Pattee 1980).

This growing demand can be expected to continue at an accelerated rate as the number and proportion of the elderly in the total population increase. The number of people 65 and over, who comprise 84 percent of all nursing home residents (U.S. Bureau of the Census 1979b), Is expected to increase from 25.5 million in 1980 (U.S. Bureau of Census 1981a) to approximately 45 militon by 2020. At that time this grcup may represent as much as 13 percent of the total U.S. population (U.S. 
Bureau of the Census 1976). In addition population projections predict that those people 75 years of age and over, who have the greater need for nursing home care, will be increasing three times as rapidly as those aged 60 to 74 (U.S. Bureau of the Census 1979a). Oregon is experiencing similar trends. The state's elderly population of 303,284 (U.S. Bureau of the Census 1981b) represents 11.5 percent of its total population. Over 8,000 of the state's 15,000 nursing home beds are occupied by individuals whose care is being paid by the federal Medicaid program. Between 1974 and 1980 the proportion of Medicaid nursing home residents increased 30.4 percent while the estimated group of non-Medicald residents actually decreased by 4.2 percent $^{1}$ (Oregon Dept. of Human Resources 1981). Institutional services received 57 percent or $\$ 45$ million from the total Oregon Department of Human Resources funded programs for the elderly in the 1979-80 year (Saslow 1981). In the last quarter of 1980, each Medicaid nursing home stay cost the public sector $\$ 652^{2}$ per month in contrast to $\$ 130$ per month for substitute home services and $\$ 185$ per month for in-home services (Oregon Dept. of Human Resources 1981).

Oregon is addressing the crisis of increased nursing home demand amidst reduced state funding. Through the implementation of certificate of need and wafver policies, the state seeks to to reduce the number and use of nursing home beds and to redirect clients to less costly alternatives. Both the federal certificate of need policy (U.S. Code 1974)

${ }^{1}$ Computed from data in Table 2.

2 This figure does not include the average $\$ 260$ per month which the client contributes toward his total cost of care. 
and the state certificate of need policy (Oregon Revised Statutes 1973), require justification of need prior to new construction or major expansion of nursing homes. The Oregon State Health Plan now recommends that Oregon's 50.5 beds per 1000 population aged 65 and over be reduced to 40 over the next five to ten years. It further recommends that the determination of need be tied to the functional needs of the population rather than user rates or desired occupancy levels (Oregon State Health Planning and Development Agency 1981).

Oregon has introduced two wafver policies to allow funds previously limited to nursing home care to be used for community services. In addition to passing its own Senate Bill 955, Oregon became the first state to receive a statewide federal waiver under the Social Security Amendment, The Omnibus Reconciliation Act of 1981. The key to successful implementation of each walver policy lies with the accurate assessment of individual client functional needs rather than provider needs or goals.

PRE-ADMISSION SCREENING

Each waiver policy depends upon an initial screening of an individual to determine service eligibility. In Oregon the screening program is called Pre-Admission Screening (PAS). Mandated statewide by the Department of Human Resources in 1981, Pre-Admission Screening is intended to standardize nursing home eligibility determination under Medicaid. It is also an attempt to restrict authorization of nursing home placement to those individuals whose functional needs cannot be met In the community. 
Pre-Admission Screening is required for all Medicaid clients seeking nursing home admission and for all nursing home residents who will become Medicaid eligible within 90 days. The screening is also avallable to others upon request.

In the brief period of time since it was initiated, PAS has demonstrated its success in the implementation of the waiver and certificate of need policies. It has successfully reduced utilization of nursing home beds and diverted clients to less costly alternatives. Between September 1980 and March 1981 Oregon nursing home admissions dropped 14 percent compared with the previous six months (Ladd 1981). The Pre-Admission Screening Report for 1981 identified 31 percent of all nursing home applicants as diverted to either a lower level of care or to another financial resource (Oregon DHR 1982a).

The Pre-Admission Screening Program is not, however, Inexpensive to administer. Each screening is conducted by a team of professionals, the screening process is lengthy, and the number of screening requests is high.

Like most comprehensive assessments, PAS is conducted by a multidisciplinary team which gathers information from a variety of sources and makes a clinical judgment after conferencing. The soctal worker completes a psycho-social and a functional assessment, the registered nurse completes a medically orlented assessment, the adult service worker evaluates the avallability of community resources, and the assistance worker establishes financlal eligibility. According to a 1981 Department of Human Resources time study conducted in Multnomah and Marion regions, those portions of PAS completed by the registered nurse 
and social worker took an average of seven hours in Multnomah and eight hours in Marion, varying only with the amount of travel time required (Oregon DHR 1981b). The Department of Human Resources has also estimated that the services of the PAS soctal worker and registered nurse cost the state $\$ 20$ an hour (Hinkle 1982).

The total number of requests for Pre-Admission Screening has been high. In 1981 over 3900 requests came from Western Oregon alone (Oregon Department of Human Resources 1982a). Simple mathematics can provide an estimate of the cost of administering the Pre-Admission Screening program. Considering only the cost of the registered nurse and the social worker, a screening which takes seven hours to complete costs the state approximately $\$ 140$. Multiplication of the cost per screening by the 3,147 screenings completed in 1981 (Oregon Department of Human Resources 1982a) provides an estimated annual cost of $\$ 440,580$. This calculation does not include the 20 percent of all requests which were inappropriate or otherwise withdrawn prior to client placement but required considerable PAS team time. Processing these requests can be estimated to add as much as $\$ 100,000$ to the total cost of administering the Pre-Admission Screening program.

PURPOSE OF THIS DISSERTATION

The purpose of this dissertation is to evaluate the suitability of the Placement Information Base (PIB) for use as a substitute for the entire preadmission screening process (PAS) In nursing home placement decisions. 
The use of predictive instruments as substitutes for clinical judgment is well established in many fields and is increasing within the long term care planning and delivery system (Foley et al. 1980).

The advantages of predictive instruments are both theoretical and practical. On the theoretical side, data obtained through the use of predictive instruments can be used to acquire a better understanding of the dynamics underlying the behavior which is being measured. On the practical side, a predictive instrument permits individual, groups, and society to operate more effectively (Sawyer 1966).

The issue of whether statistical or actuarial prediction (the use of specific decision rules) is superior to clinical prediction (clinical judgment) has been debated for years.

A review of the status of the argument and a critical evaluation of the published survey evidence were conducted by Holt (1970). He reviewed the surveys of Meeh1 (1954), Gough (1963), and Sawyer (1966) each of whom had concluded that statistical methods of prediction were at least equal to and of ten superior to clinical methods in terms of accuracy.

Holt contends that many of the studies are methodologically unsound. His greatest criticism, however, is the misleading dichotomy between statistical and clinical prediction. The issue, according to Holt, is not which method is better, since statistical prediction, except for the last step, is founded on clinical judgment. Issues identifled by Holt include (1) the extent to which the process of clinical judgment can be programmed for a computer or other mechanical decision-making device, (2) the value of the clinical concepts and 
theories, (3) the contribution of statistical prediction to understanding the nature of the behavior under study, and (4) the practicality of using a statistical prediction for a specific type of decision.

In this dissertation, the suitability of using PIB as a substitute for clinical judgment in nursing home placement decisions is evaluated In terms of each of the above issues. Recommendations are made only after an examination of the accuracy of statistical predictors, the relevance of the theoretical constructs which are being measured, the influence of intervening vartables, and the practicality of administering such an instrument as part of a large scale program.

When this research study was planned, it was assumed that the vast majority of all nursing home residents would have been evaluated by a PAS team rather than a caseworker only. The program is required and is being Implemented in all but a few of the more remote areas of the state. When the PIB data were obtained, however, it was found that 43 percent of all nursing home residents had been evaluated by a caseworker only.

After determining that there were no significant differences between the PIB scores of those nursing home residents evaluated by caseworkers and those evaluated by PAS teams, the scores from the two groups were combined. Unless otherwise noted, all references to substituting PIB for the entire PAS process can be interpreted as substituting PIB (using the a priorl or mathematically derived decision rules) for all screening completed under the aegis of the PAS program. 
PLACEMENT INFORMATION BASE

The Placement Information Base (PIB) has several characteristics which appear to make it suited for use as a screening instrument to replicate PAS team judgments (Oregon Medical Association 1980). First, PIB was designed specifically to assist the worker in making placement and service plans. Developed and tested during the Southern Oregon Flexible Intergovernmental Grant/Waiver Project from 1978-1981, PIB was designed to provide a standardized data base of significant factors that affect proper placement of a client. Five of the seven factors included in PIB are identified by the instrument designers as characterizing individuals for whom nursing home placement may be a cost effective choice. Second, decision rules have been developed a priori to guide level of care judgments. Risk factors (for the probability that nursing home placement is the cost effective choice) have also been assigned a priori to each of the 25 PIB items. Third, PIB can be administered in a moderate period of time by individuals not possessing highly technical skills. Reliability studies have been conducted which indicate that PIB can be completed within an hour by trained intake workers. Fourth, PIB's response mode is quantified and able to be programmed on a computer. PIB data are already being collected and computerized for a variety of poor and elderly populations within Oregon (Oregon Department of Human Resources 1981a). 


\section{BENEFITS OF THIS DISSERTATION}

There are many potential advantages of using PIB rather than the total Pre-Admission Screening process for making nursing home placement decisions.

PIB is less costly and professionally less demanding than a full interdisciplinary team assessment. PIB takes approximately one hour plus transportation to complete; PAS takes at least six hours plus transportation (Oregon Department of Human Resources 1981b). Non-professionals, such as volunteers, can be trained to administer PIB, whereas the PAS process and similar assessments usually require registered nurses and social workers. Time and salary savings generated by using PIB rather than a more lengthy assessment can be reallocated to other clients or programs. Professionals can be freed for other clinical responstbilities. The latter is particularly important in regions of Oregon or other states which are sparsely populated and have limited professional resources.

The administration of PIB rather than a more lengthy interdisciplinary team assessment may also create savings by reducing the time a client spends in a hospital or nursing home awaiting assessment and less restrictive placement. In 1981, 33 percent of all screening requests were made in behalf of clients in acute hospitals; 34 percent were in behalf of clients already residing in nursing homes (Oregon Department of Human Resources 1982a). 
Another advantage of using PIB rather than PAS is the ease with which PIB scores can be interpreted. The response to each PIB item is scored on a 1 to 5 likert type scale in contrast to the narrative and checklist response mode found in PAS and similar assessment mechanisms. The Likert response mode allows a varlety of statistical analyses to be conducted on PIB data. Knowledge of predicting factors can be used in two different but complementary ways. First, an understanding of factors which predict placement might also suggest ways in which nursing home placement can be delayed or prevented through manipulation of those predicting factors. Specific services, for example, may need to be added or expanded. Second, knowledge of predicting factors could, to the extent that the factors are theoretically sound, be used to develop decision-making rules regarding the need for nursing home placement. Standardization of practice is particularly important in a large scale program such as the one being implemented in 0regon. In this program, placement dectsions are being made by twelve different teams throughout the state. Some of the teams are lacking either a nurse or social worker. In other parts of the state, the placement decisions are still being made by Senior Services Division caseworkers rather than a PAS team. Rater bias or variation in placement criteria employed by these different raters has yet to be thoroughly examined. Knowledge of factors which are predictive when employed by the PAS team as a whole, could, therefore, be one step toward establishing decision rules which could be used by all raters. This type of standardization would tend to diminish the effect of rater bias. 
The PIB response mode would allow the instrument to be modified to reflect changes in placement deciston-making rules. Any alteration in the criteria for nursing home placement could easfly be reflected in PIB. Items could be eliminated or critical thresholds could be raised or lowered to correspond with the modified criteria.

Internal audits of appropriate placement should be easier with PIB scores than with the narrative summaries provided by PAS. Since most record reviews under PIB would not require an understanding of medical terminology, the reviews could be completed by clerical workers or by computer rather than by professionals.

The use of PIB instead of the PAS process has potential benefits for the individual client. Since PIB takes a shorter time to administer and does not require the repetition of information to several team members, the administration of PIB should be less exhausting for the client. The use of PIB should also reduce the amount of rater judgment needed and therefore provide the individual with a standardized and equitable system of being screened for placement. As the ratio of nursing home beds within the state is lowered, PIB would become an increasingly valuable tool in assigning beds to individuals on a priority basis.

Like Oregon, other states may benefit from the use of PIB as a screening instrument capable of replicating clinical judgment. Virtually all states are facing the same crisis of reduced funding and Increased demand for nursing home placement. Many states are trying to develop a plan to become eligible for a federal Medicaid waiver under the Soctal Security Amendment of 1981. These states may be interested 
in adopting PIB as a screening instrument since the amendment specifically requires an implementation plan indicating how the state will determine that an individual requires nursing home care (U.S. Code 1981).

FINDINGS OF THE PROPOSED DISSERTATION

Findings of this research study are used to make suggestions for strengthening PIB in its function as a screening instrument for nursing home placement. Findings are also used to provide insight into the criterion itself. Recommendations are then made regarding the use of PIB as a substitute for the Pre-Admission Screening process in the implementation of both the State and Federal Medicaid waiver policles. 


\section{CHAPTER II}

\section{REVIEW OF LITERATURE}

The review of literature is presented in five sections. The first section contains a discussion of the psychometric characteristics which are destrable in an instrument for nursing home placement screening. In the second section, psychometric characteristics of a selected number of instruments used for nursing home placement are evaluated. In the third section the psychometric characteristics of the Placement Information Base $(P I B)$ is evaluated. The fourth section contains a discussion of factors which are thought to influence nursing home placement and therefore would be expected to influence the results obtained from the administration of PIB. The fifth and final section of the literature review presents the conceptual framework for the proposed study.

\section{DESIRABLE PSYCHOMETRIC CHARACTERISTICS OF INSTRUMENTS}

USED FOR NURSING HOME PLACEMENT

Placement in a nursing home can dramatically change the lives of a large number of our society's elderly population. Any instrument used to make placement decisions, particularly on the scale needed in Oregon, should be both reliable and valid. That is, the instrument should be capable of measuring variance due to true score differences rather than random error and it should be capable of measuring what it was intended to measure (Anastas1 1970). Since there are various classifications of rellability and validity and since rellability and validity are specific 
to the use to which an instrument is put rather than the instrument itself (Nunnally 1978), this section of the literature review will provide definttions of several of these classifications and will discuss their Importance in relation to a nursing home screening instrument. Different procedures for data quantification and their contribution to a nursing home screening instrument will also be discussed.

Reliability

Reliability of an instrument refers to the extent to which measured variance is due to true score rather than random error (Anastasi 1970). Reliability is a prerequisite to using the score for any purpose and is expressed as a coefficient ranging from 0 to 1.0 . The higher the reliability, the lower the proportion of random or measurement error. An instrument is considered rellable to the extent that repeated measurement (in the absence of real change) gives consistent results for the individual; to the extent that his score or position within a group remains constant. In practice, procedures for establishing reliability are seldom based on the correlation between repeated measurement of a single individual. Instead reliability is often based upon the correlation between scores obtained from two administrations of an instrument using a larger sample of individuals (Thorndike 1969).

Two aspects of reliability which are relevant for this study are internal consistency reliability and inter-rater reliability.

Internal Consistency. This type of reliability reflects the homogeneity or degree to which items on a measure are interrelated and measure a single trait or characteristic. Internal consistency is 
concerned with the internal structure of a test rather than the correlation between total test scores (Brown 1976).

Internal consistency can be computed from a variety of formulas. Many are derived from a basic equation which states that reliability can be expressed in terms of the average inter-1tem correlation. The higher the inter-item correlation, the more homogeneous the test.

According to Nunnally (1978) the Coefficient Alpha is the basic formula for determining internal consistency. Its estimate of error variance is based on content sampling, making it a good estimate of reliability in most situations (Nunnally 1978, p. 212).

Factor analysis is another approach to internal consistency favored by many (Brown 1976). Factor analysis is a statistical technique which reduces items into the minimum number of constructs (factors) necessary to account for the intercorrelations or covariance among the group of items. If one factor accounts for all of the variance, the test is considered homogeneous; if not, the test is heterogeneous.

Internal consistency or homogeneity of all items would not be desirable in a screening instrument used for nursing home placement. It is thought that several factors are reflected in placement criteria, e.g. physical, emotional, and social functioning.

Tests of internal consistency would, however, be helpful to sort the instrument items into separate subsets or dimensions, each of which would cover a different aspect of the criteria (Anastasi 1970). Used in this way, internally consistent subsets of items could increase the breadth of coverage of the test and thereby enhance the establishment of both construct and criterion-related validity. 
Inter-rater Rellability. A measure of rater agreement, interrater reliability can be established by correlating the sets of scores obtained from a sample of individuals independently tested by two or more raters. Low reliability often indicates the need for more explicit instructions or the revision of instrument items (Kerlinger 1973) and is particularly important in a nursing home screening instrument which is to be administered by a large number of raters of varying background.

\section{Validity}

According to Kerlinger (1973) the most important classification of types of validity is that prepared by a joint committee of the American Psychological Association, the American Educational Research Association, and the National Council on Measurements Used In Education. The three types of validity which were outlined by that comittee are content, construct, and criterion related validity.

Content Validity. The ability of the instrument to adequately represent the properties which are being measured is called content validity. It should be evaluated on two levels. First, the items should represent all relevant dimensions and constructs. Second, within each dimension and construct the items should capture the functional. continuum of the population being studied.

Content validity is, to a large extent, a matter of judgment and 1s built into the instrument through the choice of appropriate items following a thorough literature review as well as consultation with subject matter experts (Nunnally 1978). 
According to Messick, trying to define content validity as separate from construct validity produces a "dysfunctional strain" (1980, p. 1018). He cites Tenopyr (1977) as recommending that we inquire how content considerations contribute to construct validity and how we might strengthen that contribution.

Together with construct validity, to be discussed subsequently, content validity may make a valuable contribution to a nursing home screening instrument. By insuring that criterion constructs are adequately represented and that the items measure the functional range necessary to assess the population in question, content validity may both enhance the predictability of an instrument and the understanding of the criterion itself.

The content which should be sampled for a nursing home screening instrument appears to be that of Health Status. As defined by the World Health Organization (1958), health status includes the dimensions of physical, emotional, and social status. These dimensions can be found In a number of instruments designed to assess the elderly; The OARS Multi-dimensional Functional Assessment Questionnaire (Fillenbaum \& Smyer 1981), the Comprehensive Assessment and Referral Evaluation: (Gurland et al. 1972-78) and Patient Appraisal and Care Evaluation (U.S. Dept. of HEW 1974) are three examples.

Content categorles which should be considered in conjunction with the dimensions of physical, emotional and social status were reported by Brook et al. (1979). In an extensive review of literature completed as part of an evaluation of the Rand Health Insurance Study, they identified the following measures. In the area of phystcal status the 
measures included the major functional categories of self, care, moblitty, physical, role, household and leisure activities. In the area of mental status, anxiety, depression, posttive well-being, and self control were included. Social status was measured by interpersonal and social participation in the categories of family, social, community and work roles.

Construct Validity. The extent to which an instrument may be said to measure the theoretic construct or trait under consideration is called construct validity. It differs from content and criterion validity in that its focus is on the underlying theory accounting for covariance among the measures rather than upon prediction or representation. According to Cronbach (1970), construct validity is an analysis of the meaning of test scores in terms of psychological concepts or "constructs" and is established through a long continued interplay between observation, reasoning, and imagination. Construct validation is generally approached in one of two ways. The measure is either examined through procedures such as tests of internal consistency and factor analysis or the measure is correlated with other variables whose underlying theory is better understood (Cronbach 1970; Anastasi 1970). Like content validity, construct validity has often been treated as a type of validity separate from criterion-related validity and unnecessary if criterion-related validity is established. Messick, however, points out that criterion validity is concerned with "useful relationships under applied settings (and is narrowly defined in terms of) specific sets of data and applied settings" (1980, p. 1017). 
Construct validity, on the other hand, is more general and can provide a "rational basis for judging the relevance of the test to the criterion domain" (Messick 1980, p. 1017). Messick also cites James (1973) and Gulliksen (1950) as emphasizing the importance of identifying criterion constructs, particularly when a criterion measure is impure or contaminated.

Construct validity can thus be considered important for a nursing home instrument where the criterion is less than ideal. Clinical judgment, the criterion for nursing home placement, is poorly understood, does not appear to be uniformly applied, and will undoubtedly be modified as the demand for nursing home placement outstrips the availability of nursing home beds.

It may be concluded that construct validity, together with content and criterion validity, may provide insight into the criterion itself by Identifying constructs which currently predict placement. The identification of these constructs would allow a critical examination of the way clinical practice currently mixes and separates senior citizens through placement decisions. This examination would in turn provide a basis for modifying both clinical practice and the screening instrument to promote a more desirable and untformly applied criterion for placement.

Criterion-Related Validity. The effectiveness with which a test or instrument predicts an individual's behavior in specified situations is called criterion-related validity.

Although any criterion-related validity is predictive in the broad sense, validity is often called predictive validity if it is established by checking the scores against a future outcome. It is called 
concurrent validity if the scores are checked against a criterion which Is already avallable. According to Anastasi (1970), the logical distinction is not based on time but the objectives of the testing. Concurrent validity is relevant to tests employed for the diagnosis of existing status rather than the prediction of future outcomes. Concurrent rather than predictive validity is therefore relevant for a nursing home screening instrument. Although it would be useful to have an instrument which could predict either the future need for nursing home placement or one which could identify those who would fare better if Institutionalized, that is not the purpose of the instrument under study. The purpose of the screening instrument is to serve as a substitute for clinical judgment in the diagnosis of an existing need for placement.

The criterion employed for testing concurrent validity is usually an established test or other accepted method of collecting the necessary data. According to Cronbach (1970, p. 122),

If the existing method is considered useful for dectsion making, it is appropriate to ask whether the new test agrees with the present source of Information. In this comparison, the existing procedure is accepted as giving the information desired . . . If there is agreement, the test measures what the other procedure does.

In the case of a nursing home screening instrument the source of data most commonly used as a criterion has been some type of clinical judgment. This has usually been in the form of a multidisciplinary team and has been supported with data gathered along disciplinary lines.

Criterion validity is very important for a nursing home screening Instrument because it allows the instrument to be confidently 
substituted for the more costly team approach to decision making. Since screening by its very definition is not expected to be error free (Kane \& Kane 1981), criterion validity can provide an estimate of both the stze and direction of the error for a varlety of threshold levels. This information can then be used for selecting a particular threshold and for planning the necessary client follow-up.

Quantification of Data

The elderly can be screened for nursing home placement with an open-ended interview instrument that does not result in quantified responses. Such responses, however, are difficult to interpret and difficult to test for reliability and validity. Numerical quantification of responses, in contrast, generates scores for each Individual which can be summarized and more readily compared with the scores of others and with established criteria for nursing home placement. In addition, numerical quantification of scores allow the instrument itself to be empirically tested for reliability and validity through a variety of procedures.

Numerical data can be organized in several ways to replicate clinical judgment in nursing home placement decisions. Foley and Sneider (1980), In a recent review of classification systems developed for long term care placement, identified three basic methods: maximum need, additive, and multiple contingency.

Maximum Need. One system of screening individuals for placement is to determine their greatest "maximum" need and match that need to the required level of care. The advantage of this system is its simplicity. 
The major disadvantage, however, is its insensitivity to individuals who may require nursing home placement because of the additive effect of moderate disability in several dimensions.

Additive. A second system to classify individuals for long term placement is the additive system. In this system the level of care for an individual is selected on the basis of total points obtained by adding the points assigned to clients' descriptor statements. The actual placement is determined by total point threshold values set for each level of care. The advantage of this system is the ease of its interpretation and its sensitivity to various combinations of functional need. The major disadvantage, however, is the difficulty of selecting items and assigning weights so that the total score reflects a balance between all dimensions considered important for nursing home placement.

Multiple Contingency. The third system used to classify individuals for placement is called multiple contingency. In this system summary scores are obtained on a variety of dimenstons considered important to placement. Level of care decisions are then made by a set of contingency rules and are based upon more than one summary statement about the individual. The advantage of this system is its sensitivity to all dimensions. The disadvantage is the complexity of translating summary scores into placement decisions.

Summary

Each of the types of reliability and validity fust discussed are important for a nursing home screening instrument. Inter-rater reliabiity and criterion-related validity are essential. Although criterionrelated validity is sometimes adequate by itself, the nature of the 
criterion, clinical judgment, makes content and construct validity highly desirable. Also desirable is a quantifiable response mode which allows scores to be more easily tested and interpreted.

PSYCHOMETRIC CHARACTERISTICS OF A SELECTED NUMBER OF INSTRUMENTS USED FOR NURSING HOME PLACEMENT

The literature review for this research study was carried out in several steps. First, a med-line computer search was conducted. This search identified several instruments used for geriatric assessment. None, however, had been designed specifically for placement decisions.

Next, the major gerontological journal publications beginning with 1965 were manually reviewed. This review was supplemented with a review of U.S. government publications covering the same period of time. These two sources provided data on the characteristics of the geriatric population and identified instruments associated with geriatric assessment. Most of the instruments, nowever, were not designed specifically for placement decistons. Those which were designed for placement decisions were not described in enough detail to evaluate their psychometric characteristics.

To obtain more information on the instruments designed for placement declsions, telephone interviews were conducted with the agency or individual credited with authorship. As a follow-up to these interviews, the researcher recelved various documents describing some of the instruments in greater detail.

It became apparent that much of the work being conducted in the area of preadmisston screening for nursing home placement has yet to be 
published in the journals. The researcher therefore began to survey each state in an attempt to 1dentify additional screening instruments. Telephone interviews were conducted with representatives of the states of Michigan, Illinois, Ohio, New York, Connecticut, New Jersey, Mississippi, and Massachusetts. Several of the states were not conducting pre-admisstons screening. Others were conducting pre-admission screening but were using instruments which do not appear to meet the psychometric characteristics considered desirable in a screening instrument.

At this point the survey method was modified. It had been difficult to locate the state agency responsible for nursing home placement decisions and many states had no pre-admission screening program. Instead of interviewing representatives from each state, interviews were limited to the thirteen states which, in addition to Oregon, received a federal Medicald waiver prior to July 1, 1982 (Howe 1982). See Figure 6 In Appendix $A$ for an outline of the interview schedule. Interview data have been supplemented with follow-up materials sent by some of the states.

For the purposes of discussion, the instruments evaluated in the review of literature are divided into three groups: (1) instruments commonly associated with geriatric assessment, (2) instruments developed specifically for placement decisions, and (3) fnstruments used by other states granted a federal Medicaid wafver. The instruments evaluated in the first group have been selected on the basis of their familiarity and widespread use. The instruments evaluated in the second and third group 
represent the total number identified in the extensive literature search.

This section of the review of literature will evaluate the functional assessment instruments in terms of their sultability as substitutes for clinical judgment in a large scale nursing home placement screening program. Each of the instruments w1ll be evaluated against psychometric characteristics considered desirable or essential in a screening instrument. These characteristics were discussed in the previous section of the literature review and are: (1) design for a geriatric population, (2) measurement along a functional continuum, (3) measurement of physical, mental and social content, (4) acceptable inter-rater relfability when administered by non-professionals, (5) criterion validity related to nursing home placement, and (6) quantification of data.

Instruments Commonly Associated with Geriatric Assessment

A review of the literature revealed the existence of many instruments which have been used to assess the needs of the elderly. Most, however, were not designed for placement decisions and do not have specific rules for translating scores into level of care determinations. Because of their widespread use and famillarity, however, eighteen of these instruments will be evaluated in this section of the literature review. Unless otherwise noted, the reference used to support the evaluation will be that initially cited.

Design for a Geriatric Population. Of the elghteen instruments under study, fifteen were deslgned specifically for the elderly: The 
01der Americans Research and Service Multidimensional Functional Assessment Questionnaire, OARS-MFAQ (Fillenbaum \& Smyer 1981); its shortened version the 01der Americans Research and Service Functional Assessment Inventory, OARS-FAI (Pfeiffer et al. 1981); the Older Americans Research and Service Short Portable Mental Status Questionnaire for the Elderly, OARS-SPMSQ (Pfelffer 1975); the Philadelphia Geriatric Center Instrumental Activities of Daily Living, PGC-IADL (Lawton \& Brody 1969); the Philadelphia Geriatric Center Physical Self-Maintenance Scale, PGC-PSMS (Lawton \& Brody 1969); the Philadelphia Geriatric Center Multilevel Assessment Instrument, PGC-MAI' (Lawton et a1. 1982); the Performance Activities of Daily Living, PADL (Kane \& Kane 1981); the Patient Classification Form, PACE II (U.S. Dept. of HEW 1974); the Sandoz Clinical Assessment-Geriatric, SCAG (Goga \& Hambacher 1977); Its derivative, the Self Assessment Scale Geriatric, SASG (Yesavage et al. 1981); the Stockton Gerlatric Rating Scale, SGRS (Meer \& Baker 1966); Pluchek's Geriatric Rating Scale, GRS (Smith et al. 1977); its shorter alternative the Parachek Geriatric Behavior Rating Scale, GBRS (Miller \& Parachek 1974); the Comprehensive Assessment and Referral Evaluation, CARE (Gurland et al. 1977-78); and the Physical and Mental Impairment of Function Evaluation in the Aged, PAMIE (Gurel et a1. 1972).

The three remaining instruments were designed for use with all age levels Including the elderly: the Sickness Impact Profile, SIP (Bergner et al. 1981); the Katz Index of Activities of Daily Living, Index of ADL (Katz et al. 1970); and the Duke University of North Carolina Health Profile, Duke-UNC-Health Profile (Parkerson et al. 1981). 
Measurement Along a Functional Continuum. In order to be useful for nursing home placement decisions, an instrument must be capable of measuring behavior on a functional continuum broad enough to separate the elderly living in the community from their more dependent counterpart living in nursing homes.

Nine of the eighteen instruments were designed to measure varying degrees of independence and many have been used with individuals residing in the community as well as in nursing homes. These instruments are the OARS-MFAQ, the OARS-FAI, the OARS-SPMSQ, the PGC-IADI, the PGCPSMS, the Index of ADL, the SIP, the SCAG, and the SASG.

The remaining instruments were designed to measure only one end of the functional continuum and are therefore less suited for nursing home placement screening. CARE, PGC-MAI, and the Duke-UNC-Health Profile were each designed to be used with community residents and do not contain items which measure the more functionally dependent elderly. Conversely, PACE II, and the PAMIE scale were designed for nursing home residents and do not contain items which measure the more functionally independent elderly. PADL, Pluchek's GRS, Parachek's GBRS, and the Stockton GRS were each designed for psychiatric inpatients and also measure a limited functional continuum.

Measurement of Physical, Mental and Social Content. It is also desirable that an instrument used for nursing home placement screening reflect the physical, mental and soctal needs of the elderly. Only seven of the instruments reviewed appear capable of doing this. SIP has three areas of content: physical, psychosocial, and what is referred to by its authors as an independent category (i.e. miscellaneous). The 
OARS-MFAQ and the OARS-FAI reflect five domains: physical, mental, economic, social, and ADL. The PAMIE scale measures physical, psychological, and social-interpersonal disabilities. CARE generates data in the areas of physical, medical, psychological, and social need. The PGC-MAI measures seven domains: physical health, cognition, ADL, time use, soclal interaction, personal adjustment, and perceived quality of life. The Duke-UNC-Health Profile covers symptom status, physical, emotional and social function.

of the seven instruments which measure the desired content, only three (OARS-MFAQ, OARS-FAI, and SIP) also measure a functional continuum. Of these three, only the OARS-MFAQ and the OARS-FAI were designed specifically for the elderly.

Eleven of the eighteen instruments do not appear to adequately measure physical, mental, and social content. Although the GBRS, GRS, SASG, SGRS and SCAG have items in each of the content areas, the majority of these items were selected to measure psychiatric symptoms. The remaining instruments are essentially one dimensional. The OARSSPMSQ was designed to measure mental status. The PGC-IADL, the PGCPSMS, PADL, Index of ADL, and PACE II were each designed to measure physical functioning.

Acceptable Inter-Rater Reliablitity. To be useful in a large scale screenting program such as the one Oregon is undertaking, a nursing home placement instrument should be capable of being administered by trained non-professionals and should have acceptable inter-rater reliability. 
of the eighteen Instruments reviewed, half were designed to be administered by non-professionals: PAMIE, the Duke-UNC-Health Profile, OARS-SPMSQ, OARS-FAI, OARS-MFAQ, PGC-MAI, SIP, PADL, and the SGRS.

The first four of these instruments, however, have not reported inter-rater reliability. The fifth, OARS-MFAQ, has acceptable interrater reliability (Fillenbaum \& Smyer 1981) but that reliability is dependent upon a training program available only in Florida. The sixth Instrument, PGC-MAI, has reported poor reliability $(r=.51)$ when administered by housing personnel with long term knowledge of the subjects. Reliability for raters from diverse backgrounds was also reported to drop as low as .58 for PGC-MAI items measuring social interaction.

Each of the remaining instruments designed to be administered by non-professionals appears to have acceptable inter-rater rellability. The SIP has been tested in a variety of settings by raters of varying skills and has reported total score reliability ranging from .75 to .92 . As reported by Kane and Kane (1981) PADL has a pilot study raterobserver relfability of .90 . The Stockton GRS has undergone numerous reliability studies and has reported correlations over .80 between a principal rater and registered nurses, nurses aides, and psychiatric assistants (Taylor \& Bloom 1974).

of these three instruments, SIP is the only one which also appears to meet the functional continuum and content criteria previously discussed. SIP was not, however, designed specifically for a geriatric population. 
Two of the instruments designed to be administered only by professionals appear to have acceptable Inter-rater reliability. According to Kane and Kane (1981) the Index of $A D L$ has reported differences among raters in less than one out of twenty evaluations when ratings were made on simultaneous observations. Inter-rater reliabilfty reports for the GRS range from .87 to .94 . A third instrument, PGC-IADL has acceptable reliability $(r=.85)$ but on a sample limited to twelve older persons. Inter-rater reliability on a fourth instrument, CARE, was found to vary between professional raters and between content domains. Agreement appeared to be based upon experience with the instrument rather than common disciplinary backgrounds. Inter-rater reliability was not reported on the final four instruments designed to be administered by professionals only.

SASG, the only instrument reviewed which can be self administered, reported low rellability-over-time on thems measuring soclability; reliability for other items ranged from .50 to .91 .

Criterion Validity Related to Placement. Criterion validity is also desirable for a screening instrument used for nursing home placement. It is important to have an external standard which confirms an Instrument-based decision.

The two instruments which have developed criterion validity most suited to a nursing home screening instrument are the OARS-MFAQ (F11lenbaum \& Smyer 1981) and 1ts shortened version the OARS-FAI. The living arrangement of a group has been found to correspond with that group's mean score on each of the instrument's content domains. The variation between service settings was in the expected direction; 
community residents were the least impaired, institutionalized residents the most Impaired. Rules for using the score responses for Individual placement decisions have not, however, been developed.

Although several of the other instruments have been subjected to criterion validity studies, the methodology or results make them appear unsulted for the type of nursing home screening needed in Oregon.

The PGC-MAI study was based on a non-institutionalized population. When individuals receiving in-home services and those on nursing home walting lists were compared with others living in the community, correlation on most domains was below .45 . The authors attribute the low results to error inherent in the criterion groups approach and the dichotomous nature of the criterion. The low correlations may also reflect a true similarity between the groups on the measures employed. Individuals on nursing home waiting lists may still have intact social support systems. In addition, waiting lists often include individuals who do not "need" institutionalization or who will reject it when offered admission (Sherwood et al. 1975). Although low, correlations for the PGC-MAI were those expected by the authors. The greatest difference between the two groups was in the areas of physical health, ADL, and personal adjustment. The areas of least differonce were time use, social interaction, and perceived environment.

Three of the four SGRS factors (i.e. physical disability, apathy, and communication failure) were found to differentlate between three groups of psychfatric state hospital patients: those who would, within a year, leave the hospital, those who would remain in the hospital, and those who would die (Meer \& Baker 1966). The criterion varlable was, 
however, defined as leaving the hospital for any reason or any length of time and did not imply ability to function in the community.

Criterion validity for the PAMIE scale was established by dividing a nursing home population into a high and low group based upon scores on ten factors. Eight of the factors were able to discriminate between those in need of more nursing care where the variables of need and appropriateness were determined by the staff. It is not known, however, how the staff determination was made.

The toileting item on the Index of ADL divided a group of former rehabilitation hospital patients into groups that required significantly different amounts of assistance. It also differentiated between those who did and those who did not enter an Institution within a year. The study, however, was limited to hemiplegic patients.

Quantification of Data. With the exception of CARE, which contains some items with a descriptive response mode, each of the eighteen instruments, evaluated in this section of the literature review, generates scores which are numerically quantiflable. In addition, all but four (PACE II, PGC-IADL, CARE, and PGC-PSMS) provide domain, factor, or total summary scores. As previously mentioned, none of these instruments have rules for translating scores into level of care determinations.

Summary. None of the instruments evaluated in this section of the literature review appear suited for use as a screening instrument for nursing home placement (Table I). While the Sickness Impact Profile (SIP), the OARS Multi-dimensional Functional Assessment Questionnaire (OARS-MFAQ), and the OARS Functional Assessment Inventory (OARS-FAI) 
meet most of the conditions, each has limitations. The SIP has not been studied with elderly samples and does not have criterion validity. The two OARS instruments do not have placement decision making rules to accompany their criterion valldity studies. In addition, inter-rater reliability for both of these instruments is dependent upon a costly training program.

Instruments Developed Specifically

for Level of Care Decisions

The review of literature also identified twelve instruments which have recently been developed for the specific purpose of replicating clinical judgment in level of care placement decistons. These instruments will be discussed in this section of the literature review and evaluated for their suitability for use in a large scale nursing home placement screening. Like the instruments in the previous section, these twelve instruments will be evaluated against the following criteria: (1) design for a geriatric population, (2) measurement along a functional continuum, (3) measurement of physical, mental, and social content, (4) acceptable inter-rater rellability when administered by non-professionals, (5) criterion validity related to nursing home placement, and (6) numerical quantification.

Design for a Gerlatric Population. Eleven of the twelve instruments were designed for a predominantly geriatric population. Each of the following was developed to determine an appropriate level of care for individuals either seeking placement or already residing in nursing homes or elderly housing. These instruments are the Colorado LTC-101 
TABLE I

PSYCHOMETRIC CHARACTERISTICS OF INSTRUMENTS COMMONLY ASSOCIATED WITH GERIATRIC ASSESSMENT

\begin{tabular}{|c|c|c|c|c|c|c|c|c|c|}
\hline & \multicolumn{9}{|c|}{ Criteria for Evaluating Instruments } \\
\hline & 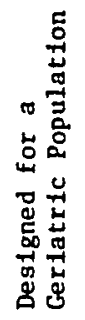 & 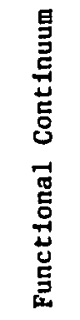 & 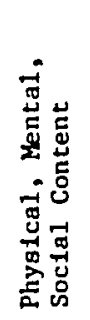 & 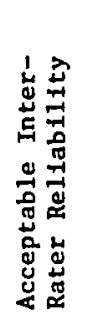 & 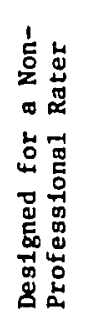 & 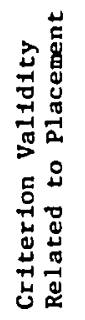 & 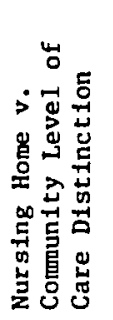 & 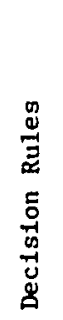 & 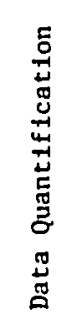 \\
\hline OARS-MFAQ & Yes & Yes & Yes & Yes & Yes & Yes & Yes & No & Yes \\
\hline OARS-FAI & Yes & Yes & Yes & n.r. & Yes & Yes & Yes & No & Yes \\
\hline OARS-SPMSQ & Yes & Yes & No & n.r. & Yes & No & No & No & Yes \\
\hline \multicolumn{10}{|l|}{ Duke UNK } \\
\hline Health Pro. & No & No & Yes & n.r. & Yes & No & No & No & Yes \\
\hline PACE II & Yes & No & No & n.r. & No & No & No & No & Yes \\
\hline PGC-IADL & Yes & Yes & No & No & No & No & No & No & Yes \\
\hline PGC-PSMS & Yes & Yes & No & n.r. & No & No & No & No & Yes \\
\hline PGC-MAI & Yes & No & Yes & No & Yes & No & No & No & Yes \\
\hline PADL & Yes & No & No & Yes & Yes & No & No & No & Yes \\
\hline SCAG & Yes & Yes & No & n.r. & No & No & No & No & Yes \\
\hline SASG & Yes & Yes & No & Yes & No & No & No & No & Yes \\
\hline SGRS & Yes & No & No & Yes & Yes & No & No & No & Yes \\
\hline GRS & Yes & No & No & Yes & No & No & No & No & Yes \\
\hline GBRS & Yes & No & No & n.r. & No & No & No & No & Yes \\
\hline CARE & Yes & No & Yes & No & No & No & No & No & No \\
\hline PAMIE & Yes & No & Yes & n.r. & Yes & No & No & No & Yes \\
\hline SIP & No & Yes & Yes & Yes & Yes & No & No & No & Yes \\
\hline \multicolumn{10}{|l|}{ Index of } \\
\hline $\mathrm{ADC}$ & No & Yes & No & Yes & No & No & No & No & Yes \\
\hline
\end{tabular}

n.r. = not reported.

NOTE: The data for this table were obtained from an analysis of the literature. Specific references are in the text. The instruments are listed by complete title in Figure 4, Appendix A. 
PSRO Certification and Transfer Document (Colorado Foundation for Medical Care 1980); the Commun1ty Care Program of Illinois Determination of Need Scale (Welch 1982); the University of Western Ontario Assessment Form (Cape et al. 1977); the Sandoz Pharmaceutical Evaluating Patients' Required Level of Care (Foley \& Sneider 1980); the Geriatric Functiona1 Rating Scale, GFRS (Grauer \& Birnbom 1975); the Hebrew Rehabilitation Center for the Aged models, HRCA (Sherwood et al. 1975); the University of Arizona survey instrument (Greene \& Monahan 1981); the Baltimore PSRO models (Kane et a1. 1981); the Massachusetts Department of Public Health Survey instrument (Mass. Office of Health Planning and Statistics 1975a); the New York State DMS-1 Assessment Form (New York State Office of Health 1978) and the Woodville State Hospital Screening Instrument (Haddad 1981).

Only one instrument was not designed specifically for a geriatric population. The New York State Department of Mental Hygiene Level of Care Instrument (Furman \& Lund 1979) was developed for 'ísychiatric hospital patients over the age of twenty-one. Studies have not been reported for use of this instrument with an elderly population. Measurement Along a Functional Continuum. Seven of the twelve instruments reviewed in this section appear to measure along a functional continuum which would make them suited for distinguishing between those elderly needing services in the communtty and those needing nursing home placement. The New York State Mental Hygiene instrument (Furman \& Lund 1979) was designed for placement review and differentiates between ten levels of care ranging from independent community living to skilled nursing facility care. As reported by Foley and 
Sneider (1980), The Sandoz Pharmaceutical instrument was designed to assist the professional in selecting the appropriate level of care and differentlates between four levels ranging from supportive care in the community to skilled nursing care. The University of Western Ontario Assessment Form (Cape et al. 1977) was designed to review appropriate placement and differentiates between the need for a continuing care hospital, nursing home, home for the aged, or community placement. The Illinois Comunity Care instrument (Taber et al. 1980) was designed to identify elderly community residents at risk of institutionalization for whom it would be cost effective to provide alternative care. The remaining instruments, the Colorado LTC-101 (Colorado Foundation for Medical Care 1982), the GFRS (Grauer \& Birnbom 1975), and the HRCA models (Sherwood et al. 1975) were each designed to be used as a screening instrument and differentiate between those needing institutionalization and those requiring a less supervised setting.

The five instruments which do not appear to measure a functional continuum were designed to differentfate between levels of care within an institutionalized setting. The Massachusetts instrument was designed for research and review and differentlates five levels of care ranging from rest home to a hospital rehabilitation unit (Mass. Office of Health Planning and Statistics 1975a). The University of Arizona instrument (Greene \& Monahan 1981) and the New York State DMS-1 instrument (New York State Office of Health 1978) differentiate between the need for skilled nursing care and intermediate or health related care. The Arizona instrument was designed for research purposes (Greene \& Monahan 1981), the New York Instrument for continued stay reviews (Orr 1982). 
The Woodville instrument (Haddad 1981) was designed for research purposes and divides the nursing home population into those needing skilled care, intermediate care, and psychiatric care. The final instrument, the Baltimore PSRO mode1(s), was designed for research purposes and differentiates between the need for skilled care and the need for less than skilled care (Kane et al 1981).

Measurement of Physical, Mental, and Social Content. Six of the twelve instruments contain items designed to measure elderly characteristics in the areas of physical, mental, and social functioning. The New York Mental Hygiene Instrument (Garnett 1980) contains 100 mathematically derived items in the dimenstons of self-care, psychological behavior, acceptable social behavior, skilled nursing service needs, and supervision and treatment needed for somatic illness. The Sandoz Pharmaceutical instrument (Foley \& Sneider 1980) measures ten dimensions selected a priori such as personal care, mobility, thinking clearly and making decisions, Initiative to complete routine tasks, and medical history. The Colorado LTC-101 instrument contains fifteen items selected a priori (Mitchell 1982) in the areas of ADL, mobility, nutrition, sensory status, communication, skin care, medications, ordered therapies, motivation and behavior. The GFRS (Grauer \& Birnbom 1975) contains 30 1tems, selected a priori, measuring physical, mental and functional abilities as well as adequacy of living quarters, financial status, and support from relatives and friends. The HRCA models (Sherwood \& Feldman 1970; Sherwood et a1. 1975) contain items from a variety of established instruments. Through clinical judgment and discriminant function analysis these items were reduced to reflect the areas of $\mathrm{ADL}$, living 
arrangement, functional health, financial situation, occupation and morale. The Arizona instrument (Greene \& Monahan 1981) contains twentytwo items selected a priori in the areas of ADL, psychosoclal health and sensory communication.

The six remaining instruments fall to adequately represent the desired content areas, particularly the area of social functioning. Items for the UnIversity of Western Ontario instrument were selected a priori (Cape et al. 1977) and measure mental status, vision, hearing, ADL, mobility, and falls. Items for the Baltimore models (Kane et al. 1981) were obtained from a medically oriented PSRO instrument and reduced through discriminant function analysis to variables measuring $A D L$, mental problems, medical condition, treatments, and use of medication. Content for the Woodville survey instrument was borrowed from five behavior rating scales reflecting physical, emotional, social, and economic content. When the subscales of these instruments were reduced by discriminant function analysis, however, the subscales which remained measured care needed, ADL, and psychiatrically orfented characteristics such as mood and communication.

Items for the New York State DMS-1 instrument (New York Office of Health Systems Management 1978) were also mathematically selected and reflect mental status, sensory and communication impairment, incontinence, nursing care and therapy needs. According to the Massachusetts Department of Public Health (1975c), the patient survey models do not delve Into social and psychological dimensions, except superfictally. Specific content is not reported for the Illinois instrument (Taber et a1. 1980). 
Acceptable Inter-Rater Reliability. Out of twelve Instruments reviewed in this section, inter-rater reliability is reported in only two, the Ontario Assessment instrument and the GFRS. The first appears suited for a large scale nursing home screening program, the second needs additional study. The Ontario instrument has reported (Cape et al. 1977) inter-rater rel.iability of .81 to 1.00 on all items when administered by trained students. Rater blas, however, was encountered with the GFRS. When administered in conjunction with the Wisconsin Community Care Organization (Applebaum et a1. 1980) a difference of approximately thirty points was found between the score obtained in the context of service delfvery and the score obtained for independent evaluation. Service delivery personnel found the clients significantly more at risk.

With the exception of the HRCA models (Sherwood \& Feldman 1970) which were designed to be administered by an intake secretary and the Colorado instrument which is accompanfed by detailed instructions (Colorado Foundation for Medical Care 1982), it is questionable whether acceptable inter-rater reliability can be established for nonprofessionals with the remainfing instruments. Extensive client knowledge is required to administer the New York Department of Mental Health instrument (Furman 1982), the Unfversity of Arizona instrument (Greene \& Monahan 1981), the Woodville survey instrument (Haddad 1981) and the Illinois Community Care instrument (Illinois Department on Aging n.d.). Medical judgment seems to be required for the administration of the New York DMS-1 (New York Office of Health Systems Management 1978), the Massachusetts survey Instrument (Mass. Office of Health Planning and 
Statistics 1975a), and the Baltimore PSRO models by Kane et al. (1981). Lack of information (Essner 1982) on the Sandoz Pharmaceutical instrument precludes its evaluation.

Criterion Validity Related to Placement. Seven of the twelve instruments reviewed have reported criterion validity. None, however, has validated a predictive equation which can make the level of care distinction required by Oregon and other states implementing the Social Security Waiver Program. While the waiver requires a differentiation between those needing nursing home care and those who can remain in the community (U.S. Code 1981), these seven Instruments have been designed for other level of care decisions. In addition, each instrument has been validated with a population which is more restricted than the elderly population in Oregon.

Five of the instruments, the New York DMS-1, the Arizona Survey, the Woodville State Hospital, the Mass. Department of Public Health, and the Baltimore PSRO models have discriminant function equations for separating individuals needing skilled nursing care from those needing intermediate or health related care. The New York (New York Office of Health Systems Management 1978), Woodville (Haddad 1981), and Massachusetts (1975a) equations were able to accurately predict skilled nursing or intermediate care placement for seventy-two percent or more of the patients sampled. The best Baltimore model was able to correctly place eighty-six percent of the skilled nursing facility and sixty-three percent of the non-skilled nursing factlity patients. According to the authors, any improvements in the accuracy of prediction for one group resulted in a less accurate identification of the other group (Kane 
et al. 1981). The Arlzona Instrument (Greene \& Monahan 1981) was able to accurately place seventy-three percent of the skilled care patients but only fifty-five percent of the intermediate care patients. Although it was able to accurately Identify seventy-six percent of those patients needing personal care only, this level of care category is not used in Oregon.

None of these five instruments has equations for separating those needing nursing home care in general from those who can be maintained in the community. None has been validated with a sample containing community residents. The Woodville sample was further restricted to inpatients with a psychiatric diagnosis.

A sixth instrument developed through discriminant function analysis and other methods separates those for whom HRCA care appears "best" from those for whom HRCA care is considered "not best" (Sherwood et al. 1975). Since HRCA offers residentlal care In addition to nursing care, the equation which identifies HRCA "best" also Includes individuals who could be maintained in the community. Like the other instruments just discussed, the HRCA instrument was validated with a restricted population. The sample was drawn from HRCA applicants who were generally of immigrant population and may not represent the needs of the elderly in general.

A seventh instrument, The Geriatric Functional Rating Scale, used patient outcome as the criteria (Grauer \& Birnbom 1975). When administered to 130 Canadian elderly sampled from sentor centers, day hospitals and geriatric hospital applicants, GFRS scores were found to correlate with client outcome 18 months later. Eighty-three percent of those 
predicted to need nursing home care were either institutionalized or dead; 90 percent of those predicted to need their own home were still at home. Although this instrument does make the distinction between the need for home services versus the need for nursing home care, that distinction is based on Canadian level of care definitions. It is not known how these definitions compare with those of the United States. Quantification of Data. Each of the twelve instruments evaluated in this section of the literature review generates scores which are numerically quantifiable. In addition, each has established decisionmaking rules for translating these scores into level of care determinations.

Maximum need is the classification system used by three of these instruments. With the Baltimore PSRO empirical model, a client is classified as needing skilled care if he meets any one of four criteria developed by Dr. Carl Adam of the National Health Corporation (Kane et a1. 1981). According to Foley et al. (1980) placement with both the Massachusetts survey and the Sandoz Pharmaceutical instruments is based upon the highest need Identifled in several patient assessment dimensions. That need is expressed as an index which is directly related to level of care.

Multiple contingency is the classification system used by an additional three Instruments. The New York Mental Hygiene Level of Care Instrument simultaneously considers client self-care ability and the amount of skilled assistance needed (Furman 1982). Placement recommendations using the Ontario system are based upon a total ADL score, but can be overridden by client incontinence or cllent inability to get to 
the washroom (Cape et al. 1977). Placement with the Illinois Community Care instrument is based upon a combination of client need and provider wilingness to provide the necessary service (Welch 1982).

Some type of additive system is more commonly used for classification. The total raw score is the basis of placement with both the Colorado LTC 101 (Mitchell 1982) and the GFRS (Grauer \& Birnbom 1975). Placement is based upon a total discriminant function score for the New York DMS-I (New York 1978) the University of Arizona instrument (Greene \& Monahan 1981), the Woodville State Hospital Screening Instrument (Haddad 1981), HRCA (Sherwood et al. 1975), and the Baltimore Logistic Regression Model (Kane et a1. 1981).

Summary. None of the twelve instruments reviewed in this section of the 1iterature appear suited for use in a large scale nursing home screening program (Table II). Five of the instruments do not have validation studies to support their level of care placement criteria. Although the seven remaining instruments have established criterion validity, six of the instruments do not address the level of care category which differentiates the elderly needing nursing home placement from those who can remain in the community. With the exception of the HRCA Instrument, none of the six instruments appear to measure a functional continuum or the desired content. None has reported inter-rater reliability. The GFRS (Grauer \& Birnbom 1975) is the only instrument with established criterion validity which also makes the necessary distinction between the need for nursing home placement and community care. It also appears to measure a functional continuum and the desired content. Problems have been reported, however, with inter-rater 


\begin{tabular}{|c|c|c|c|c|c|c|c|c|c|}
\hline \multirow[b]{2}{*}{ Instruments } & \multicolumn{9}{|c|}{ Criteria for Evaluating Instruments } \\
\hline & 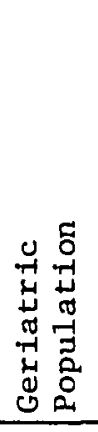 & 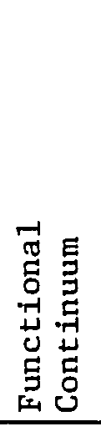 & 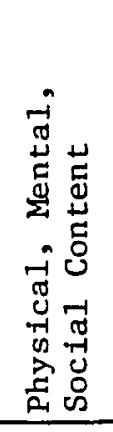 & 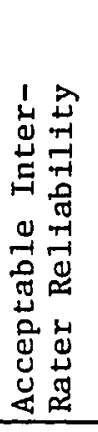 & 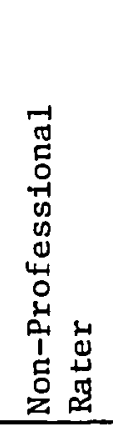 & 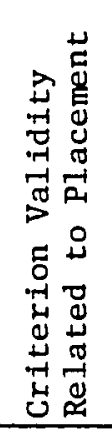 & 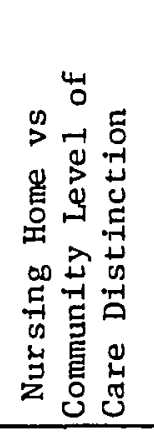 & 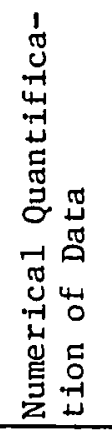 & 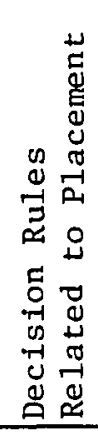 \\
\hline New York State DMSI & Yes & No & No & n.r. & n.r. & Yes & No & Yes & Yes \\
\hline GFRS & Yes & Yes & Yes & No & n. r. & Yes & Yes* & Yes & Yes \\
\hline Woodville St. Hosp. & Yes & No & No & n.r. & n.r. & Yes & No & Yes & Yes \\
\hline HRCA & Yes & Yes & Yes & n.r. & n.r. & Yes & No & Yes & Yes \\
\hline Baltimore PSRO & Yes & No & No & n.r. & n.r. & Yes & No & Yes & Yes \\
\hline Mass. & Yes & No & No & n.r. & n.r. & Yes & No & Yes & Yes \\
\hline Colorado & Yes & Yes & Yes & n.r. & n.r. & No & Yes & Yes & Yes \\
\hline New York Dept. & & & & & & & & & \\
\hline Mental Hyglene & No & Yes & Yes & n.r. & n.r. & No & Yes & Yes & Yes \\
\hline Sandoz Pharm. & Yes & Yes & Yes & n.r. & n.r. & No & Yes & Yes & Yes \\
\hline Illinols & Yes & Yes & n.r. & n.r. & n.r. & No & Yes & Yes & Yes \\
\hline Arizona & Yes & No & Yes & n.r. & n.r. & Yes & No & Yes & Yes \\
\hline Ontario & Yes & Yes & No & Yes & n.r. & No & Yes* & Yes & Yes \\
\hline
\end{tabular}


rellability (Applebaum et al. 1980). In addition this instrument was developed in Canada and has not been validated with an institutionalized elderly population or against U.S. level of care placement criteria.

Instruments Used by Other States Granted a Federal Waiver

Iike Oregon, other states which were granted a Medicaid waiver under the Social Security Amendment of 1981 (U.S. Code 1981) must have a plan for determining the need for nursing home placement. Since these plans and their supporting instruments are often not reported in the literature, telephone interviews were conducted with personnel from each of the thirteen states which, in addition to Oregon, had been granted a Federal Medicaid walver prior to July 1981 (Howe 1982).

The instruments being used by these states will be evaluated in terms of the previous criteria: (1) design for a gerlatric population, (2) measurement along a functional continuum, (3) measurement of physical, mental, and social content, (4) acceptable Inter-rater rellability when admintstered by non-professionals, (5) criterion validity related to nursing home placement, and (6) numerical quantification of data. Unless otherwise noted, the evaluation of the instruments used by these states are based upon a single interview.

Design for a Geriatric Population. Nine of the thirteen states contacted have waivers which apply to the elderly population in general. These states are Minnesota (Feldman 1982), Rhode Island (Treistman 1982), Georgla (Goldman 1982), Florida (Landrum 1982), Iowa (011ver 1982), Kansas (Gumb 1982; Kansas 1980), Louisiana (Sims 1982), Virginia Carnes \& Cook 1977), and Colorado (Mitchell 1982). Each state is using 
an instrument or combination of instruments which has been developed specifically for a geriatric population. Most of the instruments have been designed by the department which is administering the program, some in conjunction with a state university. The instrument being used in Colorado is the Colorado LTC-101 PSRO Certification Document (Colorado Foundation for Medical Care 1980 and 1982; Mitchell 1982) and has been evaluated in a former section of the literature review.

Four of the states contacted have waiver programs which apply to groups representing few elderly. The program in both Nevada (Dyer 1982) and South Dakota (Fecht 1982) is limited to the mentally retarded. Vermont's (Melzer 1982) and Montana's (Uda 1982) program is limited to the mentally retarded and mentally 111 . Understandably none of the instruments used with these programs were designed for the elderly. Montana is, however, planning to expand its program to include the elderly and will use the GFRS (Grauer \& Birnbom 1975). This instrument has also been evaluated in a former section of the literature review. Measurement Along a Functional Continuum. As described in the interviews, all of the instruments used in the waiver programs for the elderly and for the mentally disabled were designed to measure a functional continuum. Inspection of the Vermont instrument, however, identified community related items which might be difficult to reliably complete for individuals residing in nursing homes (Vermont 1982). Measurement of Physical, Mental, and Social Content. All of the instruments designed for the mentally disabled and seven of the instruments designed for the elderly are reported to be comprehensive. The instruments used for the elderly in two states have limited content. 
Designed to reflect state and federal regulation, the Virginia instrument (Virginia Office of Medical Assistance n.d.) contains many items on diagnosis and disability, but none on social functioning. The instrument used in Georgia contains medical items only.

Acceptable Inter-Rater Reliability. Inter-rater reliability has not been established for any of the instruments being used to implement the federal Medicaid waiver program. In addition, each instrument was designed to be administered by a designated professional rather than a non-professional. Instruments being used in Rhode Island, Florida, Iowa, Kansas, Louislana, and Virginia (Carnes \& Cook 1977) were designed to be administered by multi-disciplinary terms.

Criterion Validity Related to Placement. Studies to establish criterion validity have not been conducted for any of the instruments being used in the walver program. The Colorado LTC-101 PSRO instrument (Mitchell 1982b) is the only one which has established dectsion making rules relating score responses to placement. The rules, however, have not been validated. With the exception of this instrument, all of the waiver instruments are being used as a guide for clinical judgment rather than a substitute for clinical judgment.

Quantification of Data. Not one of the instruments used by the thirteen states with Medicald waivers has explicit rules for making level of care decisions. In addition, ten of the instruments contain items with descriptive response models making numerical quantification and validation difficult. Information is not complete for Rhode Island, Montana, and Nevada. 
Summary. Not one of the thirteen instruments being used to implement the Federal Medicald walver program meets the criteria which would make it sultable for use in a large scale nursing home screening program (Table III).

Although seven of the instruments meet three of the five criteria (i.e. design for a geriatric population, measurement along a functional continuum, and measurement of physical, mental, and social content), none was designed to be administered by non-professionals or has established inter-rater reliability and criterion validity. In addition, none has reported a numerically quantifiable response mode or decisionmaking rules which would allow tt to be readily validated for use as a substitute for clinical judgment in nursing home placement decisions.

\section{PSYCHOMETRIC CHARACTERISTICS OF THE}

PI ACEMENT INFORMATION BASE (PIB)

Like the instruments evaluated in the previous section, the Placement Information Base will be evaluated against the following criteria: (1) design for a geriatric population, (2) measurement along a functional continuum, (3) measurement of physical, emotional, and social content, (4) acceptable inter-rater reliability when administered by non-professionals, (5) criterion validity related to nursing home placement, and (6) numerical quantification of data. 
TABLE III

PSYCHOMETRIC CHARACTERISTICS OF INSTRUMENTS USED BY OTHER STATES GRANTED A FEDERAL WAIVER

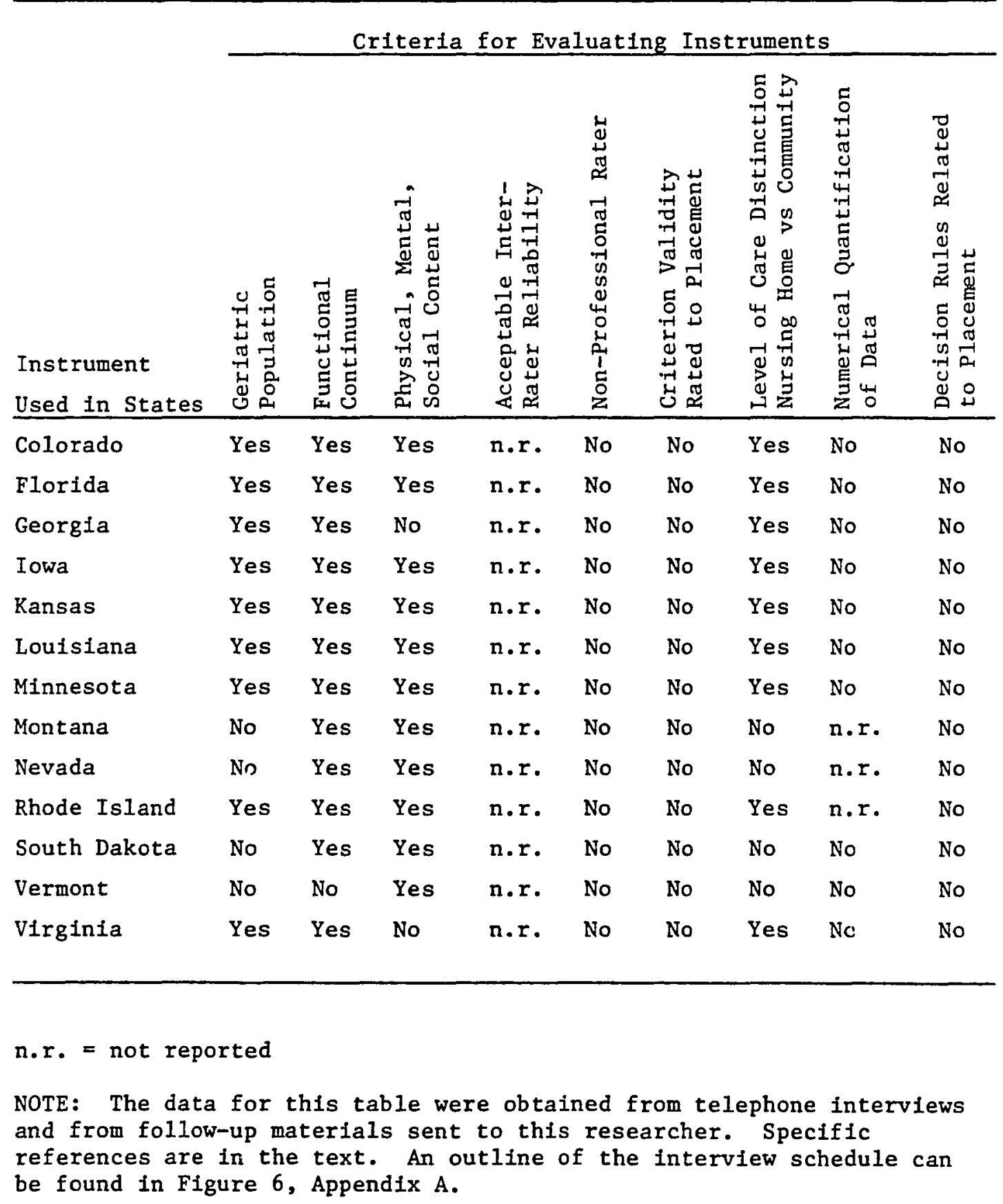




\section{Design for a Geriatric Population}

The Placement Information Base (PIB) was developed for the Southern Oregon Flexible Intergovernmental Grant/Waiver Continuum of Care Project for the Elderly, 1978 to 1981. It was designed to "provide a data base for matching the functional profiles of elderly individuals with the service capacity profiles of various institutional and alternative resources" (Oregon Department of Human Resources 1979). PIB for Oregon Project Independence and is being implemented statewide for both alternative care and nursing home care under the Department of Human Services Adult and Family Service program (Oregon State Health Planning and Development Agency 1981).

\section{Measure Along a Functional Continuum}

PIB was designed to measure along a functional continuum and to be used with elderly in a variety of living arrangements. Field tests conducted in several institutional and alternative program settings, ranging from hospitals to in-home and community services, were reported to indicate generally adequate results (Oregon Medical Association 1980).

The adequacy with which PIB Items can measure the mental functioning of elderly clients was recently questioned by Dingman (1983). In a study comparing the PIB scores of twelve elderly nursing home clients with the results of indepth interviews, Dingman concluded that PIB items $1,12,14,16$, and 21 appear sensitive to cognitive functioning, but insensitive to specific levels of cognitive functioning. She suggested that PIB be revised "to fnclude an item 
which reflects the presence of dangerous behavior such as wandering, in conjunction with a disorientation to time" (1983, p. 57).

Measurement of Physical, Mental and Social Content

PIB was designed to measure functional data relevant to placement decisions and contains the following seven dimensions: communication, mobility, household and food management, social and emotional, finances, health, and self-care. Content was suggested from a variety of sources: Department of Human Resources guidelines, the Greater Oregon Professional Services and Review Organization criteria for authorization of level of care stays, the National Center for Health Statistics Long Term Care Minimum Data Set, PACE II, and surveys of Adult and Family Service workers and long term care providers (Oregon Medical Association 1980).

\section{Acceptable Inter-Rater Reliability}

One of the criteria in the development of PIB was that it should not require specialist training to complete (Oregon Department of Human Resources 1979). Inter-rater reliability with a varfety of raters was therefore studied during its development period.

The first three PIB "observational schedules" were tested with fifty elderly residents in skilled nursing, intermediate and residential units at a single nursing center. When PIB was administered by a paired nursing staff rater and observer, item agreement, by patient, was reported to average 83.7 percent for observational schedule no. $1,77.6$ percent for observational schedule no. 2 , and 70.7 percent for observational schedule no. 3. In addition, the average percent of items, by patient, on which the paired raters either agreed, or disagreed by only 
one scale level, was 96.6 percent for observational schedule no. 2 and 90.6 percent for observational schedule no. 3 (Oregon Medical Association 1980).

Inter-rater reliability for the fourth observational schedule was tested with a broader sample and with non-professional as well as professional raters. The sample Included elderly from a variety of living arrangements ranging from in-home to acute hospital. Raters included college students and homemaker afds as well as nurses. According to the authors, items found to be either unproductive or unreliable were subsequently rewritten or dropped (Oregon Department of Human Resources 1979). Specific reliability findings have yet to be reported.

Field studies were not conducted for the fifth and final version of PIB. Questions have been raised, however, regarding several items. According to Reed (1982), the number of nursing home residents who appear dependent in the areas of shopping, housekeeping, telephone use and medication administration would suggest that, for this group of elderly, opportunity rather than functional ability is being reported on PIB. Nursing home residents who do not have the need or opportunity, for example, to grocery shop or handle their own medication administration may be receiving dependent scores on these PIB items. This would artificially inflate the number of residents who appear functionally dependent in these areas. Inter-rater reliability of selected PIB items was also questioned by Dingman (1983). In a study of twelve elderly nursing home clients, she found substantial discrepancles on five items measuring cognitive functioning. 
Criterion Validity Related to Nursing Home Placement

Criterion validity was not established during the development of

PIB. Dependency in any one of five items was, however, Identified a priori as indicating a very high probability that nursing home placement was necessary. Levels of dependency which indicate a low, moderate, or high probability of placement have also been established a priori (Oregon Medical Association 1980).

These high risk items are now being studied by the Oregon Department of Human Resources. Preliminary analysis on limited samples indicate that the PIB scales most likely to distinguish between Adult and Family Service nursing facility clients and community-based clients are management of medications, grooming and dressing, bathing and showering, using the tollet, and Incontinence (Oregon State Department of Human Resources 1981a, p. 150). In a second analysis, as many as 60 percent of the Adult and Family Service clients residing in nursing homes were found to have no high risk score except inability to manage their own medications (Oregon Department of Human Resources 1981a, p. 155). The first analysis, however, was conducted using data on a sample of clients which included nursing home residents who were placed in a nursing home prior to the Implementation of the Pre-Admission Screen program. The second sample was limited to 60 elderly nursing home residents.

Quantification of Data

PIB generates item responses which are numerically quantifiable. Each item has five descriptor statements ranging from independent to dependent and a score response ranging from one to five. Although the 
items have been categorized by dimension, guidelines have not been established for summing the score responses and using either a dimension or total score for placement decistons.

Placement decisions can be based on responses to individual item scores using a set of decision rules established a priori by the developers of the instrument. The deciston rules are a form of maximum need and contingency. Individuals are considered to need nursing home placement if their maximum need is equal to or greater than a specified value and if their scores on other selected items are equal to or less than specified values. Declsion rules have been established for five probability levels of needing placement. These levels are very high, high, moderate, low, and no probability.

\section{Summary}

PIB appears to meet many of the criteria which would make it suited for use as a screening instrument in nursing home placement decisions. It was designed for a geriatric population, appears to measure a functional continuum and the desired content, has undergone preliminary inter-rater reliablifty testing, and has a numerlcally quant 1 flable response mode. Additional rellability and validity studies need to be conducted, however, before PIB is recommended for use as a screening instrument.

SELECTED FACTORS RELATED TO NURSING HOME PLACEMENT

This section of the literature review will discuss five factors commonly assoclated with nursing home placement. The first three are 
demographic factors. Certain patterns of institutionalization have been observed in relation to an elderly person's age, sex, and socto-economic status. The fourth factor is functional limitation. Different levels of functional limitation have been noted between the institutionalized and non-institutionalized in the areas of mobility, $\mathrm{ADL}$, instrumental $A D L$, vision and hearing, and mental functioning. The fifth and finalfactor, the avallability of nursing home beds, is thought by many to influence placement; an Increase in the number of beds tends to lead to an increase in the number of placements.

These factors are considered in this section of the literature review because they appear to influence placement and can be expected to Influence the results obtained by the administration and testing of the Placement Information Base, PIB.

$\underline{\text { Age }}$

Age is one factor associated with nursing home placement. With advancing age beyond sixty five, rates of institutionalization increase sharply, notably among those eighty five and older. Although the rate of institutionalization is less than 0.06 percent for those under sixty five it is almost 5 percent for those 65 and older. The rate begins at 0.8 percent for those aged sixty five to seventy four, increases to 3.9 percent for those aged seventy five to eighty four, and reaches 15 percent for those eighty five and older (Riley 1968). The Oregon rate of institutionalization (into nursing homes) follows this pattern but is higher; beginning at 1.3 percent for those aged sixty five to seventy 
four, it increases to 26.8 percent for those elghty five and over (Oregon Office of Elderly Affairs 1979). In addition to having higher rates of institutionalization, the "old old" are overrepresented in the nursing home population. While those over eighty years of age represent only 20 percent of the total elderly population (U.S. Bureau of the Census 1976) this group represents 63 percent of all elderly nursing home residents (U.S. Bureau of the Census 1979b). In Oregon this older age group represents 46 percent of all nursing home residents (Oregon Department of Human Resources 1981a).

Age as a factor associated with nursing home placement was studied by both Palmore (1976) and Vicente (1979). Although Palmore found little or no difference in total chance of institutionalization between persons who were younger or older at the beginning of the study, Vicente found the differences to be significant. Vicente found that the proportion of the sample with at least one stay in a nursing home increased with age; 68 percent of those eighty five and over at the beginning of the study in contrast with 35 percent of those sixty five to seventy four were institutionalized at least once before their death.

Age appears to be associated with the incidence of institutionalization, at least in part, because of its correlation with physical functioning. Nearly one fourth of the elderly nursing home applicants studied by Kraus et al. (1976) cited old age, frailty, and physical deterforation as reasons for seeking placement. In an eight nation study, Kamerman (1976) confirmed that frailty, chronic illness and physical incapacity were more marked among the eighty and over age group 
than in the sixty five to seventy five age group. He also found higher rates of institutionalization among this older group.

The correlation between age and mental functioning is less clear. Brook et al. (1979) found no significant differences in overall mental health as a function of age when the mental health measures were defined primarily in terms of psychological constructs. Measures that included physiological or physical in addition to psychological definitions of mental health indicated a slight tendency for older people to report poorer mental health. Because of the correlation between physical health and age, this finding may reflect a confounded definition rather than a true relationship between mental functioning and age.

$\underline{\text { Sex }}$

Being female is a factor which is assoctated with nursing home placement. A recent study of elderly Oregon Adult and Family Service nursing home residents indicated that the ratio of women to men was 71 to 29 (Oregon Department of Human Resources 1981a). This ratio is consistent with national nursing home figures (U.S. National Center for Health Statistics 1973a). In the total elderly population the disparity between the number of men and women is not as great. According to the U.S. Bureau of Census (1976) 59 percent of all elderly individuals are female and 41 percent are male.

Being female and of advanced elderly age is also associated with nursing home placement. Although the rates of institutionalization increase with age for both men and women, it is more dramatic for women; 8 percent of all women seventy five years of age and over are 
institutionalized in contrast with 6 percent of the men in the same age group (U.S. Bureau of the Census 1973). Between the ages of sixty five and sixty nine women are only slightly overrepresented in nursing homes; they constitute 54 percent of the total elderly population in that age

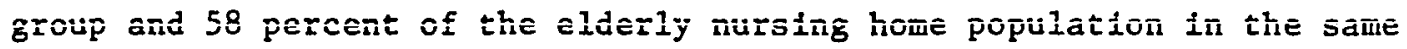
age group. The distribution shifts, however, so that by age eighty five and over women represent 64 percent of that age group in the total population and 76 percent of that age group in nursing homes (U.S. Bureau of the Census 1979a; U.S. National Center for Health Statistics 1973a).

Although it is apparent that more women than men are institutionalized, there is growing evidence that this pattern is better explained by marital status and living arrangement than by sex; women more frequently live alone, are widowed, separated or never married and may be less able to get help when they begin to fall mentally or physically. In longitudinal studies of elderly community residents, both Palmore (1976) and Vicente (1979) found that being female was significantly related to institutionalization. Being female did not, however, make a significant contribution when entered by Palmore into a multiple regression equation after living alone, marital status, and the number of living children. Similar findings were reported by Vincente. When entered into a multiple discriminant analysis after marital status and living arrangement, being female did not make a significant contribution to the incidence of nursing home placement. 
Soctal and Economic Characteristics

Marital Status. In 1979 only 15 percent of the elderly nursing home population were married; 15 percent had never married, and 64 percent were widowed (U.S. Bureau of the Census 1978). Th1s profile is quite different than that of the total elderly population reported in 1973. For the total group 72 percent were married, 17 percent unmarried, 7 percent never married, and 4 percent unreported (U.S. Bureau of the Census 1973).

Living Arrangement. Living alone or in a non-family situation also seems to be associated with nursing home placement. According to the Survey of Institutionalized Persons (1978), less than 29 percent of the residents had been living with a famlly member prior to institutionalization. Although the number of non-institutionalized elderly living with a family member is not reported, it is known that 49 percent are living with a spouse and an additional 28 percent are living with a more distant relative or a friend (U.S. Bureau of the Census 1973).

Since marital status and living arrangements are interrelated it is difficult to determine the contribution of each to the risk of being placed in a nursing home. Palmore, for example, in a longitudinal study of community residents, found that marital status contributed significantly to placement while living alone or the number of living children did not (1976). Vicente (1979) on the other hand, reported that not having a spouse and living alone or in a household with only one other person each contributed significantly to nursing home placement. Both studies concluded, however, that marital status was an indication of the availability of social support, not only from the spouse but also from 
children. Those who were currently marrled or who had in the past been married were more likely to have children who could provide a home or supportive care and thereby delay or reduce the Incidence of Institutionalization.

This explanation is supported by three additional studies. In a survey of Detroft area nursing homes, Barney (1977) reported that the few marrled people who were admitted to the nursing homes were likely to be functionally more dependent than those who were not married; those who had children or were visited by members of the immediate family were likely to be functionally more dependent than those who were single. Based on data from the OARS Survey of Institutionalized Elderly, Whanger and Lewis (1975) reported higher rates of mental and physical impalrment among the elderly married residents. A study of the well being of older people in Cleveland (U.S. General Accounting Office 1977) found that the Incidence of nursing home placement was greatest for those who were both greatly impaired and living alone. Of the elderly considered greatly or extremely impaired at the beginning of the study one percent had entered an institution within one year. Of this one percent none had been living with a spouse or offspring, 18 percent had been living with a more distant relative, 6 percent with a friend, and 76 percent had been living alone. In contrast, 29 percent of the greatly or extremely 1mpaired who remained in the community lived with a spouse and an additional 25 percent lived with an offspring. Only 10 percent lived with a more distant relative, 5 percent with a friend, and 31 percent lived alone (U.S. General Accounting Officer 1981). 
Income. Low income is an additional socio-economic factor associated with nursing home placement. While only 14 percent of the total elderly population is at poverty level, over 50 percent of all elderly nursing home residents are financlally disadvantaged and receiving Medicaid (Delury 1977; U.S. Bureau of the Census 1978; Saslow 1981). It is not clear, however, whether low income increases the incidence of Institutionalization or whether institutionalization increases the incidence of becoming low income. Vicente (1979) found that having an inadequate or marginal income contributed significantly to institutionalization. Two explanations were proposed for this finding. First, poorer people were more likely to qualify for Medicaid insurance. Second, those who had adequate income were able to postpone or avold nursing home placement by buying services which enabled them to remain at home. This finding runs counter to that of Palmore (U.S. National Center for Health Statistics 1973). He found that those who responded that they "cannot make ends meet" had a lower rate of institutionalization than all other response categorfes. He concluded that lack of money reduced the low income groups access to nursing home placement. Thess data were, however, collected prior to the passage of Medicare and Medicald.

The relationship is probably a combination of these two positions. It is known, for example, that many people enter nursing homes on a private basis and "spend down" to a low 1ncome. A Detroit area nursing home study found that almost half of all residents entered the institutions paying for their care through private means (Barney 1977). At the end of two years, however, less than 30 percent were still 
private patients. A recent report from the Oregon Senior Services Division confirms a similar trend in Oregon (1982). Over one third of all clients screened for nursing home services under Medicald payment were already residing in a nursing home, presumably on a private pay basis.

Functiona1 Limitations

The U.S. General Accounting office (1981) has reported a substantial difference of impairment between the institutionalized and the noninstitutionalized elderly. When OARS data on the noninstitutionalized elderly in Cleveland were combined with the OARS data on the institutionalized elderly in Durham, 87 percent of the Institutionalized elderly were estimated to be greatly or extremely impaired. In contrast, only 14 percent of the elderly living in the community and 17 percent of that total population were estimated to be greatly or extremely impaired.

Differences in specific functional limitations between the elderly residing in nursing homes and those residing in the community are difficult to evaluate. Studies have not employed comparable time periods, instruments, definitions, or methods of sampling. Despite these constraints imposed by methodology, a brief review of the major studies Indicate that a disproportionate number of elderly residing in nursing homes are functionally limited due to physical or mental disabilities. Mobility. One of the major functional areas in which elderly nursing home residents seem to have proportionately more difficulty than the noninstitutionalized elderly is the area of mobility. An estimated 
14 to 25 percent of the elderly nursing home population is confined to bed (U.S. Bureau of the Census 1978; U.S. National Center for Health Statistics 1974) compared to one or two percent of the noninstitutionalized elderly (U.S. National Center for Health Statistics 1974; Shanas 1974). Although the percentages vary due to differing methods of defining levels of mobility, both the Natlonal Health Survey and the Survey of Institutionalized Persons estimated that more than half of all nursing home residents were considered nonambulatory and unable to leave the premises (U.S. National Center for Health Statistics 1974; U.S. Bureau of the Census 1978). Th1s is in sharp contrast with the four to eight percent of the noninstitutionalized elderly estimated to be housebound by Shanas (1974) and the National Health Survey (U.S. National Center for Health Statistics 1974).

Activities of Daily Llving (ADL). The performance of activities such as eating, dressing, bathing, and toileting is another functional area in which elderly nursing home residents appear to have proportionately greater needs than the noninstitutionalized elderly. Again the estimate of the number needing assistance varies from study to study but the difference between those in nursing homes and those in the community remains fairly constant. While the estimated percent of nursing home residents needing ADL assistance ranged from 60 percent (Barney 1977; Miller 1965) to 100 percent (Whanger \& Lewis 1975), the estimates for communfty restdents ranged from less than 16 percent (U.S. National Center for Health Statistics 1974) to 21 percent (Pfeiffer 1975). The ADL needs of both nursing home and community residents reported by the two OARS studies appears inflated because of the way terms are defined. 
In addition to personal care needs, the OARS instrument defines ADL to include instrumental activities of daily living such as shopping, laundry, traveling around town, handling finances, and taking medications. These two studies, however, probably present the best comparison of the two populations since the same instrument is used for both. According to their findings there are five nursing home residents to every one community resident in need of ADL assistance.

Comparisons between nursing home and community residents on specific ADL needs is not possible because of lack of data for the community residents. Although the National Health Survey instrument included Items on continence, toileting, eating and dressing, findings regarding these specific areas have not been released. In their community studies, Shanas (1974) and Palmore (1976) gathered data on several but not all of these activities. When reporting their findings, however, the response to these items was combined with those measuring mobility and housekeeping activities.

Some information regarding specific ADL needs of nursing home residents is available. The Survey of Institutionalized Persons estimated that 44 percent of all residents had no bowel or bladder control (U.S. Bureau of the Census 1978). This finding was supported by a New York State study of skilled nursing facilities and health related care facilities. In surveying over 7000 elderly from 89 facilities statewide, Orr (New York Office of Health Systems Management 1978) found that 45 percent of the sample was incontinent of urine, with 23 percent frequently incontinent. Forty percent were incontinent of stool, with 20 percent frequently incontinent. This survey also reported 38 percent 
of the sample to be in need of assistance with eating, 57 percent in need of assistance with tolleting, 75 percent in need of assistance with dressing and 88 percent in need of assistance with bathing. Although the vast majority of those needing assistance with eating did not requuire total help, almost half of those needing assistance in the other areas did require total help.

Instrumental Activities of Daily Living. As just noted, studfes have frequently not reported $A D L$ and instrumental $A D L$ functional levels or have combined the results when making reports. Data from the 1976 Survey of Institutionalized Persons (U.S. Bureau of the Census 1978), however, provide some insight into the type and amount of care needed by institutionilized elderly. In this survey, nursing home personnel estimated that 15 percent or fewer of the total institutionalized population would have been able to remain at home if services had been provided in the areas of food delivery, housekeeping and errands, home health care, day care, transportation, or other types of care.

In addition the personnel estimated that over 96 percent of the institutionalized elderly needed total care on a regular basis, with 80 percent needing nursing care, 60 percent medical care, 0.5 percent psychiatric care, 14 percent physical or speech therapy, 22 percent occupational or recreation therapy, 6 percent transportation, 42 percent special equipment, and 76 percent needing dietary or medication assistance. The survey also found that less than 12 percent of nursing home residents handled their own finances.

Vision and Hearing. Elderly nursing home residents are also thought to have proportionately more impairment in the areas of vision 
and hearing. The National Health Survey (U.S. National Center for Health Statistics 1973c) found that 22 percent of all elderly nursing home residents had seriously impaired vision. Although it did not report the percentage of noninstitutionalized elderly who were also serfously impaired, that percentage must be smaller; those with vision impairments of all levels of seriousness represented less than 15 percent of the total noninstitutionalized elderly. Unfortunately it is not possible to draw similar conclusions regarding hearing impairments. Although the National Health Survey estimated that 16 percent of the elderly nursing home residents had serfous hearing impairments, it also estimated that 23 percent of the noninstitutionalized had some level of hearing impairment. The percent with serious impairment was not reported.

Mental Functioning. Another area in which the elderly residents of nursing homes appear to have proportlonately more limitations than the noninstitutionalized elderly is mental functioning. Although no large scale study has been conducted to establish the incidence of mental impairment among the elderly residing in the community, Blenkner (1967) in a review of isolated studies found estimates to range from 14 to 17 percent for this population.

In contrast, the National Health Survey found that an estimated 56 percent of all nursing home residents were considered senile by their administrator and that nearly two thirds of this number were thought to have advanced senility (U.S. National Center for Health Statistics 1973c). Zimmer's New York findings were similar. In a study of Rochester County nursing home admissions, he found that 59 percent were 
forgetful and confused and that 8 percent were severely confused (Zimmer 1975). The New York statewide study reported by Orr (New York Office of Health Systems Management 1978) found confusion among 64 percent of the nursing home residents, with 18 percent always confused. In addition it classified 14, 21 and 18 percent, respectively as sometimes being assaultive, abusive, and needing restraints. While less than one half of one percent were judged to be always abusive or assaultive, almost 10 percent were always restrained.

This contrast between the mental limitations of the elderly in nursing homes and those in the community was also found in the Monroe County Health Care of the Aged Study (1968). Among those in the community 10 percent were judged to need intermittent supervision for mental Impairment. Among those in nursing homes, however, 46 percent were judged to need intermittent supervision and an additional 6 percent to need continual supervision.

It is apparent from the literature review that functional limitations are more prevalent among the elderly nursing home population than among the noninstitutionalized elderly. There is also evidence that the functional areas are correlated. Kahn, Goldfarb, Pollack, and Gerber (1960) found that mental functioning was significantly related to physical functioning. In a study of admissions to New York Institutions they reported that as the severity of physical impairments increased, the proportion of residents with moderate or severe mental impairment also tended to increase.

A recent OARS study of elderly in a variety of living situations, found a .38 correlation between mental and physical health. It also 
found that the correlations between ADL and physical and mental health were 0.57 and 0.70 , respectively (Pfeiffer et al. 1981, p. 436). These correlations support earlier OARS findings; a validation study of the Short Portable Mental Health Status Questionnaire (Smyer et al. 1979) found that the variables which loaded highest on the discriminant function separating the intact/mildly intellectually impaired from the moderate/severely impaired were continence, ability to use the telephone, ability to cook for oneself, and ADL activity.

A correlation between mental functioning and ADL was also found by Miller (1965). He reported that limitations in mental functioning interfered with the ability to perform personal activities of daily living. Of the 32 percent studied by him who were physically capable of performing these tasks for themselves, less than two thirds were also behaviorally capable.

Functional limitations are thought to be correlated with other factors associated with nursing home placement. Kraus et al. (1976) and Kamerman (1976) both confirmed that physical limitations and the prevalence of multiple disabling conditions increase with age. An extensive review of the literature by Brook et al. supports this association (1979). The relationship between physical health and age was found to be curvilinear with functional limitations accelerating with age. The U.S. General Accounting office (1981) estimates that 8 percent of the people who are 65 to 74 years old are functionally impaired as compared to 18 percent of those 75 years of age and older. Although Brook et a1. (1979) found no significant relationship between physical health and sex in the general population, certain 
limitations which are frequently found among nursing home residents appear to be sex linked. According to the National Center for Health Statistics (1973) men have the higher rate of cardiovascular accidents (strokes) which is the condition most prominent in causing "restriction to bed" or "up in a wheelchair for only a few hours." Women were found to have different chronic conditions; they have significantly higher rates of senility, arteriosclerosis and arthritis or rheumatism.

\section{Availability of Nursing Home Beds}

There is increasing evidence which suggests that the very presence of available nursing home beds stimulate the volume of demand and the risk of being placed in a nursing home. Traditional economic theory explains the relationship between the number of nursing home beds and the number of elderly placed in them in terms of supply and demand; the supply increases in response to an increased demand while the demand remains independent of the supply. Under this theory any increase in the supply of nursing home beds would have been preceded by an increased volume of demand created efther by an increase in the number of elderly or by the elderly becoming more dysfunctional.

There is growing evidence that the supply of nursing home beds is more strongly influenced by financlal considerations than by the number of elderly or their functional needs. The evidence suggests that it is supply which is stimulating demand rather than demand stimulating supply (Somers \& Somers 1977). Since the availability of Hill Burton construction funds and the passage of Medicare and Medicald legislation which each favor nursing home placement above alternatives, the number 
of nursing home beds has fncreased at a rate disproportionate to that of the elderly population. Between 1963 and 1973 the supply of nursing home beds in the United States expanded 160 percent, from 0.5 million to 1.3 million (Pattee 1980). During that same time the elderly population grew less than 21 percent (U.S. Bureau of the Census 1979a). With no evidence to suggest that the elderly had become more dysfunctional (U.S. National Census for Health Statistics 1971, 1973b) the proportion of nursing home beds increased from 29 beds per 1000 elderly to 66 beds per 1000. Although nursing home expansion has been tempered somewhat by certificate of need and professional services review legislation, the 1976 nationwide ratio of nursing home beds per 1000 elderly was estimated to be 48.3 (U.S. Bureau of the Census 1979a; Delury 1977). It may be argued that the pre-1965 supply of nursing home beds was artificially depressed since the elderly had limfted sources of payment and therefore could not financlally "demand" that their needs be met. This would explain the functional similarity of the population pre- and post-Medicare and Medicaid and would explain the sudden surge in demand and the corresponding increase in nursing home bed supply.

Under this argument, however, three conditions would be expected. First, the increased number of beds would be uniformly distributed based on population. Second, the geographic areas which have the larger number of beds per 1000 elderly would have lower occupancy rates. Third, the beds would be occupled by elderly whose functional needs justify nursing home placement.

Nursing home beds are not uniformly distributed. Florida, for example, has fewer than 24 beds per 1000 elderly while Oregon has over 
50 (Ladd 1981). Within Oregon, two counties have no nursing home beds and the number of beds in the remaining countles range from 25.6 to 99 per 1000 elderly population (Saslow 1981).

Occupancy levels do not seem to be influenced by the supply of nursing home beds. Although the number of beds per 1000 elderly vary markedly within Oregon, occupancy rates by county are surprisingly similar, ranging from 90 to 98 percent occupancy (Saslow 1981).

Many nursing home beds are filled by elderly whose functional needs do not justify that level of placement. A 1976 review of the literature by the State of Georgla (1977) indicated that 25 to 40 percent of the elderly currently placed in nursing homes could be cared for in less restrictive settings. According to the U.S. General Accounting Office 25 percent of the patients in hospitals and nursing homes are treated in facilities which provide a higher level of care than needed. A 1970 study of nursing home patients in Massachusetts concluded that nearly two thirds of all nursing home patients did not require the level of services that the homes were required to provide (Mass. Office of Health Planning 1975). New York's Monroe County study (1968) evaluated the health care needs of almost 62,000 elderly in a variety of living situations. It reported that only 3.04 percent of the total elderly population (or 30.4 per 1000) needed nursing home care. Another study of over 164,000 elderly in six New York countles found the need for nursing home placement to range from 2.87 to 4.02 with an average of 2.74 percent or 27.4 nursing home beds per 1000 elderly (New York Department of Comprehensive Health Planning 1970). It might be concluded from these studies that Oregon's supply of 50 nursing home beds 
per 1000 elderly cannot be explained on the basis of functional need alone.

Summary

The risk of institutionalization in a nursing home appears greatest for those elderly who are female, over 75 , and living alone or with a non-relative. The risk also appears greater for elderly living in a community which has a large supply of nursing home beds.

Although there are many elderly living in the community who are functionally limited, the presence of these limitations appears to increase the risk of institutionalization. Despite the fact that differing methodologies make comparisons difficult, the most conservative estimates report that the number of elderly nursing home clients who are impaired in the areas of ambulation and confinement to bed, activities of daily living, and mental functioning are 4 to 7 times higher than the number of non-institutionalized elderly with simflar complaints.

\section{CONCEPTUAL FRAMEWORK}

The purpose of this dissertation is to evaluate the suitability of the Placement Information Base, PIB, when used as a substitute for the entire Pre-Admission Screening process in nursing home placement decisions. Such a substitute is attractive because of the continuing demand for Pre-Admission Screening (Oregon Department of Human Resources 1982b) and because of the high costs of administering such a screening program (Oregon Department of Human Resources, 1981c, 1982a; Hinkle 1982). 
The review of 1iterature has indicated a growing use of mathematically or empirically derived equations as a less costly substitute for clinical judgment (Foley \& Sneider 1980). None of the reviewed instruments, however, appear suitable for use In Oregon's nursing home screening program or with the programs of the other states implementing the Federal Medicald waiver program.

One half of the instruments designed specifically for placement do not meet the psychometric criteria considered desirable for such an instrument (Cape et a1. 1977; Welch 1982; Foley \& Snelder 1980; Furman \& Lund 1979; Colorado Foundation for Medical Care 1980; Grauer \& Birnbom 1975).

The other half of the instruments designed for placement appear to meet the psychometric criteria. None, however, address the level of care category which differentiates between the elderly needing nursing home placement and those who can remain in the community (New York 1978; Haddad 1981; Sherwood et al. 1975; Kane et al. 1975; Mass. 1975a; Green \& Monahon 1981).

For these reasons it appears justifiable to extend the evaluation of PIB's psychometric characteristics and to make recommendations for improving its effectiveness as a screening instrument used for nursing home placement.

This research study seeks to answer two basic questions. The first question is one of measurement. It addresses the issue of whether or not PIB items are capable of measuring constructs, characteristics, or traits consldered useful in nursing home placement decisions. The second question is one of utility. It addresses the issue of how well 
PIB items are correlated with nursing home placement as determined by the total Pre-Admission Screening process.

These two questions address what Messick calls "the rational foundation for predictiveness and relevance" (1980, p. 1012). According to Messick it is not enough to verify the existence of a relationship and to estimate the strength of that relationship. It is also necessary to Identify "'useful' relationships under applied conditions" (1980, p. 1017).

The identification of useful relationships is a function of criterion-related validity. It is particularly important in a study of the relationship between PIB and the PAS process. According to both James (1973) and Gulliksen (1950) construct validity is critical if the criterion measure is impure or contaminated.

The Pre-Admission Screening process as a criterion measure should be considered potentially contaminated. Decisions are not being made by a single source, but come from twelve teams through the state. Although the PAS teams have received the same inservice training and use the same instruments, it is not known to what extent the decision-making process is standardized or corresponds to the a priori deciston rules. It has yet to be established that different PAS teams are making the same level of care recommendations for cllents with similar functional limitations. While the teams are famillar with the a priorl deciston rules, they have not been required to follow them.

Establishing construct validity in addition to criterion-related validity would, therefore, provide a more rational basis for using PIB as a substitute for PAS in nursing home placement decisions. This study 
evaluates both the construct and criterion-related validity of PIB. Because of their impact upon construct and criterion-related validity, this study will also evaluates aspects of PIB's content validity and reliability.

For the ease of presentation and discussion, the specific questions and anticipated findings of this study are be presented under the headings of content validity, construct validity, criterion-related validity, and reliability.

\section{Content Validity}

Content validity can enhance both construct and criterion-related validity by insuring that important constructs are adequately represented and that the 1tems measure the functional range necessary to assess the population.

PIB appears to have items in each of the desirable content areas. There are items designed to measure physical, mental, and social health. The questions which are addressed by this study concern the scalability of the PIB ftems and the varfability of PIB scores on the items.

Scalability is a measure of the extent to which items pertaining to the same dimension will combine into multi-item measures. The advantage of scaling is to reduce the number of variables and to make it easier to relate those variables to other variables. According to Guttman (1944, p. 148), scaling "provides an Invariant quantification of the attribute for predicting any outside variable."

There are several types of scales. The one which is employed in this study is called a Summated Rating Scale. This type of scale has 
two major characteristics (Kerlinger 1973). First, each item within the scale is thought to be of equal value and to contain the same proportion of variance about the construct. Second, the scale allows for an intensity or wide range of response.

It is anticipated that the PIB items can be grouped into multiitem scales. Each of the PIB items has been grouped a priorf, each has a five point response range, and many PIB items are thought to contribute equally to the probability of nursing home placement (Oregon Medical Association 1980). Appropriateness of the a priori groupings are evaluated through statistical methods including factor analysis and the coefficient alpha.

The variability of scores refers to the distribution of item scores across the possible range of responses. Insufficient variability may indicate that the items: (1) do not adequately assess the construct of Interest; (2) do not distinguish differences at selected points in range of values, or (3) do not assess one end of the functional continuum (Brook et al. 1977).

Variability of PIB scores is evaluated by visual examination of frequency distributions and by comparing item responses to the findings of other studies. It is expected that the items measuring physical limitations will be roughly symetrically distributed. The Health Insurance Study and other studies of health measures reviewed by Brook et al. (1979) revealed a negative skew on most physical health measures. These studies were, however, conducted with non-geriatric populations. Studies of the elderly, on the other hand, indicate that there are Individuals with severe functional limitations living in both the community 
(Shanas 1974) and in nursing homes (U.S. National Center for Health Statistics 1974).

It is also anticipated that the ftems measuring mental functioning are falriy normally distributed. The population which will be sampled in this study contains a disproportionate number of nursing home residents (Oregon State Department of Human Resources 1981a). Studies of nursing home residents have estimated, however, that fewer than 65 percent of the residents were judged to need supervision because of mental limitations (Health Care of the Aged Study 1967; New York Office of Health Systems Management 1978; Zimmer 1975). On the other hand, there are elderly with severe mental limitations living in both the community (Blenkner 1967) and in nursing homes (New York Office of Health Systems Management 1978; Health Care of the Aged Study 1967). PIB Items measuring social health are evaluated by visual examination only. According to the literature review conducted in conjunction with the Health Insurance Study (Brook et al. 1979), findings of other studies are difficult to compare. Operational definitions have not been comparable and the sampled populations have been chiefly psychiatric.

\section{Construct Validity}

As previously discussed, construct validity identifies underlying constructs or traits measured by an instrument or test. It is extremely important where the nature of the criterion is poorly understood or in some way contaminated (Gulliksen 1950; James 1973; Messick 1980). This study tries to identify underlying theoretical constructs which are measured by PIB items. It attempts to determine the extent to 
which PIB items assess functional status and whether the PIB items assess the particular dimension which they were intended to assess. Using correlational statistics, tests of significance, and factor analysis, the strength and direction of a variety of hypotheses are tested. The first set of hypotheses concerns the strength and direction between the PIB items themselves. Based on the convergent discriminability theory which holds that different measures of the same construct should be correlated (Kerlinger 1973), it is expected that PIB items will be related to one another. This is anticipated because PIB items were each designed to measure some aspect of a single construct, functional limitations. It is also expected that items or scales within a dimension will be more highly related with one another than with other dimensions. For example it is expected that grooming, bathing, using the tollet, and continence have more variance in common with one another than they do with items in the household and food management dimension.

The second set of hypotheses focuses on the strength and direction of the relationship between selected PIB items or scales and the demographic factors of age and sex. Based on the findings of other studies it is anticipated that items measuring physical functioning will be significantly and negatively correlated with age (Brook et al. 1979; Kraus et al 1976; Kamerman 1976), and not significantly correlated with sex (Brook et al. 1979). It is also anticipared that items measuring social support will be significantly and negatively associated with being female (Vicente 1979; Palmore 1976).

There are several construct-related relationships which are not being evaluated in this study. Income is one of these. Although it has 
been associated with functional Iimitations regardless of age (Brook et al. 1979), income cannot be addressed with this study's sample. All of the clients in this sample are on Medicaid and therefore are economically comparable. All subjects were efther recelving Medicaid or were presumed to be Medicaid eligible at the time of the PIB administration. Correlations between demographic factors and mental health are not evaluated in this study. According to Brook et al. (1979) studies of mental health are frequently unclear about the expected direction and magnitude of the association. Mental health items are often defined in physiological terms, thus confounding the association. Correlations between demographic factors and social health will not be evaluated. Restricted populations and lack of coiparable definitions make social health items difficult to compare (Brooke et al. 1979).

\section{Criterion-Related Validity}

Criterion-related validity is a measure of the extent to which one measure yields the same or similar information as another. In criterion-related validity, it is the relationship between the test and the criterion, not the test itself, which is being validated (Guion 1980). According to Cronbach (1970) it is appropriate to ask if the new test agree with the present source of information if the original test or procedure is useful.

One of the questions addressed by this study is whether data obtained by PIB agrees with the present source of information, the PreAdmission Screening process. In other words, can PIB items or 
combinations of Items differentiate between those individuals who need or do not need nursing home placement based on the PAS team recommendations. The hypotheses which flow from this question are concerned with: (1) whether the maximum need items identified a priori can adequately predict placement; (2) whether a mathematically derived prediction equation can adequately predict placement; and (3) which of these two methods is the more accurate predictor of placement. The maximum need system for PIB is based on the relationship between PIB levels of functioning and the probability that nursing home placement is necessary. These probabilities were established a priori by Mike Saslow and Jan Yamodis after consultation with clinicians and providers (Oregon Medical Assoctation 1980). A score of five on any of one of five different PIB Items in combination with low scores was thought to place individuals at a very high probability of needing nursing home placement.

Based on previous PIB studies by Oregon's Department of Human Resources (1981a) It is expected that the five "very high" probability items will adequately predict placement. Over 90 percent of all nursing home residents were rated at very high risk on the medication item compared with less than 8 percent of those living at home. The reliability of the medication item 1s, however, being questioned (Reed 1982). Ninety percent is thought to be too high. If the medication item is dropped from the analysis, it is expected that the four remaining items will not adequately predict placement. The Department of Human Resources study of forty Adult and Family Service clients newly admitted to intermediate care facilities indicated that 60 percent had 
no high risk PIB rating except for managing medications (Oregon Department of Human Resources 1981a, p. 155).

The mathematical prediction equations which are evaluated in this study are derived from the statistical procedure called discriminant analysis. This procedure is a method of weighing and combining discriminating variables in such a way that the two groups, those who need and those who do not need nursing home placement, are forced to be "as statistically distinct as possible" (Klecka 1975, p. 435). The weighted discriminating variables form what is called the discriminant function equation.

If the discriminant function equation derived from PIB scores can adequately predict placement for individuals with known placement, that equation can be used to predict placement for individuals whose placement has not been determined but for whom PIB scores are available. In this study the discriminant equations are derived from half of the total sample for whom placement is known. The equation is then be crossvalidated on the other half of the sample.

Based on the findings of other studies it is anticipated that the mathematically derived PIB equations will adequately predict placement. It is expected, however, that the accuracy of prediction will differ between the group who needs nursing home placement and the group who does not. The discriminant function equation derived from the Woodville State Hospital survey instrument was, for example, able to accurately predict placement for 87 percent of its skilled nursing care patients and 74 percent of its intermediate care patients. Accuracy dropped to less than 66 percent when the equation was used with psychlatric 
patients (Haddad 1981). Similar findings were reported by HRCA

(Sherwood et al. 1975), Arizona (Greene \& Monahan 1981), Baltimore (Kane et al. 1981), and Massachusetts (Mass. Office of Health Planning 1975).

It is also anticipated that any attempt to improve the accuracy of one group will come at the expense of the other group. Kane et al. (1981) tested a series of mathematical equations based on logistic regression. They found that the best overall equation was able to correctly identify 86 percent of those needing skilled care and 63 percent of those not needing such care. Other equations were able to more accurately Identify one group but always at the cost of incorrectly identifying a large proportion of the other group. The New York State Long Term Care Survey reported similar findings (1978). Using an equation based on discriminant function analysis and conditional probabilities, accuracy levels were evaluated for a variety of thresholds. The threshold which could accurately predict placement for 95 percent of the skilled nursing patients misclassified almost 30 percent of the healthrelated facility patients. Conversely, the threshold which could accurately predict 95 percent of the health- related facility patients misclassified almost 40 percent of the skilled nursing care patients. It is not within the scope of this study to recomend threshold levels for PIB. That dectsion should be based on economic and ethical considerations. It is important to recognize, however, that the levels of accuracy which are be reported in this study reflect the "threshold" which is currently being operationalized through the Pre-Admission Screening program. If that threshold is rafsed or lowered to reflect 
changes in the availability of resources, the predictive accuracy of PIB will also change.

As previously discussed, it is anticipated that both the a priori maximum need system and the mathematical equation will be capable of adequately predicting nursing home placement. Each method will be evaluated by computing the number and proportion of correct classifications which it can make for a group of elderly whose placement is already known. The accuracy of the two methods are then compared. The wathematically derived equation is expected to be more accurate than the maximum need system when the medication item is dropped from the analysis. There are two reasons to anticipate these results. First, a derived equation can be sensitive to all levels of functioning and has an additive effect. An individual could, for example, be judged by the PAS team to need nursing home placement on the basis of moderate limitations in a number of functional areas but have no high risk PIB scores. Th1s individual might be accurately placed by the mathematical equation but would be misplaced by the maximum need system. The second reason for anticipating a higher level of accuracy is based on studies of the characteristics of nursing home residents. Although many nursing home residents are functionally limited in the areas identified by the PIB high risk items, large numbers are also limited in the PIB non-high risk areas of toileting, dressing, and bathing (Oregon Department of Human Resources 1981a; New York Office of Health Systems Management 1978; Barney 1977; Miller 1965; Whanger \& Lewis 1975).

It should be noted again that the accuracy of the a priori decision rules and the mathematically derived equation will be compared 
with current practice or clinical judgment. As previously discussed, clinical judgment may not be the ideal criterion. At this point in time, however, it is considered acceptable by the Oregon Department of Human Resources.

$\underline{\text { Reliability }}$

Although inter-rater rellability is one method of estimating the presence of measurement error in an instrument, it is not be directly evaluated in this study. Secondary data are used for all analyses. Inter-rater reliability is, however, addressed indirectly. If PIB findings are not what would be expected based on other studies, PIB reliability will be questioned.

In general there is reason to feel that inter-rater reliability is acceptable. First, extensive inservice was provided for all PIB raters. Second, although PIB is a part of the total Pre-Admission Screening process, PIB scores have not in themselves been used as a determinant of placement. This would reduce the likelihood that PIB items are being scored high in order to assure nursing home placement. Third, as described in an earlier section reliability studies have been conducted with PIB and are reported to be within acceptable limits (Saslow 1982). The type of reliability which is evaluated by this study is internal consistency. As discussed previously, tests of internal consistency can be used to assign items to different subsets or dimensions which are thought to measure aspects of placement criteria. In this study some PIB items are grouped a priorl and others are grouped 
by factor analysis. The coefficient alpha is used to derive an index of reliability.

It is anticipated that the PIB items will group into the three dimensions of physical, mental, and social health. It is further anticipated that each of these dimensions will be reliable. An extensive review of health measures was conducted by the Rand Corporation in connection with its Health Insurance Study. According to their review, all physical measures were reported to be highly reliable and all mental health measures were reported to be moderately reliable. In addition reliability estimates for social health measures were reported to be moderate to high (Brook et a1. 1979).

Summary

The conceptual framework of this study is a combination of utility (criterion-related validity) and measurement (content validity, construct validity, and reliability). It is important that both utility and measurement be evaluated. If PIB is to be considered a substitute for the total Pre-Admission Screening process, it should, within acceptable limits of accuracy, be capable of replicating the PAS team placement decisions. PIB should also measure constructs considered Important to placement decisions. These decisions affect the lives, sometimes irreversibly, of a large number of elderly.

If PIB is able to replicate PAS decisions it cannot be assumed that it also measures the desirable constructs. Although PAS has been considered successful from the standpoint of reducing nursing home bed utilization in Oregon, it has not been extensively studied and may 
reflect influences from factors other than the functional limitations of the elderly.

This study, therefore, evaluates both the prediction and measurement capabilities of PIB. Recommendations regarding the suitability of substituting PIB for the entire PAS process are based on both aspects of this evaluation. 
CHAPTER III

METHODOLOGY

This study uses secondary data gathered on elderly recipients of services through the Oregon Department of Human Resources Senior Services Division. The data are used to answer two questions. The first question is one of measurement and addresses the issue of whether PIB items are capable of measuring constructs or traits considered useful in nursing home placement decisions. The second question is one of utility and addresses the issue of whether PIB items can adequately predict nursing home placement for the elderly.

\section{SUBJECTS}

The subjects of this research study consist of 2545 elderly individuals admitted to the State of Oregon Department of Human Resources Social Service Division between January 1, 1982 and December 31, 1982. The sample includes only those elderly clients who were newly admitted or readmitted to the programs within the division during 1982 and who were 65 years of age or over at the time of admlssion. Elderly clients already receiving on-going program services are not included in the sample. For many of these on-going clients, PIB data were obtained after placement decisions were made. For others, data were obtained with a Service Activity Report which has since been revised.

The sampling method chosen for this study is a combination of quota and total sampling for a one year perlod of time. The one year 
sampling period was selected to increase the representation of the elderly within the sample. One year should assure an adequate representation of clients from less populated areas of the state, especially Eastern Oregon. One year should also assure a broad range of functional and demographic characteristics among the subjects. Many illnesses which affect the elderly are known to be seasonal and more prevalent among certain age groups. A one year sampling period should minimize seasonal influences on the data.

The calendar year 1982 was selected for methodological reasons. Prior to 1982, Pre-Admission Screening teams were not functioning in Eastern Oregon. In addition, the DHR-280 Service Activity Report, which is the source of data for this study, was undergoing minor revisions. Completion instructions for the PIB portion of the report were modified in 1980 and 1981 but have remained unchanged throughout 1982.

The proportion of newly admitted elderly clients selected for this study varies with the living situation of the elderly. In order to assure adequate representation of the more functionally able elderly, the sample includes 100 percent of the newly admitted elderly clients residing in the community and in substitute homes. The sample also Includes 50 percent of the newly admitted elderly clients living in nursing homes and other types of institutions. This latter group was selected by choosing every other record on file with the Oregon Department of Human Resources. The sample excludes clients living in fac1l1ties designated for the retarded or mentally $i 11$.

As 1llustrated in Table IV, the 2545 elderly clients in this sample are predominantly female, white, and widowed. The mean age of 
TABLE IV

SELECTED DEMOGRAPHIC CHARACTERISTICS OF THE

TOTAL SAMPLE OF ELDERLY CLIENTS $(\mathrm{N}=2545)$

\begin{tabular}{|c|c|c|c|}
\hline Characteristics & $\begin{array}{l}\text { Number and } \\
\text { Percentage }\end{array}$ & Characteristic & $\begin{array}{l}\text { Number and } \\
\text { Percentage }\end{array}$ \\
\hline Sex & & Marital Status & \\
\hline Female & $1748(68.7 \%)$ & Married & $426(16.7 \%)$ \\
\hline Male & $797(31.3 \%)$ & $\begin{array}{l}\text { Widowed } \\
\text { Single never }\end{array}$ & $1402(55.1 \%)$ \\
\hline Age $^{a}$ & & $\begin{array}{c}\text { married } \\
\text { Divorced or }\end{array}$ & $188(7.4 \%)$ \\
\hline 65 to 74 & $769(30.2 \%)$ & separated & $286(11.2 \%)$ \\
\hline 75 to 84 & $980(38.5 \%)$ & Refused to answer & $19(0.7 \%)$ \\
\hline 85 and above & $796(31.3 \%)$ & Missing cases & $224(8.8 \%)$ \\
\hline Race & & Current Lfving Situatio & \\
\hline White & $2441(95.9 \%)$ & Own or relative's & \\
\hline Asian & $17(0.7 \%)$ & home & $1077(42.3 \%)$ \\
\hline Negro & $60(2.4 \%)$ & Substitute home & $367(14.4 \%)$ \\
\hline Alaska American & & Nursing home & $1096(43.0 \%)$ \\
\hline Indian & $9(0.4 \%)$ & Speclal institution & $4(0.2 \%)$ \\
\hline Spanish American & $18(0.7 \%)$ & Missing data & $1(0.0 \%)$ \\
\hline
\end{tabular}

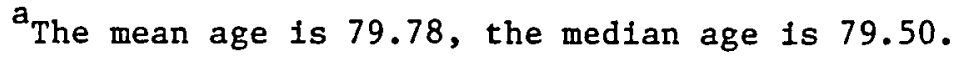


the elderly clients is 79.78 and the distribution of elderly clients between the community and nursing homes is comparable.

of the 2545 elderly clients selected, 250 are missing data on all PIB items. Replacement could not be made for those residing in the community or in substitute homes since that total population is already being used. A decision was made not to replace the elderly nursing home clients who have missing PIB data. That number is less than 8 percent of the total number of nursing home clients. In addition, the differences, using chi square, between nursing home clients with and without PIB data are not significant for age or marital status. Although there are significantly more women than men without data, the actual numbers are so small that the difference is probably of no practical significance.

Of the 2287 elderly clients with PIB data, 488 have a score of zero on PIB 6 (Mobility with Aids). A zero score is generally considered a missing score which can be either estimated or dropped from analysis. Before deciding how to handle the zero scores on PIB 6, additional Information was obtained on these elderly receiving this score. Cross tabulation between PIB 6 and PIB 5 (Mobility Without Aids) indicates that the zero score on PIB 6 is being used primarily to identify individuals not needing aids. Since this group represents some of the more mobile clients in the sample, a decision was made to conduct future analysis both with and without PIB 6 .

When PIB 6 was found to have Iimited predictive power as a single item, no attempt was made to estimate its zero score for that use. However, when PIB 6 was found to contribute to the reliability of both the 
$\mathrm{ADL}$ and Physical scale constructed by this researcher, an estimate was made for the zero score. When PIB 6 is used as a scale 1tem, a score of zero is estimated to be equal to the average score for the other items in the same scale. This method was selected because of the high correlation which exists between PIB 6 and the other items in the ADL and Physical scale and because the method is easy to compute in a clinical setting.

Future references to missing PIB data or complete PIB data will pertain only to those elderly clients who have data on PIB 1 to 5 , and PIB 7 to 25, or those who have no data on PIB 1 to 5, and PIB 7 to 25. When PIB 6 is omitted from analysis, it will be noted as such.

In this study, the entire sample of elderly clients is used for research question one and part of research question three. A reduced sample is used for research question two and part of research question three. As just described, the entire sample consists of 2545 elderly clients living in the community, substitute homes, nursing homes, and other institutions. Analysis were performed on the 2287 who have complete PIB data.

For research question two, a reduced sample of 1996 was used. This sample includes only those elderly clients residing in the community or in nursing homes. Elderly living in substitute homes or non-nursing home institutions are excluded. This sample is further restricted by including only those elderly clients for whom there is agreement regarding the approprlate living situation. This last condition is judged to be met if there is agreement between the scores in the DHR 280 box 17 (PAS Recommendation), box 35 (Living Situation 
Needed), and box 36 (Current Living Situation). Two hundred and twenty-four elderly clients meeting the above criteria are missing complete PIB data. Analyses for research question two were, therefore, performed on a sample of 1772 . Analyses within research question two were performed on various subsets of this sample. The number and characteristics of these subsets will be discussed in the next chapter in conjunction with the findings.

Since research question three is based upon the findings of both research question one and two, the sample varies with the specific analysis. The number and characteristics of the elderly clients in each sample will be described in the next chapter in conjunction with the findings.

\section{STUDY INSTRUMENT}

The instrument which was used to collect data for this study is the Department of Human Resources DHR-280 Service Activity Report, revised in February 1980 (see Appendix B). This instrument is the basic source of soctal service data used for the preparation of statistical reports to state and federal officials. It 1s completed for each service case which goes beyond the intake phase to recelve one-time services or on-going services.

The Service Activity Report contains a descriptive intake section and a coded section. The coded section is the source of data which will be used in this research study. The coded section is divided into 58 items called boxes and provides a variety of data including PIB data. 
The coded section is scored by selecting the number or letter of the response which best describes the client or his service needs. The response range varies from box to box. The responses for PIB items are on a 5 point range. Other boxes, such as those identifying service needs, contain over 80 response options. Most have fewer, however. The response options and the corresponding code numbers or letters are not printed on the DHR-280 Service Activity Report. They must be obtained from the DHR-280 Desk Manual.

Eleven of these boxes contain data on variables that are thought to be important to this study (see Figure 1 for a list and description of these variables). Six of the boxes provide basic demographic data necessary for describing the sample and for testing several of the construct validity hypotheses. A single box, number 50, is the Placement Information Base PIB and contains 25 items describing the client's functional limitations. For a list of PIB items, descriptor statements, and coding Instructions, see Figure 10 in Appendix B. Scales constructed from the 25 items will be used for all three research questions.

The DHR-280 Service Activity Report was desfgned to provide a uniform data base. It is to be completed on the basis of information obtained through the interview process. Preliminary rellability studies have been conducted for the PIB portion of the report. As previously described, findings were within satisfactory limits. Reliability and validity have not been reported for the other variables contained in the coded section of the DHR-280 Service Activity Report. Extensive Inservice has been provided, however, for all DHR caseworkers and PAS team 


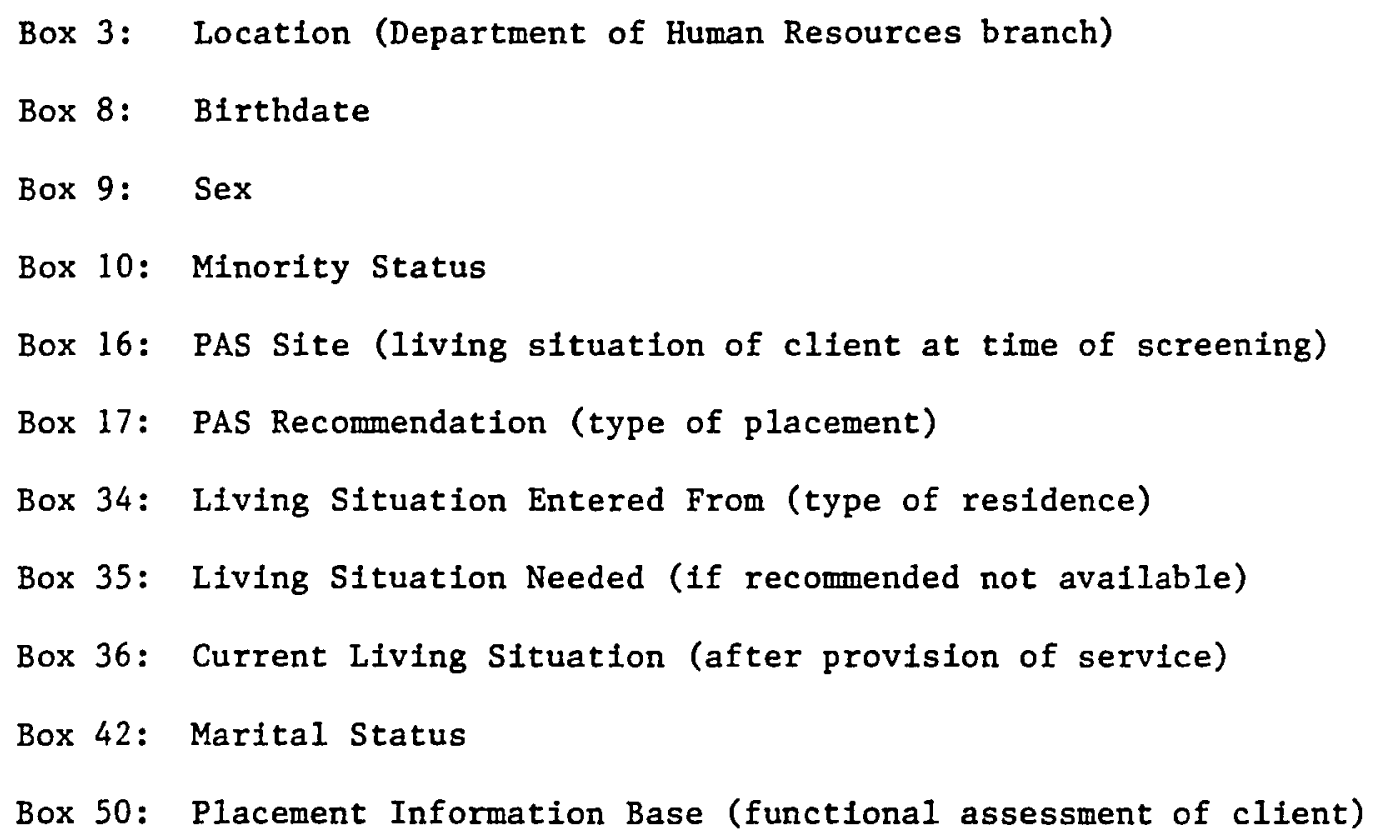

Figure 1. Varlables selected from boxes included on the State of Oregon Department of Human Resources Service Activity Report, DHR-280, revised in $2 / 80$.

members. In addition, the DHR-280 Desk Manual is available and provides detafled instructions for completing the report.

\section{PROCEDURE}

The data which are used in this research study are secondary data collected on the DHR-280 Service Activity Report and submitted to the Department of Human Resources in Salem, Oregon. Because the data are secondary, the rellability of the data collection is outside the control of this researcher. What is known about the conditions under which the data were collected is, however, described at this time. 
The completion and submission of the Service Activity Report are the responsibility of the DHR caseworker. Parts of some reports are, however, completed by the Pre-Admission Screening teams. The PAS team completes the PIB portion for all clients requesting nursing home placement. In addition, the PAS team completes boxes 16, 17, and 18 for these clients. These boxes contain information regarding the site of screening, date of PAS admission, and the PAS team recommendation. It is estimated that half of the Service Activity Reports which will be used in this study will have been completed entirely by DHR caseworkers assigned to one of 36 DHR branch offices throughout the state. The other half of the Service Activity Reports will have been partially completed by one of the 12 Pre-Admisston Screening teams assigned to DHR regions. Most regions represent more than one branch. The activity needed to complete the Service Activity Report is obtained through the interview process. The interview may be conducted in the DHR office, the client's place of residence, or in a temporary client location such as an acute hospital. In addition to the client, family or friends of the client may be contacted and asked to provide necessary information.

In summary, this research study uses data from the DHR-280 Service Activity Reports for clients who were opened to service between January 1, 1982 and December 31, 1982. As discussed earlier, these dates were chosen to Increase the uniformity of data collection methods, to increase representation among the subjects, and to provide a large enough data base to carry out the necessary statistical procedures. 
DESIGN AND ANALYSIS FOR THE FIRST RESEARCH QUESTION

\section{Research Question 1}

Are the PIB items capable of measuring constructs or traits considered useful in nursing home placement decisions? This question addresses the issues of content validity, internal consistency reliabilIty, and construct validity.

\section{Content Validity}

As previously discussed, the content validity for PIB was established by expert judges during the development stage of the instrument. This research study will extend the evaluation of PIB content validity. The design which is being used is, in some ways, the reverse of the design used to develop the instrument. Rather than identifying the desired content domain and constructing items to measure each dimension of the domain, this study uses the previously constructed items to identify the content domain. It evaluates the extent to which PIB items cluster or group under the dimensions of physical, mental and soctal health. It also identifies other dimensions which may be included in the PIB content domain. In addition, this study evaluates the extent to which PIB items measuring a single dimension can be reduced through scaling procedures. According to Stewart (1982, pp. 1-2), "Composite indexes have numerous theoretical and methodological advantages over individual items ...."

The identification of content dimensions and the construction of composite Indexes or multi-item scales were carried out in progressive steps. First, frequency distributions, including measures of central 
tendency, were obtalned on all items. The distributions were

examined for score variability on each ftem. Based on the review of literature, it was anticipated that PIB items measuring physical and emotional health would be normally distributed.

Second, some items were grouped a priort under the dimensions of physical, mental, and social health. Pearson product-moment correlations were then obtained for items within each of these dimensions. Items that are highly correlated were used to construct multi-item sales. Items with low correlation were considered for inclusion in another scale.

Third, factor analysis was used to group PIB items into factors which were examined in light of a priori grouplngs. The factor analysis was also used to identify other items which are correlated with these groupings and should be considered for inclusion. In addition, it was used to identify additional groupings or dimensions measured by PIB items. Based on a visual examination of the PIB and the content validity reports of PIB, it was anticipated that the PIB items would factor into at least three dimensions. Those dimensions were expected to reflect physical, mental, and social functionings.

Fourth, summated mult1-item scales were constructed from items which theoretically measure the same dimension and statistically correlate highly with one another. These items were submitted to item analysis. The method which was be used in this study is the corrected Pearson product-moment item-total correlation. According to Nunnally (1967), the correlated formula is desirable when the number of items is 
very small. This formula correlates the item score with the total score minus the score of the item being examined.

Items whose corrected item-total correlations did not reach .30 were discarded or considered for inclusion in another scale. It was anticipated that some items would be discarded. Those items which were retained were given a unit weight of one (Nunnally 1978) and averaged to provide a total dimension score.

Fifth, frequency distributions were obtained for the newly constructed scales. Since choosing items on the basis of item-total correlation almost always produces a symetrical distribution of scores (Nunnally 1967), it was anticipated that the PIB scores obtained from the newly constructed scales would also be symetrically distributed.

Internal-Consistency Reliability

As previously discussed, reliability is a prerequisite for validity. In this study the coefficient alpha was used to evaluate the reliability of PIB scales. According to Nunnally, measures used to compare individuals with one another must be highly reliable. "In those applied settings where important decisions are made with respect to specific test scores, a reliability of .90 is the minimum that should be tolerated, and a rellability of .95 should be considered the desirable standard" (Nunnally 1967, p. 226).

\section{Construct Validity}

In this study, tests of construct validity are an extension of content validity and internal consistency relfability tests. To identffy underlying constructs or traits measured by PIB, this study tested 
hypotheses about the relationships between and within PIB dimensions. The dimensions were those identifled during the examination of content validity and found relfable based on tests of internal-consistency. Construct validity was evaluated by testing specific hypotheses which examine the association among measures of the same dimension, between measures of different dimeñsions, and between PIB measures and other variables. All associations were evaluated by using a Pearson product-moment correlation procedure.

Hypothesis 1. All PIB items and scales will be positively correlated with one another.

Hypothesis 2. PIB 1tems within each scale will be more highly correlated with one another than with the items of other scales.

Hypothests 3 . PIB scales measuring physical functioning will be significantly correlated with age. It is expected that the older subjects will be more physically dependent than the younger subjects.

Hypothesis 4. PIB scales measuring physical functioning will not be significantly correlated with sex.

Hypothesis 5. PIB scales measuring social support will be significantly correlated with sex. Because they are not as likely to have a living spouse, women are expected to be more functionally dependent than men in the area of social support.

DESIGN AND ANALYSIS FOR THE SECOND RESEARCH QUESTION

\section{Research Question 2}

Can PIB items accurately predict nursing home placement as determined by the total Pre-Admission Screening process? This is a question 
of criterion-related validity and can be tested in hypothesis form. This study, however, employs a more exploratory approach. The reason for this approach is twofold. First, as previously 1llustrated, high levels of accuracy can usually be obtained for either nursing home elderly or community-reslding elderly, but not both. Second, since the criterion, PAS team recommendation for placement, must be considered contaminated, lack of predictive accuracy on the part of PIB could be interpreted as a reflection of the criterion measure rather than the PIB.

This study, therefore, addresses the question of criterion validity by separately exploring the extent to which placement can be accurately predicted by the a priori decision rules and by the mathematically derived equations. The predictive items and scales are examined for theoretical relevance and comparisons are made between the two methods.

A Priort Decision Rule. The predictive accuracy of the a priori decision rule was estimated by counting the frequency with which elderly community and nursing home clients have a very high, high, or moderate probability of needing nursing home placement based on PIB scores. The decision rule for each level of probability is that which accompanies the revised draft (1979) of the Placement Information Base. A description of the decisions rules are found in Figure 9 in Appendix B.

Mathematically Derived Decision Rule. Estimating the predictive accuracy of a mathematically derived equation was completed in two stages. First, nine discriminant function equations were derived from PIB scores using one half of the reduced sample. This sample was ran- 
domly selected from the 1772 elderly community and nursing home residents. Second, the discriminant function equations were cross-validated with the remaining half of the reduced sample. The scores which were used for both the derivation and cross-validation of the discriminant function equations were obtained from PIB items and the PIB scales constructed earlier in this study.

This researcher had intended to both derive and validate the discriminant function equation with a sample Iimited to elderly clients evaluated by a PAS team. A decision was made, however, to include the elderly clients evaluated by caseworkers. The reason for this decision was two-fold.

First, the number of elderly community clients evaluated by a PAS team is smaller than anticipated and is inadequate for the desired analyses. Only 61 of the 829 elderly communfty clients in the sample had been evaluated by a PAS team.

Community clients evaluated by a caseworker are significantly different from those evaluated by a PAS team on eight of the nine PIB scales. While it is expected that clients evaluated by a PAS team will be less functional due to the nature of the screening process, these clients may not be representative of community clients in general. A discriminant function equation derlved from such a limited sample could lead to misclassification if used in a large scale program.

Second, the elderly nursing home cllents evaluated by a caseworker are not significantly different from those evaluated by a PAS team on seven of the nine PIB scales constructed by this researcher. The groups are significantly different on the Mental scale and the Social scale. 
These differences are of interest, but are probably of no practical importance in this analysis. The sample size is large and the proportion of variance which can be attributed to the difference in raters is small. When the scale for the largest $t$-value was evaluated with omega squared. less than .5 percent of the total variance could be accounted for by the type of evaluator.

DESIGN AND ANALYSIS FOR THE THIRD RESEARCH QUESTION

Does PIB have acceptable inter-rater reliability? This question is of secondary importance in this study because it cannot be evaluated directly. Data for this study have already been collected by the Oregon Department of Human Resources staff.

This study addresses the question of inter-rater reliability from four approaches, all indirect. First, discrepancies are noted between the findings on the first research question and the expected findings based on other studies. Second, comparisons are made between some of the functional characteristics of this sample, as measured by PIB, and the expected characteristics of the sample based on the literature. Third, elderly nursing home clients from different geographic areas in the state are examined for functional similarity. Inter-rater reliablity can be assumed if the expected findings are confirmed, if the functional characteristics of the clients are similar to those reported in the literature and if the discriminant function equation can predict placement with consistent accuracy across the subgroups. 
Failure to confirm the expected findings, lack of similarity, or failure to predict accurately across subgroups does not, however, necessarily mean that PIB has poor inter-rater rellability. Discrepancies may be coming from other sources. For example, the subjects in this sample may be functionally different than subjects in other studies. The criterion employed in this study, placement recommendation, may be inconsistently applied. In both of these situations, PIB could be accurately measuring the subjects' functional limitations. Further study would be required, however, to confirm PIB inter-rater reliability. 
CHAPTER IV

FINDINGS AND DISCUSSION OF FINDINGS

The research questions in this study are sequential in nature. The findings regarding the first question influence those of the second and third questions. The findings of the second question influence those of the third question. To assist the reader in following the sequence of the analyses and in understanding the rationale for decisions made by the researcher, both the findings and the discussion of findings are incorporated into this chapter.

\section{RESEARCH QUESTION I}

Are the PIB ftems capable of measuring the constructs or traits considered useful in nursing home placement decisions? This question was addressed by examining content validity, internal consistency reliability, and construct validity of the PIB items. As described earlier, 1799 elderly clients have complete data on all twenty-five PIB items. An additional 488 elderly clients have a score of zero on PIB 6 (Mobility with Aids). Unless otherwise noted, all analyses for research question one are based on the combined sample of 2287.

\section{Content Validity}

The examination of content validity was conducted in progressive steps. 
Score Variability. As anticipated, the scores on the items measuring physical and mental function span the entire response range. These items as well as all other PIB items have a score varlability ranging from one to five.

It was also anticipated that the scores on the twenty-two items measuring physical and mental function would be normally distributed. As can be seen in Table $\mathrm{v}$, however, eight of the items have a positive or negative skew exceeding values of 1.00 . Distributions for two of the items measuring physical function are positively skewed, four are negatively skewed. The elderly clients appear very functional on PIB 3 (Hearing) and PIB 11 (Eating). They appear quite dysfunctional on PIB 4 (Trave1), PIB 7 (Housekeeping), PIB 8 (Personal Shopping), and PIB 9 (Food Shopping and Preparation). Distributions for two of the items measuring mental function are also positively skewed. The elderly appear very functional on PIB 1 (Self-Identification) and PIB 14 (Emotional Control).

An examination of the relative frequency distributions found in Figure 11, Appendix $C$, suggests that eight physical and mental items are bimodally distributed. These items are PIB 8 (Personal Shopping), PIB 13 (Personal Independence), PIB 19 (Money Management), PIB 21 (Medication Management), PIB 22 (Grooming and Dressing), PIB 23 (Bathing or Showering), PIB 24 (Using Toilet), and PIB 25 (Continence).

Predictions were not made regarding the distribution of items measuring the social domain. It can be noted, however, that PIB 15 (Use of Telephone) and PIB 17 (Natural Support) appear to be bimodal. In 
TABLE V

DESCRIPTIVE STATISTICS FOR SCORES ON THE TWENTY-FIVE PIB ITEMS

\begin{tabular}{|c|c|c|c|c|c|}
\hline Item & 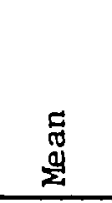 & 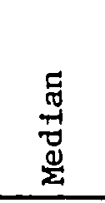 & 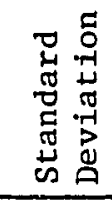 & 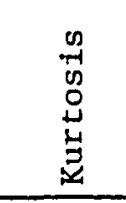 & 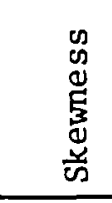 \\
\hline $\begin{array}{l}\text { 1. Self Identification } \\
\text { 2. Vision } \\
\text { 3. Hearing } \\
\text { 4. Travel } \\
\text { 5. Mobility without Aids } \\
\text { 6. Mobility with Aids } \\
\text { 7. Housekeeping } \\
\text { 8. Personal Shopping } \\
\text { 9. Food Shop/Prep } \\
\text { 10. Nutritional Habits } \\
\text { 11. Eating } \\
\text { 12. Social Activities } \\
\text { 13. Personal Independence } \\
\text { 14. Emotional Control } \\
\text { 15. Use of Telephone } \\
\text { 16. Orientation for } \\
\text { 17. Natural Support } \\
\text { 18. Personal Activities } \\
\text { 19. Money Management } \\
\text { 20. Health Condition } \\
\text { 21. Managing Medications } \\
\text { 22. Grooming and Dressing } \\
\text { 23. Bathing and Showering } \\
\text { 24. Using Toilet } \\
\text { 25. Continence }\end{array}$ & $\begin{array}{l}1.97 \\
2.06 \\
1.74 \\
4.46 \\
3.73 \\
3.20 \\
4.43 \\
4.40 \\
4.44 \\
2.56 \\
1.53 \\
2.98 \\
2.50 \\
1.69 \\
3.14 \\
3.34 \\
3.83 \\
3.72 \\
3.68 \\
2.95 \\
3.62 \\
3.14 \\
3.52 \\
2.29 \\
2.21\end{array}$ & $\begin{array}{l}1.43 \\
1.98 \\
1.34 \\
4.80 \\
4.13 \\
3.19 \\
4.73 \\
4.78 \\
4.85 \\
2.41 \\
1.26 \\
2.95 \\
2.17 \\
1.58 \\
3.28 \\
\\
3.41 \\
4.48 \\
4.01 \\
4.18 \\
2.99 \\
4.61 \\
3.74 \\
3.97 \\
1.49 \\
1.36\end{array}$ & $\begin{array}{l}1.26 \\
0.98 \\
1.01 \\
1.04 \\
1.37 \\
1.41 \\
0.94 \\
1.16 \\
1.17 \\
1.23 \\
0.85 \\
1.14 \\
1.18 \\
0.76 \\
1.52 \\
1.08 \\
1.49 \\
1.29 \\
1.50 \\
0.68 \\
1.72 \\
1.58 \\
1.48 \\
1.59 \\
1.61\end{array}$ & $\begin{array}{r}0.15 \\
-0.71 \\
-0.19 \\
3.45 \\
-0.88 \\
-1.28 \\
3.18 \\
3.52 \\
2.53 \\
-0.54 \\
1.61 \\
-0.89 \\
-0.55 \\
1.36 \\
-1.47 \\
-0.12 \\
-0.52 \\
-0.71 \\
-0.84 \\
1.87 \\
-1.41 \\
-1.53 \\
-0.94 \\
-0.99 \\
-1.08\end{array}$ & $\begin{array}{r}1.12 \\
0.44 \\
1.02 \\
-2.10 \\
-0.68 \\
-0.11 \\
-1.84 \\
-2.16 \\
-1.99 \\
0.54 \\
1.54 \\
0.08 \\
0.72 \\
1.06 \\
-0.14 \\
-0.55 \\
-1.00 \\
-0.69 \\
-0.81 \\
-0.58 \\
-0.62 \\
-0.35 \\
-0.73 \\
0.81 \\
0.81\end{array}$ \\
\hline
\end{tabular}

NOTE: $\mathrm{N}=1799$ for PIB $6 ; \mathrm{N}=2287$ for other PIB items. 
addition, PIB 17 is negatively skewed. Most elderly have no person (natural support) avallable to help except, perhaps, under the most extreme circumstance.

Although it is beyond the scope of this study, some examination should be made of the items which are not normally distributed. Items which have skewed distributions may be measuring actual functional levels or may be measuring other factors. Some of the skewed distributions may be explained by the sample itself. This group of elderly clients may represent the more functionally impaired segment of the elderly population. This could account for the high number of elderly community as well as nursing home clients who appear dysfunctional on PIB 7 (Housekeeping), PIB 8 (Personal Shopping), and PIB 9 (Food Shopping and Preparation). Some skewed distributions may reflect factors other than functional ability. The high number of elderly nursing home residents in contrast to the low number of elderly community clients who appear dysfunctional on PIB 19 (Money Management) and PIB 21 (Medication Management) suggests that these items may be reporting opportunity rather than ability to perform the tasks. This is a possibility since many of the clients were residing in nursing homes when PIB was administered.

Bimodal items should also be examined further. The low frequency for score values of 2,3 , and 4 may reflect the nature of the dimension being measured. It may be, for example, that most elderly clients are either continent or incontinent frequently, with very few being occasionally incontinent. Some bimodal items may be insensitive to the middle ranges of the measure. PIB 23 (Bathing or Showering), for 
example, may need to include descriptor statements regarding the need for assistance getting into the tub or with washing hair. Still other bimodal items may be measuring more than one dimension. PIB 15 (Use of Telephone) appears to measure both the desire and the ability to place and receive calls. PIB 4 (Travel) appears to measure both the ability to use avallable transportation and the avallability of transportation.

Although many of the items are skewed or bimodal, a decision was made to retain them for further rellability and validity analysis. The basis of the decision was two-fold. First, the items may have predictive value. Second, a skewed or bimodal distribution may, in fact, be a faithful representation of the true distribution of the characteristic of the population under study. Third, the items may be useful when combined with other items measuring some aspect of a similar construct. As previously noted, scales or composite indexes chosen on the basis of item-total correlation tend to approximate a normal distribution (Nunnally 1967) and have numerous advantages over individual items (Stewart 1982).

Content Dimensions. It was anticipated that the twenty-five PIB Items could be grouped into at least three dimensions reflecting physical, mental and social functioning. To test this expectation, three different combinations of items were evaluated. The first combination was the set of eeven dimensions listed on the PIB instrument. The second combination was an a priori grouping made by the researcher. The third combination was produced by factor analysis. The first two combinations were evaluated by examining the within dimension item 
correlations. The third combination was evaluated by examining factor loadings.

As can be seen in Table VI, within-dimension correlations for the seven dimensions of Items listed on the current PIB instrument are varled. Median correlations range from .24 for household and food management to .64 for self-care. The median of medians is .33 . The

\section{TABLE VI}

ITEM CORRELATIONS WITHIN THE SEVEN DIMENSIONS

IISTED ON THE CURRENT PIB INSTRUMENT

\begin{tabular}{lcc}
\hline & \multicolumn{2}{c}{ Item Correlation } \\
\cline { 2 - 3 } Dimension & Range & Median \\
\hline $\begin{array}{l}\text { Communication } \\
\text { (PIB 1 to PIB 3) }\end{array}$ & .16 to .30 & .27 \\
$\begin{array}{l}\text { Mobility } \\
\text { (PIB 4 to PIB 6) }\end{array}$ & .43 to .74 & .43 \\
$\begin{array}{l}\text { Household and Food Management } \\
\text { (PIB 7 to PIB 11) }\end{array}$ & .05 to .73 & .24 \\
$\begin{array}{l}\text { Social and Emotional } \\
\text { (PIB 12 to PIB 18) }\end{array}$ & .16 to .63 & .42 \\
$\begin{array}{l}\text { Finances } \\
\text { (PIB 19) }\end{array}$ & - & - \\
Health \\
(PIB 20, 21) \\
$\begin{array}{l}\text { Self-Care } \\
\text { (PIB 22 to PIB 25) }\end{array}$ \\
\hline
\end{tabular}

${ }^{a}$ Single item dimension. 
self-care, mobility, and social and emotional dimensions exhibit the highest within-dimension correlations, .64, .43, and .42 , respectively. The first two appear to measure physical functioning and the latter, a combination of social and mental functioning. Each of the remaining dimensions, however, appears to measure more than one construct. Correlations for the household and food management items, for example, range from .05 to .73 with a median correlation of .24 .

Seven dimensions were also identified by the researcher in her a priori grouping (see Table VII). Three of the dimensions, mobility, activities of daily living ( $A D L$ ), and instrumental ADL (IADL), appear to measure physical functioning. The median correlations for these dimensions are $.74, .56$, and .62 , respectively. Collapsing the dimensions into a single nine item physical dimension created correlations ranging from . 11 to .80 with a median correlation of .51 .

Two dimensions thought to measure mental function were also identified. Median correlations are .58 for the cognitive dimenston and .41 for the affective dimension. Collapsing these two dimensions into a single five item mental dimension created correlations ranging from .28 to .58 , with a median correlation of .47 .

A single social dimension composed of three items was Identified. Correlations between these items range from .47 to .56 with a median of .48 .

A health status dimenston was also Identified. This dimension Included five items, two of which had previously been considered in other scales (see Table VII). The correlations for these items ranged from .08 to .53 with a median correlation of .20 . Three items thought 
TABLE VII

ITEM CORRELATIONS WITHIN THE SEVEN A PRIORI DIMENSIONS IDENTIFIED BY THE RESEARCHER

\begin{tabular}{|c|c|c|}
\hline \multirow[b]{2}{*}{ Dimension $^{a}$} & \multicolumn{2}{|c|}{ Item Correlation } \\
\hline & Range & Median \\
\hline $\begin{array}{l}\text { Physical } \\
\text { Mobility } \\
(\text { PIB } 5 \& 6)\end{array}$ & .11 to .80 & $\begin{array}{l}.51 \\
.74\end{array}$ \\
\hline $\begin{array}{l}\text { ADL } \\
(\mathrm{PIB} 11, \mathrm{PIB} 22 \text { to } 25)\end{array}$ & .38 to .79 & .56 \\
\hline $\begin{array}{l}\text { IADL } \\
\text { (PIB } 4,7,8,9)\end{array}$ & .54 to .71 & .62 \\
\hline $\begin{array}{l}\text { Mental } \\
\text { Cognitive } \\
\text { (PIB 1, 16, 19) }\end{array}$ & $\begin{array}{l}.28 \text { to } .58 \\
.54 \text { to } .65\end{array}$ & $\begin{array}{l}.47 \\
.58\end{array}$ \\
\hline $\begin{array}{l}\text { Affective } \\
\text { (PIB 13, 14) }\end{array}$ & .41 & .41 \\
\hline $\begin{array}{l}\text { Soctal } \\
\text { (PIB 12, 15, 18) }\end{array}$ & .47 to .56 & .48 \\
\hline $\begin{array}{l}\text { Health Status } \\
(\text { PIB } 2,3,14,20,25)\end{array}$ & .08 to .53 & .20 \\
\hline
\end{tabular}

${ }^{a}$ PIB items $\# 10,17,21$ were thought to be single item dimensions and therefore are not included in this analysis.

${ }^{b}$ This dimension is not mutually exclusive from others.

to be single item dimensions were excluded from the analysis (see Table VII).

The third combination of items was obtained by factor analysis (principal components procedure). Using a minimum eigenvalue of 1.00 , five factors were extracted and then rotated using the Varimax procedure. As can be seen in Table VII these factors appear to measure IADL, 
ADL, mental function, social function, and physical limitations. With Items assigned only to the factor on which they have the highest factor loading, the median factor loadings are .75 for ADL, .66 for IADL, .62 for mental, .56 for social, and .76 for physical limitations. Seventeen of the items clearly fall on a single factor. Eight items, however, have factor loadings of .40 or greater on a second factor and are identified in Table VIII. Item correlations were also calculated for items within the five factors extracted by Varimax rotation. These correlations are presented in Table IX and can be compared with the item correlations within the seven dimensions listed on the current PIB instrument (Table VI) and with the item correlations within the seven a priori dimensions identified by the researcher (Table VII).

Scale Construction. After examining the within-dimension correlations and the factor loadings which have just been described, a final decision was made to construct multi-item scales. Using a process which will be discussed in this section, four scales were developed which contain twenty of the original twenty-five PIB items.

The scales were constructed in four steps. First, items which clearly load on a single factor were assigned to a scale bearing the same name.

Second, items which have high factor loadings on more than one factor were regrouped with Items which theoretically seem to measure the same domain. Three of the elght items in this category were regrouped. PIB 21 (Medication Management) was moved from factor I IADL to the Mental Scale. PIB 23 (Bathing) was moved from factor I IADL to the ADL 
TABLE VIII

ROTATED FACTOR LOADINGS OF THE PIB ITEMS FOR THE FIVE FACTORS EXTRACTED

Factor I. IADL

PIB 9 Food Shop/Prep

PIB 8 Personal Shop

PIB 7 Housekeeping

PIB 4 Travel

PIB 23 Bathing or Showering

PIB 21 Medication Management

Median Factor Loading

Factor II. ADL

$\begin{array}{ll}\text { PIB } 6 & \text { Mobility with Aids } \\ \text { PIB 24 } & \text { Toileting } \\ \text { PIB 20 } & \text { Health Condition } \\ \text { PIB } 5 & \text { Mobility without Aids } \\ \text { PIB 25 } & \text { Contingence } \\ \text { PIB 22 } & \text { Grooming } \\ \text { PIB } 11 & \text { Eating }\end{array}$

Median Factor Loading

\section{Factor III. Mental}

PIB 1 Self Identification $\quad .74$

PIB 15 Use of Telephone $\quad .73$

PIB 19 Money Management

PIB 16 Orientation for Living Alone

PIB 13 Personal Independence $\quad .54(.52) \mathrm{d}$

Median Factor Loading

.62

Factor IV. Social

PIB 10 Nutritional Habits $\quad .66$

PIB 14 Emotional Control .58

PIB 12 Social Activities $\quad .56$

PIB 18 Personal Activities $\quad .45(.40)^{a}$

PIB 17 Natural Support .39

Median Factor Loading $\quad .56$

Factor V. Physical Limitations

PIB 3 Hearing $\quad .77$

NOTE: Items are assigned to the factor on which they have the highest loading. All 25 PIB 1 tems are assigned to one of the factors above.

ats item's loading on Factor I.

This item's loading on Factor II.

cThis item's loading on Factor III.

$\mathrm{d}_{\text {This item's loading on Facotr IV. }}$ 
TABLE IX

ITEM CORRELATION WITHIN THE FIVE FACTORS

EXTRACTED BY VARIMAX ROTATION

\begin{tabular}{|c|c|c|c|c|}
\hline \multirow{2}{*}{\multicolumn{2}{|c|}{ Factor }} & \multicolumn{3}{|c|}{ Item Correlation } \\
\hline & & & Range & Median \\
\hline I & $\begin{array}{l}\text { IADL } \\
(\text { PIB } 4,7,8,9,21,23)\end{array}$ & .44 & to .73 & .59 \\
\hline II & $\begin{array}{l}\text { ADL } \\
(\text { PIB } 5,6,11,20,22,24,25)\end{array}$ & .35 & to .80 & .52 \\
\hline III & $\begin{array}{l}\text { Mental } \\
\text { (PIB 1, 13, 15, 16, 19) }\end{array}$ & .47 & to .69 & .47 \\
\hline IV & $\begin{array}{l}\text { Social } \\
\text { (PIB 10, 12, 14, 17, 18) }\end{array}$ & .10 & to .48 & .18 \\
\hline $\mathrm{V}$ & $\begin{array}{l}\text { Physical Limitations } \\
\text { (PIB 2, 3) }\end{array}$ & & .30 & .30 \\
\hline
\end{tabular}

scale. PIB 13 (Personal Independence) was moved from factor III mental function to the Social scale.

Third, items with corrected Pearson product-moment item-total correlations of .30 or greater were retained on the scale to which they had been assigned. Four items, PIB 2 (Vision), PIB 3 (Hearing), PIB 10 (Nutritional Habits), and PIB 17 (Natural Support) have correlations of less than .30. These items were dropped from the multi-item scales but retained as single-item scales for later analysis.

Fourth, all items were examined for theoretical relevance to the scale to which they had been assigned. A single Item, PIB 14 (Emotional Contro1) was dropped from the Social scale because it appears to be primarily a measure of affective mental functioning. The decision to drop the item was supported by both the item-total correlation and the alpha 
coefficlent of the scale. Although the 1tem-total correlation is above .30 , it is considerably lower than others in the Social scale (see Table $x)$. Examination of the alpha coefficient also suggested that the item was misplaced. If PIB 14 was deleted from the Social scale, the alpha would remain virtually unchanged. If deleted from the combined MentalSocial scale, the alpha would actually increase slightly, from .888 to .892. Since PIB 14 has an even lower correlation with items in the mental scale, a decision was made to retain it as a single-item scale.

Because such concern has been expressed regarding the reliability of PIB 21 (Medication Management), this item was dropped from the Mental and Mental-Social scale. Since poor inter-rater reliability is suspected but not confirmed, PIB 21 was retained in a revised set of scales called Mental 2 and Mental-Social 2 (Table X).

After modifying the factorially derived groupings on the basis of item-total correlation and theoretical considerations, four scales remained: $A D L$, IADL, Mental and Soclal. As illustrated in Table X, the ADL scale contains eight items with corrected item-total correlations ranging from .56 to .81 . The IADL scale contains four items with correlations ranging from .68 to .78 . The Mental scale contains four items with correlations ranging from .68 to .78 . The Social scale contains three items with correlations ranging from .55 to .59. An alternate Mental scale was also developed. This scale is titled Mental 2 and includes PIB 21 (Medication Management). Item total correlations for this scale are similar to those of the Mental scale and range from .65 to .78 . 
TABLE $X$

ITEM ANALYSIS FOR PIB SCALES

\begin{tabular}{|c|c|}
\hline & $\begin{array}{l}\text { Corrected Pearson } \\
\text { Product Moment Item- } \\
\text { Total Correlation }\end{array}$ \\
\hline PIB Scales & $\begin{array}{c}\text { Individual } \\
\text { Scales }\end{array}$ \\
\hline
\end{tabular}

Physical

\begin{tabular}{|c|c|c|c|}
\hline Activities & of Dafly Living $(A D L)^{a}$ & & \\
\hline PIB 5 & Mobility without Aids & .66 & .69 \\
\hline PIB 6 & Mobility with Aids & .78 & $\cdots$ \\
\hline PIB 11 & Eating & .56 & .5 \\
\hline PIB 20 & Health Condition & .77 & \\
\hline PIB 22 & Grooming and Dressing & .77 & 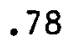 \\
\hline PIB 23 & Bathing or Showering & .73 & \\
\hline PIB 24 & Using Toilet & .81 & \\
\hline PIB 25 & Cont1nence & .71 & \\
\hline $\begin{array}{l}\text { Instrument } \\
\text { (IADL) }\end{array}$ & Activities of Daily & & \\
\hline PIB 4 & Trave1 & .68 & \\
\hline PIB 7 & Housekeeping & .76 & \\
\hline PIB 8 & Personal Shopping & .77 & \\
\hline PIB 9 & Food Shop/Prep & .78 & \\
\hline
\end{tabular}

Mental Soclal

Mental

$\begin{array}{llll}\text { PIB } 1 & \text { Self Identification } & .68 & .68\end{array}$

PIB 15 Use of Telephone $\quad .78 \quad .78$

PIB 16 Orientation of Living Alone $\quad .72 \quad .70$

PIB 19 Money Management $\quad .74 \quad .72$

Social

PIB 12 Social Activities $\quad .59 \quad .56$

PIB 13 Personal Independence $\quad .58 \quad .64$

PIB 18 Personal Activities $\quad .55$

Mental Social 2

Mental

$\begin{array}{llll}\text { PIB } 1 & \text { Self-Identification } & .65 & .67 \\ \text { PIB 15 Use of Telephone } & .77 & .78 \\ \text { PIB } 16 \text { Orientation for Living Alone } & .74 & .73 \\ \text { PIB 19 Money Management } & .78 & .75 \\ \text { PIB 21 Medication Management } & .68 & .65\end{array}$


TABLE X continued

\begin{tabular}{cllll}
\hline & & \multicolumn{2}{c}{$\begin{array}{c}\text { Corrected Pearson } \\
\text { Product Moment Item- } \\
\text { Total Correlation }\end{array}$} \\
\cline { 3 - 4 } PIB Scale & & $\begin{array}{c}\text { Individual } \\
\text { Scales }\end{array}$ & $\begin{array}{c}\text { Composite } \\
\text { Scales }\end{array}$ \\
\hline Social & & & .60 \\
PIB 12 & Social Activities & .63 & .64 \\
PIB 13 & Personal Independence & .44 & .41 \\
PIB 14 & Emotional Control & .59 & .63 \\
PIB 18 & Personal Activities & & \\
\hline
\end{tabular}

a Obtained from a reduced sampie of 1799 elderly clients.

bropped from scale.

The multi-item scales were used to create two composite scales and one alternate composite scale. The Physical scale is composed of items from the ADL and IADL scales. The Mental-Social scale is composed of Items from the Mental and Social scales. The Mental-Social 2 scale is composed of Items from the Mental 2 and Soclal scales. As can be seen in Table $x$, combining the scales causes minimal shift in correlations.

Scores for the multi-item scales, including the composite scales, are computed by adding the score for each item in the scale and dividing the sum by the number of 1tems in the scale. Missing values are estimated to be equal to the average score of the other items in the scale. As 1llustrated in Figure 2 and in Table XI, the scores on the scales are fairly normally distributed. With the exception of the IADL scale, each of the scales has a skew of less than 1.00. The IADL skew is not unexpected since the scale is composed of three negatively skewed items. When the IADL scale is combined with the ADL scale to form the Physical scale, the skew drops to -0.36 . 

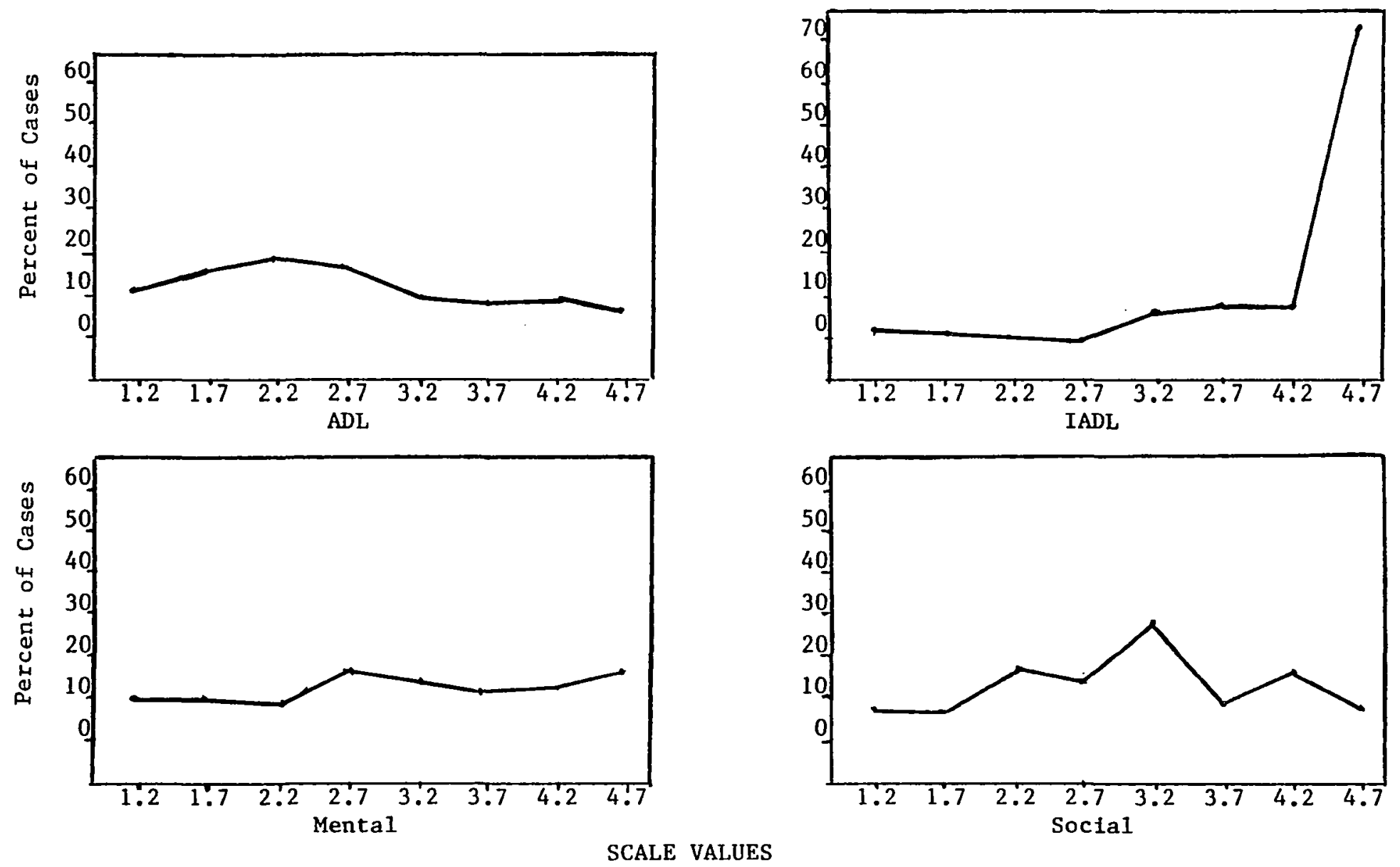

Figure 2. Relative frequency polygons of scores on PIB scales for total elderly population, $N=2287$ 

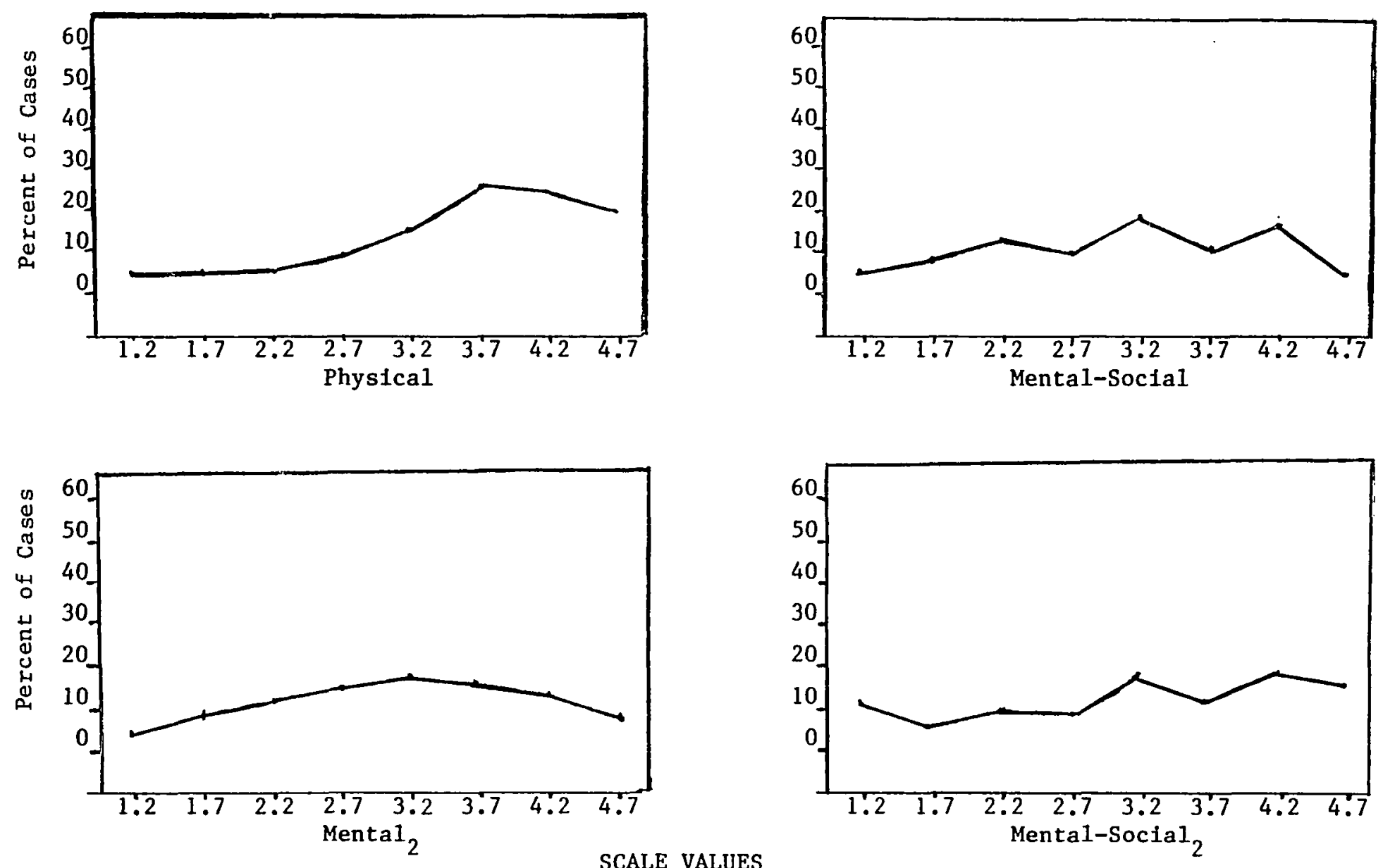

Figure 2 continued 
TABLE XI

DISTRIBUTION OF SCORES ON SCALES

\begin{tabular}{|c|c|c|c|c|c|}
\hline Scale & $\begin{array}{l}\text { Ĩ } \\
\stackrel{\mathbb{N}}{2} \\
\end{array}$ & 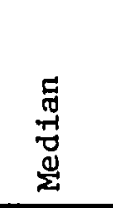 & 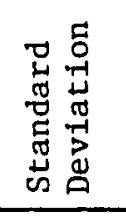 & 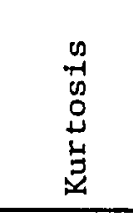 & 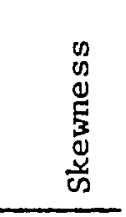 \\
\hline $\begin{array}{l}\mathrm{ADL}(\text { an average of } \mathrm{PIB} 5, \\
6,11,20,22-25)\end{array}$ & 2.79 & 2.75 & 1.05 & -1.05 & 0.22 \\
\hline $\begin{array}{l}\text { IADL (an average of } \mathrm{PIB} 4 \text {, } \\
7,8,9)\end{array}$ & 4.43 & 4.89 & 0.93 & 3.47 & -2.01 \\
\hline $\begin{array}{l}\text { Mental (an average of PIB } 1 \text {, } \\
15,16,19)\end{array}$ & 3.03 & 3.03 & 1.14 & -1.07 & -0.09 \\
\hline $\begin{array}{c}\text { Mental } 2 \text { (an average of PIB } \\
\quad 1,15,16,19,21)\end{array}$ & 3.15 & 3.26 & 1.18 & -1.06 & -0.27 \\
\hline $\begin{array}{l}\text { Social (an average of PIB } \\
12,13,18 \text { ) }\end{array}$ & 3.07 & 3.03 & 0.98 & -0.66 & -0.04 \\
\hline $\begin{array}{l}\text { Physical (an average of PIB } \\
4 \text { to } 9,11,20,22-25 \text { ) }\end{array}$ & 3.35 & 3.42 & 0.92 & 0.55 & -0.36 \\
\hline $\begin{array}{l}\text { Mental-Social (an average of } \\
\quad \text { PIB } 1,12,13,15,16,19)\end{array}$ & 3.05 & 3.05 & 0.99 & -0.86 & -0.06 \\
\hline $\begin{array}{l}\text { Mental-Social (an average of } \\
\text { PIB 1,12, } 13,15,16 \text {, } \\
\quad 19,21)\end{array}$ & 3.12 & 3.16 & 1.02 & -0.90 & -0.18 \\
\hline
\end{tabular}

Internal Consistency Rellability

Internal consistency reliability was established for all newly constructed PIB scales using Cronbach's alpha. As illustrated in Table XII the alpha coefficients range from .75 for the social scale to .91 for the overall physical scale. The median correlation is .89. Reliability for the physical scale is greater than the rellability for 
TABLE XII

INTERNAL-CONSISTENCY RELIABILITY OF PIB SCALES

\begin{tabular}{|c|c|c|c|}
\hline Scale & & $\begin{array}{c}\text { Alpha if } \\
\text { item deleted }\end{array}$ & $\begin{array}{l}\text { Alpha for } \\
\text { entire scale }\end{array}$ \\
\hline Physical & & & $.91^{a}$ \\
\hline 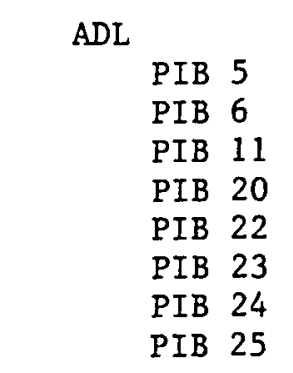 & $\begin{array}{l}\text { Mobility without Aids } \\
\text { Mobility with Aids } \\
\text { Eating } \\
\text { Health Condition } \\
\text { Grooming and Dressing } \\
\text { Bathing } \\
\text { Using Toilet } \\
\text { Continence }\end{array}$ & $\begin{array}{l}.89^{\mathrm{a}} \\
.88^{\mathrm{a}} \\
.90^{\mathrm{a}} \\
.90^{\mathrm{a}} \\
.88^{\mathrm{a}} \\
.88^{\mathrm{a}} \\
.87^{\mathrm{a}} \\
.88^{\mathrm{a}}\end{array}$ & $.90^{\mathrm{a}}$ \\
\hline $\begin{array}{l}\text { IADL } \\
\qquad \begin{aligned} \text { PIB } & 4 \\
\text { PIB } & 7 \\
\text { PIB } & 8 \\
\text { PIB } & 9\end{aligned}\end{array}$ & $\begin{array}{l}\text { Travel } \\
\text { Housekeeping } \\
\text { Personal Shopping } \\
\text { Food Shop/Prep }\end{array}$ & $\begin{array}{l}.87 \\
.85 \\
.84 \\
.83\end{array}$ & .88 \\
\hline Mental Social & & & .88 \\
\hline $\begin{aligned} \text { Mental } & \\
\text { PIB } & 1 \\
\text { PIB } & 15 \\
\text { PIB } & 16 \\
& \\
\text { PIB } & 19\end{aligned}$ & $\begin{array}{l}\text { Self Identification } \\
\text { Use of Telephone } \\
\text { Orientation for Living } \\
\text { Alone } \\
\text { Money Management }\end{array}$ & $\begin{array}{l}.85 \\
.81 \\
.84 \\
.83\end{array}$ & .87 \\
\hline $\begin{aligned} \text { SociaI } & \\
\text { PIB } & 12 \\
\text { PIB } & 13 \\
\text { PIB } & 18\end{aligned}$ & $\begin{array}{l}\text { Social Activities } \\
\text { Personal Independence } \\
\text { Personal Activities }\end{array}$ & $\begin{array}{l}.64 \\
.65 \\
.70\end{array}$ & .75 \\
\hline Mental-Social 2 & & & .89 \\
\hline $\begin{aligned} \text { Mental } & \\
\text { PIB } & 1 \\
\text { PIB } & 15 \\
\text { PIB } & 16 \\
& \\
\text { PIB } & 19 \\
\text { PIB } & 21\end{aligned}$ & $\begin{array}{l}\text { Self Identification } \\
\text { Use of Telephone } \\
\text { Orientation for Living } \\
\text { Alone } \\
\text { Money Management } \\
\text { Medication Management }\end{array}$ & $\begin{array}{l}.87 \\
.84 \\
.85 \\
.83 \\
.87\end{array}$ & .88 \\
\hline
\end{tabular}


TABLE XII continued

\begin{tabular}{cllc}
\hline Scale & & $\begin{array}{c}\text { Alpha if } \\
\text { Item Deleted }\end{array}$ & $\begin{array}{c}\text { Alpha for } \\
\text { Entire Scale }\end{array}$ \\
\hline Social & & & .75 \\
PIB 12 & Social Activities & .64 & \\
PIB 13 & Personal Independence & .65 & \\
PIB 18 & Personal Activities & .70 & \\
\hline
\end{tabular}

This coefficlent was derived from a reduced sample, $\mathrm{N}=1799$. either of the scales from which it was constructed. Reliability for each version of the Mental-Social scale is almost identical to that of the Mental scale but considerably higher than that of the Social scale. Inspection of Table XII also indicates that the alpha would not increase for any of the scales if individual items were deleted.

\section{Construct Validity}

Hypothesis 1. It was hypothesized that all PIB items and scales would be positively correlated with one another. With the exception of PIB 17 (Natural Support), all PIB items are positively correlated with one another and significant at the .001 or greater level. When PIB 17 (Natural Support) is correlated with PIB 20 (Health Condition), $r=.04$ and $p=.028$; when correlated with PIB 2 (Vision), $r=.03$ and $p=.07$; when correlated with PIB 3 (Hearing), $r=.03$ and $p=.09$.

As illustrated in Table XIII, correlations between the newly constructed single and multi-item scales are positive and significant at $p \leqslant$ .001 .

Hypothesis 2. It was hypothesized that PIB items within each scale would be more highly correlated with one another than with the 
TABLE XIII

INTER-CORRELATION MATRIX OF SINGLE ITEM AND MULTI ITEM SCALES

\begin{tabular}{|c|c|c|c|c|c|c|c|c|c|c|c|c|c|}
\hline Scales & $\begin{array}{l}N \\
\text { 是 } \\
\text { n }\end{array}$ & $\begin{array}{l}m \\
m \\
\beta \\
\beta\end{array}$ & $\begin{array}{l}0 \\
\stackrel{9}{1} \\
\text { 昌 } \\
\text { 中 }\end{array}$ & 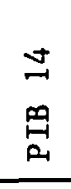 & $\begin{array}{l}\text { I } \\
\text { 息 }\end{array}$ & 宴 & 宴 & 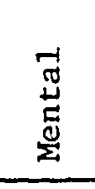 & $\begin{array}{l}\vec{\pi} \\
\stackrel{\tilde{U}}{0} \\
\stackrel{8}{8}\end{array}$ & 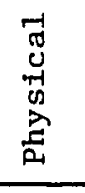 & 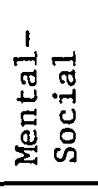 & 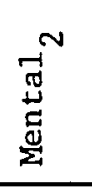 & 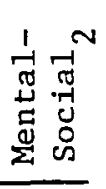 \\
\hline PIB 2 & & .30 & .07 & .08 & .03 & .20 & .17 & .22 & .20 & $.2 I$ & .23 & .22 & .23 \\
\hline PIB 3 & & & .08 & .07 & .03 & .20 & .19 & .28 & .20 & .21 & .27 & .20 & .26 \\
\hline PIB 10 & & & & .15 & .10 & .15 & .09 & .14 & .20 & .15 & .20 & .13 & .18 \\
\hline PIB 14 & & & & & .16 & .19 & .19 & .36 & .44 & .21 & .43 & .35 & .41 \\
\hline PIB 17 & & & & & & .16 & .1 .4 & .21 & .24 & .16 & .24 & .24 & .26 \\
\hline ADL & & & & & & $(.90)$ & .63 & .64 & .56 & $.96^{\mathrm{a}}$ & .66 & .69 & .68 \\
\hline IADL & & & & & & & $(.88)$ & .63 & .50 & $.81^{a}$ & .63 & .67 & .66 \\
\hline Mental & & & & & & & & $(.87)$ & .69 & .70 & $.95^{\mathrm{a}}$ & $.98^{\mathrm{a}}$ & $.95^{\mathrm{a}}$ \\
\hline Social & & & & & & & & & $(.75)$ & .59 & $.88^{\mathrm{a}}$ & .68 & $.85^{a}$ \\
\hline Physical & & & & & & & & & & $(.91)$ & .71 & .73 & .74 \\
\hline Mental Social & & & & & & & & & & & $(.88)$ & $.95^{\mathrm{a}}$ & $.99^{\mathrm{a}}$ \\
\hline $\operatorname{Mental}_{2}$ & & & & & & & & & & & & $(.88)$ & $.96^{\mathrm{a}}$ \\
\hline Menta1-Social 2 & & & & & & & & & & & & & .89) \\
\hline
\end{tabular}

NOTE: All correlations are significant at $<.001$. Alpha coefficients for multi-item scales are enclosed in parentheses along the diagona1.

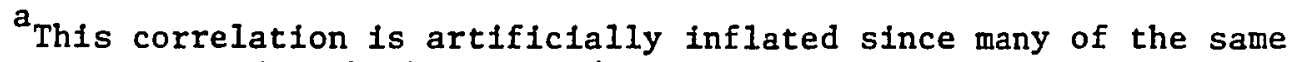
items are contained in both scales (in the form of composite or alternative scales). 
Items of other scales. As can be seen in Table XIV the median correlation coefficients within scales are consistently higher than the median correlation coefficients across scales. For the ADL scale, the median within scale correlation is .53 in contrast to .33 across scales. The median correlation for IADL is .66 within and .33 across. For Mental it is .65 within and .42 across.

TABLE XIV

CORRELATION COEFFICIENTS FOR ITEMS WITHIN SCALES AND ACROSS SCALES

\begin{tabular}{|c|c|c|c|c|c|c|}
\hline \multirow[b]{3}{*}{ Scale } & \multicolumn{6}{|c|}{ Item Correlations } \\
\hline & \multicolumn{3}{|c|}{ Within Scale } & \multicolumn{3}{|c|}{ Across Scale } \\
\hline & & Range & Median & & Range & Median \\
\hline $\mathrm{ADL}$ & .35 & to .80 & .53 & .04 & to .63 & .33 \\
\hline IADL & .58 & to .73 & .66 & .05 & to .63 & .33 \\
\hline Mental & .55 & to .69 & .65 & .11 & to .67 & .42 \\
\hline Mental & .45 & to .69 & .58 & .07 & to .60 & .41 \\
\hline Social ${ }^{2}$ & .48 & to .53 & .48 & .13 & to .54 & .36 \\
\hline Physical & .22 & to .80 & .51 & .04 & to .60 & .31 \\
\hline Mental-Social & .39 & to .69 & .52 & .01 & to .67 & .33 \\
\hline Mental-Social 2 & .33 & to .69 & .46 & .07 & to .60 & .33 \\
\hline
\end{tabular}

For Mental 2 it is .58 within and .41 across. For Social it is .48 within and .36 across. Findings for the collapsed scales exhibit the same pattern. The median correlation for Physical is .51 within scale and .31 across scales. The median correlations for Mental-Social and Mental-Social 2 are .52 and .46 within scales compared with .33 across scales.

Hypothesis 3 . It was anticipated that scales measuring physical functioning would be significantly correlated with age. Pearson product-moment correlations were computed between age and the Physical, 
ADL, and IADL scales. Correlations are .27, .24, and .27, respectively. All are significant at the .001 level, supporting the hypothesis that the elderly become physically less functional with advancing age.

Hypothesis 4. It was anticipated that scales measuring physical functioning would not be significantly correlated with sex. Pearson product-moment correlations were computed between the sex of the elderly clients and the Physical, ADL, and IADL scales. The correlation with IADL is .02 and is not significant. The correlations with ADL and Physical (which contains ADL items) are .06 and .05 , respectively, and are significant at $p<.05$. While these two correlations are statistically significant and Indicate that women are physically less functional than men in the area of $A D L$, the correlations themselves are very sma11. This suggests that the differences which do exist are probably not of any practical importance for this study. A re-examination of the literature raiscs the question of whether this hypothesis should be used to test construct validity. It is possible that the PIB ADL scale is sensitive to the sex linked debilitating conditions which are highly characteristic of the elderly (National Center for Health Statistics 1973). Although Brook et al. (1979) found no significant differences in physical functioning based on sex, their sample was considerably younger than that used in this study.

Hypothesis 5. It was anticipated that items measuring social support would be significantly correlated with sex and that women would be functionally more dependent than men. Pearson product-moment correlations were computed between sex and both PIB 17 (Natural Support) and the Social scale. Women were not found to be significantly less 
functional than men. While not tested for significance, the correlations indicate that the elderly wen in this study are somewhat less functional than women. For sex and PIB 17 (Natural Support), $\mathbf{r}=$ .07 . For sex and the Social scale, $r=.06$. A re-examination of the literature also raises the question of whether this hypothesis should be used to evaluate construct validity of the PIB scale. The findings of Palmore (1976) and Vicente (1979) suggest that women are more likely to be institutionalized because they are more likely to be widowed or living alone. Being widowed or living alone may or may not, however, be reflected in PIB 17 and the Social scale developed in this study. In addition, the hypothesis in this study was tested with all elderly clients and not just with elderly nursing home residents. The relationship between sex, living arrangement, and a social dimension warrants further exploration and appears to lack the clarity necessary to test construct validity of the PIB Items and scale measuring social support.

RESEARCH QUESTION TWO

Can PIB items and scales accurately predict nursing home placement? As previously discussed, the cllents used for analyses regarding research question two are restricted to those 1772 for whom the PAS recommendation or type of living situation needed (on the DHR-280) corresponds with the actual placement. Over half of these 1772 elderly clients are placed in nursing homes and are significantly different from the elderly community clients in terms of age, sex, marital status, and 
race. The nursing home client is more apt to be 85 years of age or older, widowed, male, and white (see Table XV).

\section{A priort Decision Rule}

When PIB was developed for use in the Southern Oregon Flexible Intergovernmental Grant/Waiver Continuum of Care Project for the elderly, a set of decision rules was established a priori which takes Into consideration a client's functional strengths as well as functional needs (Oregon Medical Assoctation 1980). A decision rule was established for each of five levels of probability that nursing home placement is necessary.

In this study three of these a priori decision rules were evaluated. The actual placement of 1772 elderly nursing home and community clients was compared with the predicted placement based on each of the three deciston rules. The a priori decision rules, as set forth on the 1979 revised draft of the Placement Information Base (Oregon Medical Association 1980, pp. 61 and 62) are expressed in a matrix and an accompanying written explanation. See Table XXI and Figure 9, presented in Appendix B.

The matrix contains different patterns of shading to indicate the relationship between all levels of functioning on each of the 25 PIB items and the a priori probability that nursing home placement is necessary. The written explanation which accompanies the matrix also contains contingency statements relating to scores on PIB items. According to the instructions, the written explanation provides a more 
TABLE XV

A COMPARISON OF ELDERLY COMMUNITY CLIENTS AND ELDERLY NURSING HOME CLIENTS ON SELECTED DEMOGRAPHIC CHARACTERISTICS

\begin{tabular}{|c|c|c|c|c|}
\hline \multirow[b]{2}{*}{ Characteristic } & \multicolumn{2}{|c|}{$\begin{array}{l}\text { Community } \\
\text { Clients }(\mathrm{N}=829)\end{array}$} & \multicolumn{2}{|c|}{$\begin{array}{c}\text { Nursing Home } \\
\text { Clients }(\mathrm{N}=943)\end{array}$} \\
\hline & Number & Percent & Number & Percent \\
\hline \multicolumn{5}{|l|}{ Sex* } \\
\hline $\begin{array}{l}\text { Female } \\
\text { Male }\end{array}$ & $\begin{array}{l}601 \\
228\end{array}$ & $\begin{array}{l}72.5 \\
27.5\end{array}$ & $\begin{array}{l}635 \\
308\end{array}$ & $\begin{array}{l}67.3 \\
32.5\end{array}$ \\
\hline \multicolumn{5}{|l|}{ Age $* \star^{a}$} \\
\hline $\begin{array}{l}65 \text { to } 74 \\
75 \text { to } 84 \\
85 \text { and above }\end{array}$ & $\begin{array}{l}321 \\
331 \\
177\end{array}$ & $\begin{array}{l}38.7 \\
39.9 \\
21.4\end{array}$ & $\begin{array}{l}186 \\
370 \\
387\end{array}$ & $\begin{array}{l}19.7 \\
39.2 \\
41.0\end{array}$ \\
\hline \multicolumn{5}{|l|}{ Race*t } \\
\hline $\begin{array}{l}\text { White } \\
\text { Asian } \\
\text { Negro } \\
\text { Alaskan American Indian } \\
\text { Spanish American }\end{array}$ & $\begin{array}{r}776 \\
6 \\
28 \\
6 \\
13\end{array}$ & $\begin{array}{r}93.6 \\
0.7 \\
3.4 \\
0.7 \\
1.6\end{array}$ & $\begin{array}{r}928 \\
3 \\
9 \\
2 \\
1\end{array}$ & $\begin{array}{r}98.4 \\
0.3 \\
1.0 \\
0.2 \\
0.1\end{array}$ \\
\hline \multicolumn{5}{|l|}{ Marital Status $* *^{b}$} \\
\hline $\begin{array}{l}\text { Married } \\
\text { Widowed } \\
\text { Single Never Married } \\
\text { Divorced or Separated }\end{array}$ & $\begin{array}{r}136 \\
438 \\
66 \\
119\end{array}$ & $\begin{array}{r}17.9 \\
57.7 \\
8.7 \\
15.7\end{array}$ & $\begin{array}{r}176 \\
575 \\
43 \\
76\end{array}$ & $\begin{array}{l}20.22 \\
66.1 \\
4.9 \\
8.7\end{array}$ \\
\hline
\end{tabular}

Mean age is 77.37 for elderly communtty clients, 82.10 for elderly nursing home clients.

${ }^{b} \mathrm{~N}=759$ for community clients; $\mathrm{N}=870$ for nursing home clients.

${ }^{*} \mathrm{p}<.05$ using Chi-square test of independence.

${ }^{* *} p<.001$ using ChI-square test of independence. 
accurate interpretation of the level of probability that nursing home placement is necessary.

To follow the decision rules, the rater examines the matrix to determine the highest probability level assoclated with his client's functional scores. The rater than refers to the written explanation corresponding to the level of probability. If the client's functional scores also meet the contingencles assoclated with that level of probability, nursing home placement may be necessary.

The written explanations accompanying the three probability levels examined in this study are:

"Very high probability" means that if the person's "worst" PIB scale or scales come out in the "very high probability" shading, the person must be in a nursing home (intermediate care facility or skilled nursing facility, depending on need for round the clock registered nurse attention), a community hospital, or a specialty hospital or institution, unless very unusual and reliable help from family, friends, or community is available.

"High probability" means that, if the person's "worst" PIB scale or scales comes out in the "high probability" shading, the person needs to be in a nursing home unless a substitute home (foster home, home for aged) alternative is avallable, or if unusual help from family, friends, or community is available (as indicated by levels 1 or 2 on scale $\#_{17}$ ) or if the individual has strong desire and capactty for living alone (levels 1, 2, or 3 on scale $\# 16$ ) as well as strong personal independence (levels 1 or 2 on scale \#13).

"Moderate probability" means that the person needs part-time or full time medical help in order to stay at home, if the person's "worst" PIB scale or scales come out in the "moderate probability" shading, unless unusual help from family, friends, or from communtty services is avallable.

In order to examine the accuracy of the decision rules associated with each of three probability levels, three equations were developed. The equations were based on an examination of the shading on the matrix 
and the above explanations. The equations are listed below in the computer terminology used by this researcher. In this terminology, EQ means equal to; $G E$ means equal to or greater than. The equations are as follows:

Very High Probability. If (( (PIBII GE 4) or (PIB14 EQ 5 ) or (PIB20 EQ 5) or (PIB21 EQ 5) or (PIB $25 \mathrm{EQ} \mathrm{5)} \mathrm{and} \mathrm{(PIB} 17 \mathrm{GE}$ 2)) probability equals very high.

High Probability. If ((PIB6 EQ 5) or (PIBI1 GE 4) or (PIB14 GE 4) or (PIB16 EQ 5) or (PIB20 GE 4) or (PIB21 EQ 5) or (PIB24 GE 4) or (PIB25 GE 3)) and (PIB17 GE 3) or (((PIB16 GE 4) and (PIB13 GE 3))) probability equals high.

Moderate Probability. If (( (PIB5 EQ 5) or (PIB6 EQ 5) or (PIB11 GE 4) or (PIB13 EQ 5) or (PIB14 GE 3) or (PIB16 EQ 5) or (PIB20 GE 2) or (PIB21 GE 4) or (PIB24 GE 4) or (PIB25 GE $3)$ ) and (PIB 17 GE 3)) probability equals moderate.

In developing the equations, the researcher made judgments regarding the interpretation of three different decision rules. In the very high probability decision rule, "very unusual help from family, friends or communfty" was interpreted to be equal to a score of one on PIB 17 (Natural Support). This interpretation was based on the high probability decision rule in which "unusual help" was equated with a score of one or two on PIB 17. The second interpretation was in the high probability decision rule. The statement "unless a substitute home alternative is available" could not be included in the equation because the researcher did not have access to information regarding substitute home availability. The third interpretation was in the moderate probability decision rule. "Needing part-time or full time medical help in order to stay home" was judged to be equivalent to needing nursing home care. 
Using each of the three equations, placement was predicted for the total sample of 1772 elderly clients. Placement was also predicted using an equation that Identified all elderly clients who had previously been identified as having either a very high, high, or moderate probability of needing nursing home placement. It should be noted that, contrary to what might be expected, the percent of elderly clients whose placement is accurately predicted is not additive as the equations go from very high to moderate. This appears to be due to the inclusion of PIB 16 (Orientation for Living Alone) and PIB 13 (Personal Independence) in the moderate probability decision rule equation but not in the other two decision rules equations.

An examination of Table XVI indicates that the very high probability equation is by far the most accurate overall predictor of placement. It accurately classifles 85 percent of all elderly nursing home clients and 87 percent of all elderly communtty clients. The high probability equation accurately predicts placement for 93 percent of the elderly community clients, but only 68 percent of the elderly nursing home clients. Conversely, the moderate equation and the combined very high, high, and moderate probability equation increase the accuracy of nursing home predictions to 94 and 95 percent, respectively. They do this, however, at the expense of inaccurately classifying almost half of the elderly community cllents.

In evaluating the predictive findings regarding the high and moderate a priori decision rules, two factors must be kept in mind. First, low predictive accuracy is a reflection of the lack of congruence between each decision rule and actual practice rather than a reflection 
of the theoretical relevancy of the decision rule. Second, the decision rules were not intended to be equivalent predictors of nursing home placement. Their very titles suggest that the number of elderly nursing home cllents meeting the very high, high, and moderate probability decision rules would be expected to diminish at each level of probability. It should be noted, however, that in this study a higher percentage of nursing home residents met the moderate probability criteria than met the very high or high probability criteria. Those percentages are $.94, .85$, and .68 , respectively.

The accuracy of the a priort decision rules was also evaluated without PIB 21 (Medication Management). With this omission, the accuracy of the very high probability equation shifts dramatically. Without PIB 21, the equation is able to accurately predict placement for 95 percent of all elderly community clients. The accuracy drops, however, to 31 percent when used with the elderly nursing home clients. The predictive accuracy of the high and moderate probability equations remains fairly stable. In general, when PIB 21 is omitted from the four equations, high levels of predictive accuracy for one group of elderly come at the expense of low levels of predictive accuracy for the other (see Table XVI).

Mathematically Derived Decision Rule

Each mathematically derived decision rule was evaluated by deriving and cross-validating discriminant function equations for two groups of elderly clients whose actual placement is known. The predictors used in the discriminant functions were PIB items and scales. 
TABLE XVI

PERCENT OF ACCURATELY PREDICTED PLACEMENT FOR COMMUNITY AND NURSING HOME CLIENTS USING THREE A PRIORI DECISION RULES, THREE MODIFIED A PRIORI DECISION RULES AND COMBINATIONS OF THE DECISION RULES

\begin{tabular}{lccccc}
\hline & & $\begin{array}{c}\text { With PIB 21 } \\
\text { (Medication } \\
\text { Management) }\end{array}$ & & \multicolumn{2}{c}{$\begin{array}{c}\text { Without PIB 21 } \\
\text { (Medication } \\
\text { Management) }\end{array}$} \\
\cline { 2 - 6 } & $\begin{array}{c}\text { Communtty } \\
\mathrm{N}=829\end{array}$ & $\begin{array}{c}\text { Nursing } \\
\text { Home }\end{array}$ & & $\begin{array}{c}\text { Commity } \\
\mathrm{N}=843\end{array}$ & $\begin{array}{c}\text { Nursing } \\
\text { Home } \\
\mathrm{N}=943\end{array}$ \\
\hline Probability & 87 & 85 & 95 & 31 \\
$\begin{array}{l}\text { Very High } \\
\text { High }\end{array}$ & 93 & 68 & 95 & 57 \\
$\begin{array}{l}\text { Moderate } \\
\begin{array}{l}\text { Very High, High } \\
\text { and Moderate }\end{array}\end{array}$ & 46 & 94 & 46 & 94 \\
\hline
\end{tabular}

The group of elderly clients used to derive the equations was randomly selected from the 1772 elderly nursing home and communtty clients in this study. The derivation group is composed of 977 clients divided about equally between the community $(N=409)$ and nursing homes $(N=$ 455). The remaining 1019 elderly clients constitute the crossvalidation group. Forty-seven percent of this group reside in the community $(\mathrm{N}=420)$ and 53 percent in nursing homes $(\mathrm{N}=488)$. Chi-square tests of significance indicate that the derivation and cross-validation groups are not significantly different in terms of age, sex, marital status, race, or living arrangement.

As a preliminary step to developing the discriminant function equations, each individual PIB item and scale was examined for its ability to differentiate elderly nursing home and community clients. Differences calculated with analysis of variance indicate that the two 
groups are significantly different on all PIB items and scales with the exception of PIB 11 (Eating). These differences between the nursing home and community clients are graphically illustrated in relative frequency polygons presented in Figures 11 and 12 of Appendix C.

Because the items and scales are both able to differentiate the two groups, a decision was made to develop discriminant function equations using the PIB items as well as PIB multi-item scales as predfCtors.

Items and scales within each of the derived functions were examined for their contribution to the explained variance of the total equation using the Wilks' lambda statistic. Wilks' lambda is an "inverse measure of the discriminating power of the original variables which has not yet been removed by the discriminant functions" (Klecka 1975, p. 442). For each function any ttem or scale which contributed at least .01 to the Wilks' lambda, 1.e. 1 percent of the variance, was retained in the equation; others were omitted.

Functions were then recomputed with these retained items and scales (see functions $1,3,5,6,7$, and 8 in Table XVII). Several alternate functions were also computed (see functions, 2, 4, and 9 in Table XVII). These latter functions omit PIB 10 (Nutritional Habits). Although this item contributes to the variance of several functions, there is some question among clinfclans regarding its appropriateness as a predictor of nursing home placement. This researcher decided, therefore, to evaluate the effectiveness of the functions both with and without PIB 10. 
TABLE XVII

SUMMARY OF THE SIGNIFICANCE OF PREDICTORS ENTERED INTO EACH OF THE TEN DISCRIMINANT FUNCTIONS

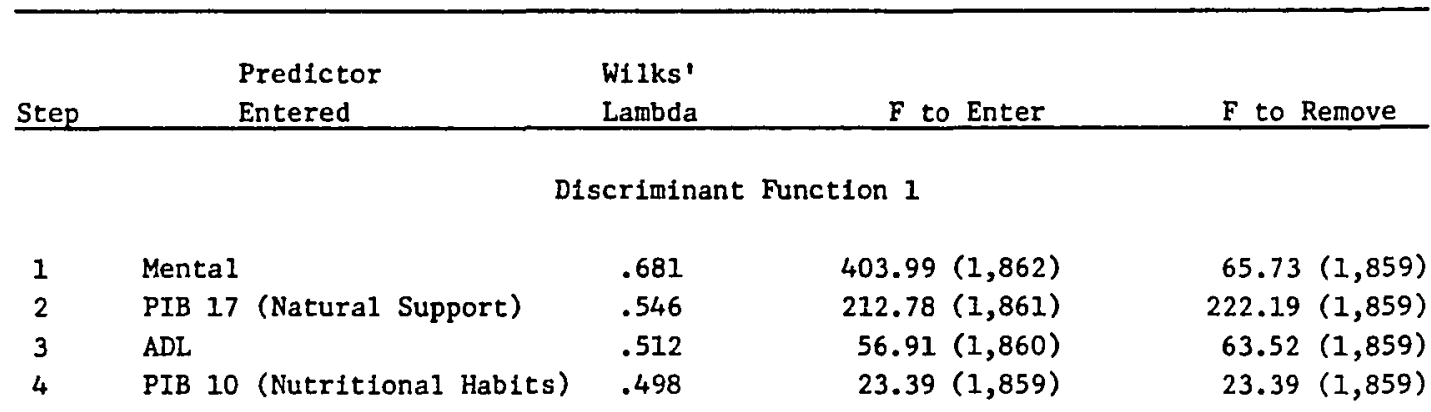

Discriminant Function 2

$\begin{array}{rlrrr}1 & \text { Mental } & .681 & 403.99(1,862) & 62.11(1,860) \\ 2 & \text { PIB 17 (Natural Support) } & .546 & 212.78(1,861) & 207.51(1,860) \\ 3 & \text { ADL } & .512 & 56.91(1,860) & 56.91(1,860)\end{array}$

Discriminant Function 3

$\begin{array}{lllrr}1 & \text { Physical } & .669 & 425.54(1,862) & 106.04(1,859) \\ 2 & \text { PIB 17 (Natural Support) } & .528 & 230.34(1,861) & 218.94(1,859) \\ 3 & \text { PIB 10 (Nutritional Habits) } & .516 & 20.44(1,860) & 25.31(1,859) \\ 4 & \text { Mental-Social } & .506 & 16.43(1,859) & 16.43(1,859)\end{array}$

Discriminant Function 4

$\begin{array}{lllrr}1 & \text { Physical } & .669 & 425.54(1,862) & 104.53(1,860) \\ 2 & \text { PIB 17 (Natural Support) } & .528 & 230.34(1,861) & 205.68(1,860) \\ 3 & \text { Mental-Social } & .521 & 11.58(1,860) & 11.58(1,860)\end{array}$

Discriminant Function 5

$\begin{array}{llrrr}1 & \text { Mental-Social } & .651 & 462.72(1,862) & 40.89(1,859) \\ 2 & \text { PIB 17 (Natural Support) } & .543 & 171.21(1,861) & 204.04(1,859) \\ 3 & \text { Physical } & .508 & 58.48(1,860) & 60.08(1,859) \\ 4 & \text { PIB 10 (Nutritional Habits) } & .492 & 27.44(1,859) & 27.44(1,859)\end{array}$

Discriminant Function 6

\begin{tabular}{|c|c|c|c|c|}
\hline 1 & Menta1-Soclal, & .651 & $462.72(1,862)$ & $33.80(1,860)$ \\
\hline 2 & PIB 17 (Naturál Support) & .542 & $171.21(1,861)$ & $190.51(1,860)$ \\
\hline & Physical & .508 & $58.48(1,860)$ & $58.48(1,860)$ \\
\hline
\end{tabular}


TABLE XVII continued

\begin{tabular}{|c|c|c|c|c|}
\hline Step & $\begin{array}{l}\text { Predictor } \\
\text { Entered }\end{array}$ & $\begin{array}{l}\text { Wilks' } \\
\text { Lambda }\end{array}$ & $F$ to Enter & F to Remove \\
\hline \multicolumn{5}{|c|}{ Discriminant Function 7} \\
\hline 1 & Mental, & .610 & $551.66(1,862)$ & $153.48(1,859)$ \\
\hline 2 & PIB $17^{2}$ & .497 & $194.33(1,861)$ & $223.65(1,859)$ \\
\hline 3 & $\mathrm{ADL}$ & .484 & $24.59(1,860)$ & $33.27(1,859)$ \\
\hline 4 & Social & .466 & $32.89(1,859)$ & $32.89(1,859)$ \\
\hline \multicolumn{5}{|c|}{ Discriminant Function 8} \\
\hline 1 & PIB 21 (Medication Mgmt.) & .554 & $693.94(1,862)$ & $159.17(1,857)$ \\
\hline 2 & PIB 17 (Natural Support) & .462 & $171.41(1,861)$ & $198.60(1,857)$ \\
\hline 3 & PIB 9 (Food Shop/Prep) & .452 & $18.54(1,860)$ & $14.08(1,857)$ \\
\hline 4 & PIB 10 (Nutritional Habits) & .445 & $13.37(1,859)$ & $15.66(1,857)$ \\
\hline 5 & PIB 23 (Bathing/Showering) & .440 & $9.65(1,858)$ & $11.48(1,857)$ \\
\hline 6 & PIB 8 (Personal Shopping) & .437 & $5.98(1,857)$ & $5.98(1,857)$ \\
\hline \multicolumn{5}{|c|}{ Discriminant Function 9} \\
\hline 1 & PIB 23 (Bathing/Showering) & .728 & $321.35(1,862)$ & $27.96(1,859)$ \\
\hline 2 & PIB 17 (Natural Support) & .570 & $239.74(1,861)$ & $234.30(1,859)$ \\
\hline 3 & PIB 15 (Use of Telephone) & .531 & $63.43(1,860)$ & $42.76(1,859)$ \\
\hline 4 & PIB 9 (Food Shop/Prep) & .507 & $39.61(1,859)$ & $39.61(1,859)$ \\
\hline \multicolumn{5}{|c|}{ Discriminant Function 10} \\
\hline 1 & Phystcal & .669 & $425.54(1,862)$ & $372.05(1,861)$ \\
\hline 2 & PIB 17 (Natural Support) & .528 & $230.34(1,861)$ & $230.34(1,861)$ \\
\hline
\end{tabular}
.01

NOTE: All $F$ values reported in this table are significant at $p<$

As a result of the decisions just described, nine shortened discriminant function equations were derived and evaluated. A comparison of the Wilks' lambda for function 3 and 4 indicates that the contribution of the Mental-Social scale is reduced to less than .01 when PIB 10 (Eating) is removed from the function. A decision was therefore made to create a tenth function, omitting the Mental-Social scale from 
function 4. These ten functions contain between two and six items or scales and have Wilkes' lambdas at the final step ranging from .528 to .437. A sumary and comparison of each of the ten functions is found in Table XVII.

An examination of Table XVII indicates that physical, mental, and social dimensions and the availability of a natural support system (PIB 17) are each important predictors of nursing home placement. While the Physical, ADL, and Mental scales account for more variance than PIB 17 (Natural Support), PIB 17 accounts for more variance than either the IADL or the Social scale.

Although appearing in each of the functions, except those from which it was deliberately excluded, PIB 10 (Nutritional Habits) is not In itself an important predictor of nursing home placement. Its $F$ to enter at the first step of the discriminant analysis is .0016 . It does, however, interact with the other items and scales to increase the total amount of predictive variance accounted for by the functions in which it is included.

Based on preliminary studies conducted by the Oregon State Department of Human Resources (1981a, p. 150), it was anticipated that the most predictive PIB Items would be PIB 21 (Medication Management), PIB 22 (Grooming and Dressing), PIB 23 (Bathing and Showering), PIB 24 (Using Tollet), and PIB 25 (Continence). PIB 21 (Medication Management) is highly predictive, followed by PIB 19 (Money Management), PIB 23 (Bathing and Showering), and PIB 22 (Grooming and Dressing). Although PIB 24 (Using the Tollet) and PIB 25 (Continence) are quite predictive, they are less so than PIB 15 (Use of Telephone), PIB 16 (Orientation for 
Living Alone), PIB 17 (Natural Support), and PIB 9 (Food Shopping/ Preparation). The failure of some of these 1tems to appear in functions 8 and 9 , or the order in which they do appear, can be attributed to the high correlations which exist among many of them. PIB 19 (Money Management), for example, is highly correlated with both PIB 15 (Use of Telephone) and PIB 21 (Medication Management). When entered into the discriminant function after either of these two items, PIB 19 does not account for enough independent variance to meet the inclusion criteria set by this researcher.

Equations for each of the ten discriminant functions were used to predict placement for elderly community and nursing home clients in both the derivation and cross-validation groups. As 11lustrated in Table XVIII, the percent of accurately predicted placements is consistently high when examined by group (derivation and cross-validation) and by type of placement (community or nursing home). With the derivation group, the percent of accurately predicted placement ranges from 79.2 to 82.4 for community clients and from 86.2 to 90.5 for nursing home clients. Accuracy levels are even higher with the cross-validation group. The percent of accurately predicted placement ranges from 81.9 to 87.6 for community clients and from 88.1 to 91.8 for nursing home clients.

An examination of predictive accuracy of each of the ten functions indicates that they are very simflar for both the derivation and crossvalidation group. Three of these functions are graphically illustrated 
TABLE XVIII

PERCENT OF ACCURATELY PREDICTED PLACEMENT FOR DERIVATION AND CROSS-VALIDATION GROUPS BY FUNCTION AND TYPE OF PLACEMENT

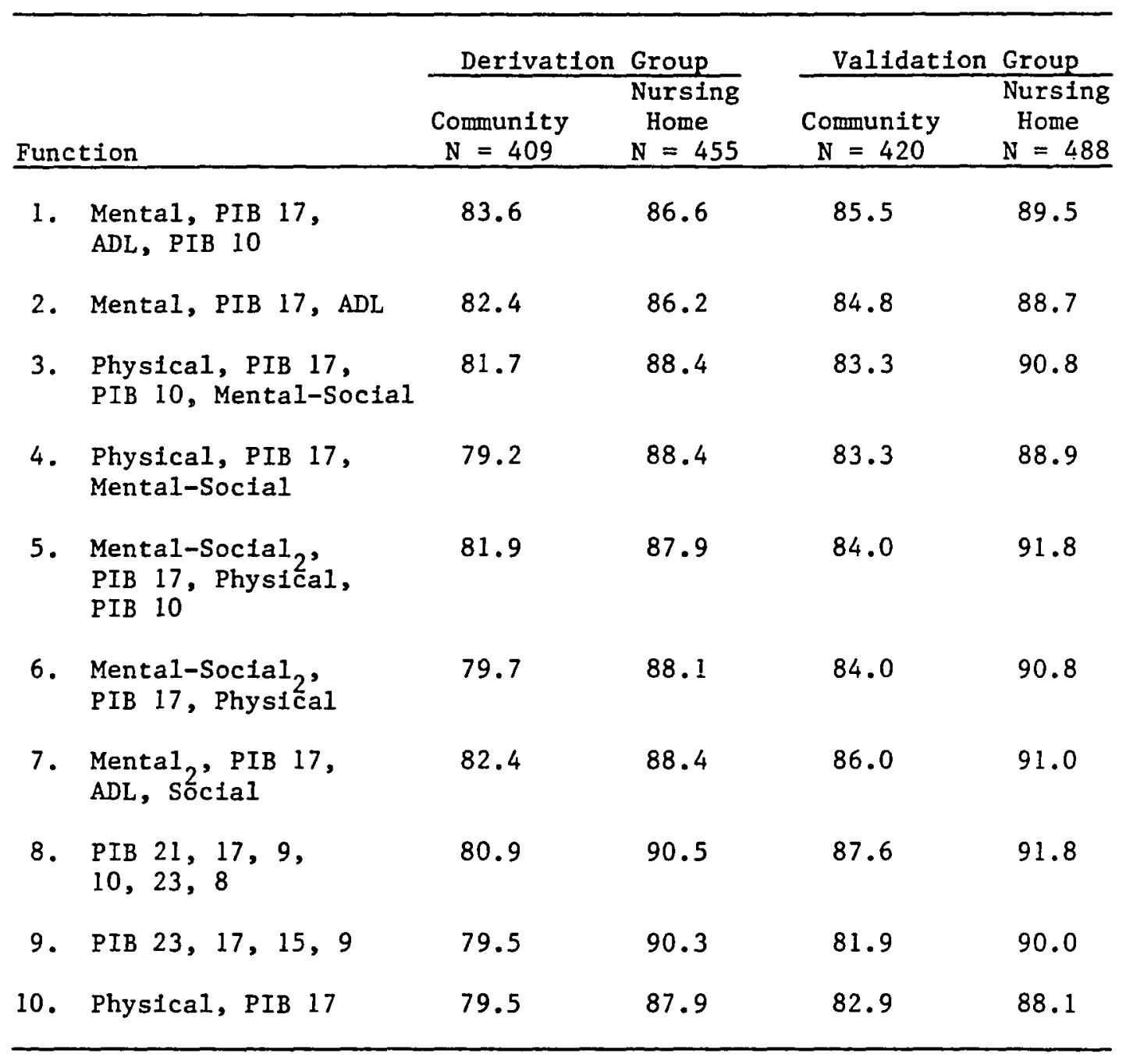

In Figure 3. The average percent of accurately predicted placement ranges from 84.6 for function 10 to 87.7 for function 8 .

Functions 2, 4, 9, and 10 were next cross-validated with subsamples of the elderly population, where the subsamples represented a breakdown by age, sex, or source of evaluation (PAS vs. caseworker). 

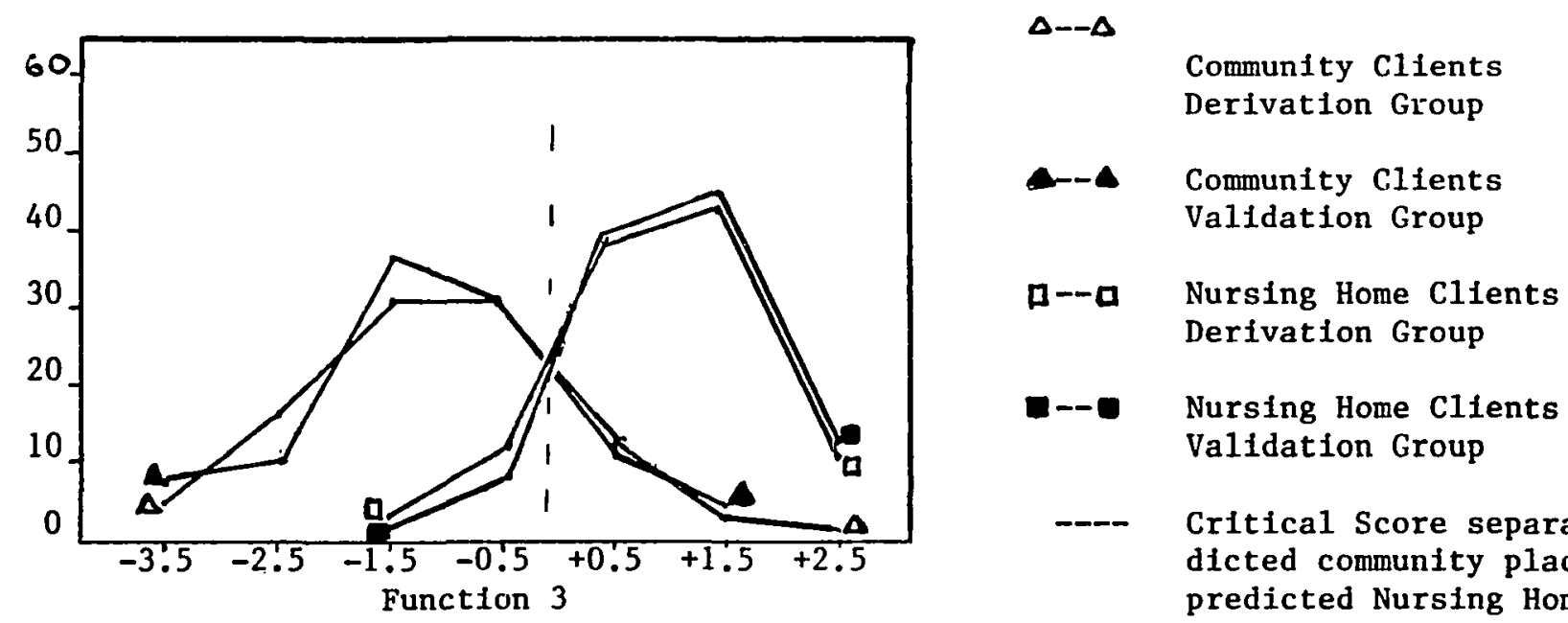

- Nursing Home clients

Validation Group

-.- Critical Score separating predicted community placement and predicted Nursing Home placement
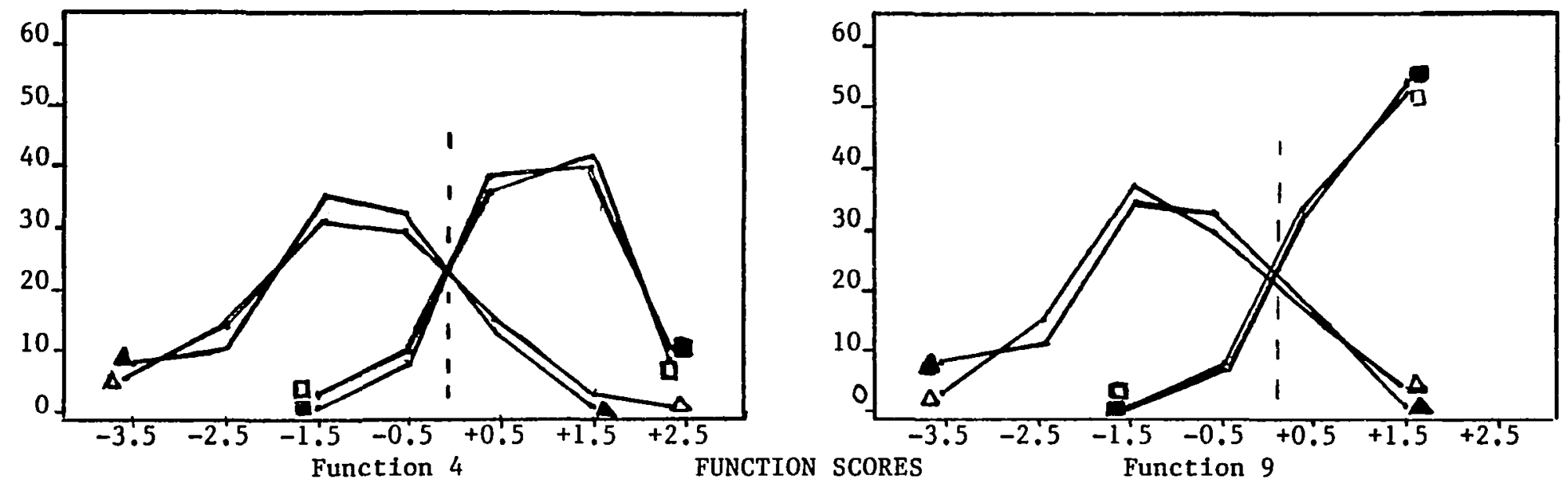

Figure 3. Relative frequency polygons illustrating Discriminant Function scores for elderly community and nursing home clients.

NOTE: Predicted communtty placement is to the left of the critical score. Predicted nursing home placement is to the right. 
These functions were selected because they are empirically similar regarding their predictive accuracy, but theoretically different in their composition. Functions containing PIB 21 (Medication Management) were omitted from this analysis (see functions $5,6,7$, and 8 ) because PIB 21 has questionable inter-rater reliability and the functions containing the ftem do not appear to have a predictive advantage over the other functions.

As 1llustrated in Table XIX, the predictive accuracy of the four functions remains high for the cross-validation group when classifications are based on sex, age, and the source of the placement evaluation. The average percent of accurate prediction ranges from 85.3 for function 10 to 86.3 for function 2. Varlation of predictive accuracy within each function is less than 7 percent and the direction of the variation is generally the same for all functions (e.g., the predictive accuracy for community clients is consistently higher for women than for men).

Because of the increased reliability and sensitivity that usually accompanies scales, it was anticipated that functions $1,2,3,4,5,6$, 7 , and 10 would be more accurate predictors of placement than functions 8 and 9 which contain only single items. However, as illustrated in Table XVIII, the functions which contain only items have predictive accuracy levels equal to or greater than most of the functions which contain scales. An examination of Table XVII indicates that this high level of predictive accuracy cannot be accounted for by a larger number of Items within these two functions. At the final step, there is very little difference between the Wilks' lambda for function 9 containing four items as predictors and for other functions containing four 
TABLE XIX

A BREAKDOWN OF THE PERCENT OF ACCURATELY PREDICTED PLACEMENT OF THE CROSS-VALIDATION GROUP BY AGE, BY SEX, AND BY SOURCE OF EVALUATION

\begin{tabular}{|c|c|c|c|c|c|c|c|c|c|c|c|}
\hline \multirow{2}{*}{\multicolumn{2}{|c|}{$\begin{array}{r}\text { Cross } \\
\text { Age } \\
\end{array}$}} & \multirow{2}{*}{\multicolumn{4}{|c|}{$\begin{array}{ll}\text { on Community Group } \\
=420)\end{array}$}} & \multirow{2}{*}{\multicolumn{2}{|c|}{$\begin{array}{r}\text { Cross } V_{a} \\
\text { Age } \\
\end{array}$}} & \multirow{2}{*}{\multicolumn{2}{|c|}{$\begin{array}{l}\text { alidation } N \\
\text { Group }(N= \\
\text { Sex }\end{array}$}} & $\begin{array}{l}\text { ursing } \\
488)\end{array}$ & \multirow{2}{*}{$\begin{array}{l}\text { g Home } \\
\text { rce of } \\
\text { luation }\end{array}$} \\
\hline & & & & & & & & & & \multirow{2}{*}{\multicolumn{2}{|c|}{$\begin{array}{l}\text { Source of } \\
\text { Evaluation } \\
\text { Case- } \\
\text { PAS worker }\end{array}$}} \\
\hline $65-84$ & $\leqslant 85$ & Male & $\begin{array}{l}\mathrm{Fe}- \\
\text { male }\end{array}$ & PAS & $\begin{array}{l}\text { Case- } \\
\text { worker }\end{array}$ & $65-84$ & $\leqslant 85$ & Male & $\begin{array}{l}\text { Fe- } \\
\text { male }\end{array}$ & & \\
\hline \multicolumn{12}{|c|}{ Function 2} \\
\hline 86.7 & 84.1 & 84.3 & 87.0 & 84.3 & 86.7 & 86.9 & 90.7 & 84.3 & 84.3 & 88.9 & 87.4 \\
\hline \multicolumn{12}{|c|}{ Function 4} \\
\hline 84.3 & 84.1 & 84.3 & 85.7 & 80.0 & 84.6 & 84.1 & 90.7 & 84.1 & 87.1 & 89.6 & 86.3 \\
\hline \multicolumn{12}{|c|}{ Function 9} \\
\hline 82.5 & 79.5 & 80.5 & 85.2 & 76.7 & 82.3 & 88.9 & 91.8 & 93.8 & 87.8 & 90.9 & 88.4 \\
\hline \multicolumn{12}{|c|}{ Function 10} \\
\hline 82.5 & 84.1 & 79.6 & 84.0 & 80.0 & 83.1 & 86.6 & 90.7 & 90.0 & 87.9 & 90.3 & 84.7 \\
\hline
\end{tabular}

predictors, some of which are scales. The explained varfance accounted in function 9 (Wilkes' lambda $=.507$ ) is slightly less than the explained variance in functions $1,3,5$, and 7 (Wilks' lambda $=.498$, $.506, .492$, and .466 , respectively).

The high levels of predictive accuracy for functions 8 and 9 appear to be attributable to the high levels of variance which can be accounted for by the individual items within the functions. For example, when taken separately at the first step of the discriminant function analysis, the Wilks' lambda for the 1tems in function 9 range from $.757[F(1,862)=277]$ for PIB 9 (Food Shopping/Preparation) to .728 
$[F(1,826)=321]$ for PIB 23 (Bathing or Showering). In contrast, the IADL scale which contains PIB 9 accounts for less varlance than PIB 9 by 1tself. The ADL scale which contains PIB 23 accounts for only a little more variance than PIB 23 by itself. Taken separately at the first step of the discriminant function analysis, the Wilks' lambda is .772 $[F(1,862)=254]$ for the IADL scale and .696 $[F(1,862)=387]$ for the ADL scale.

It is apparent that some of the PIB items have very high predictive accuracy. There is little overlap between the distribution of scores of the elderly community clients and the distribution of the elderly communty clients on these items. An examination of Figure 11 presented in Appendix C 1llustrates the small degree of overlap of three of the four items in function 9 (PIB 12 (Social Activities), 17 (Natural Support), and 9 (Food Shopping/Preparation)) and four of the six items in function 8 (PIB 21 (Medication Administration), 17 (Natural Support), 23 (Bathing or Showering), and 8 (Personal Shopping)).

It has been suggested that the high scores given to nursing home residents on the IADL items ( $P I B ~ 4,7,8$, and 9) and on the Medication Management ftem (PIB 21) may be a reflection of a lack of opportunity to perform the tasks rather than a lack of ability to perform the tasks (Reed 1982). This could account for the high predictive accuracy of PIB 8 (Personal Shopping), PIB 9 (Food Shopping/Preparation), and PIB 21 (Medication Management). It does not, however, explain the high predictive accuracy of PIB 17 (Natural Support), PIB 21 (Social Activities), and PIB 23 (Bathing or Showering). 
What is not known is the extent to which the IADC and medication Items measure the actual functional status of the client. It may be, for example, that the nature of the dimension being measured is such that most elderly clients are either functional or not functional. On the other hand, raters may be determining the desired placement and then, although not necessarily in a conscious manner, scoring the elderly according to the placement, 1.e. low for community, high for nursing home. Although it is beyond the scope of this study to pursue this concern, further exploration is warranted. It should be noted that the IADL and Medication Administration items, whose reliability have been questioned, are not necessary for high predictive accuracy. These Items are not contained in functions 1 and 2 which accurately predict placement for 82 to 90 percent of the elderly clients.

A comparison between the predictive accuracy of the ten mathematically derived equations and the a priori set of decision rules indicate that the discriminant function equations are equal to or superior to the a priori deciston rules when PIB 21 (Medication Management) is included and vastly superior when PIB 21 is omitted (see Table XVI and XVIII).

Without PIB 21, the high probability decision rule is the most accurate a priori predictor of nursing home placement. It accurately predicts placement for 94 percent of all nursing home clients but only 46 percent of all elderly community clients. In contrast, discriminant function equation 3, which also omits PIB 21, is able to accurately predict placement for 90.8 percent of all nursing home clients and 83.3 percent of all community clients in the cross-validation group. 
RESEARCH QUESTION THREE

Does PIB have acceptable inter-rater reliability? This question was addressed Indirectly using three approaches. First, findings from the hypotheses of research question one were compared with expected findings. Second, comparisons were made between some of the functional characteristics of this sample as measured by PIB and the expected characteristics based on the literature. Third, elderly nursing home clients from different geographic areas of the state were examined for functional similarity.

Findings on Research Question One

The findings on research question one tend to either support interrater reliability or to be inconclustve. As previously discussed, within scale correlations of PIB items were higher than between scale correlations. PIB scales measuring physical functioning were significantly correlated with age. Although the ADL and Physical scales were unexpectedly correlated with the sex of the elderly client, the correlation is small and may be unrelated to reliablitty. Fallure to find women more functionally dependent on the Social scale may be a reflection of lack of conceptual clarity rather than poor inter-rater reliability. In reexamining the literature, it appears that although the relationship between sex and a "social dimension" tends to be in the direction hypothesized by this researcher, the relationship is not clear and should be explored further. 


\section{Expected Characteristics Based on the Literature}

A comparison of the functional characteristics of this sample of elderly clients with those found in the literature was inconclusive due to variations in methodology. Elderly clients in this study appear similar to elderly clients reported in the literature in some functional areas but different in others. These differences, however, may be due to factors other than inter-rater reliability and should be explored further.

As measured by PIB 5 and PIB 6, elderly nursing home clients in this study appear functionally comparable to those reported in the literature but elderly community clients in this study appear less functional.

Both the U.S. National Center for Health Statistics (1974) and the U.S. Bureau of the Census (1978) estimate that more than half of all nursing home clients are non ambulatory and unable to leave the premises. In this study, 23 percent of the elderly nursing home clients need help to transfer and may need help to get out of the room. An additional 43 percent do not get around even in the room without continuous help. The clients in this study look less functional on PIB 5 (Mobility without Aids). This item does not, however, accurately reflect the functional level of elderly clients who regularly use aids and who represent 89 percent of the total nursing home population. Elderly community clients in this study appear less functional in the area of mobility than those reported in the 1iterature. As measured by PIB 6,10 percent of the community clients can get around in a room but use wheelchairs and need help to transfer. An additional 13 percent 
do not get around, even in the room, without continuous assistance by another person. In contrast, Shanas (1974) and the U.S. National Center for Health Statistics (1974) estimated that four to eight percent of the non-institutionalized elderly are housebound. These differences may be a reflection of different definitions, methodology, or population sampled, rather than inter-rater rellability. The elderly in this sample, for example, are restricted to Medicaid (welfare) recipients and may be functionally different than a random sample of elderly. The differences, however, need further exploration.

Both elderly community and nursing home clients in this study appear comparable to those reported in the literature in the area of ADL. In this study, 70 percent of the elderly nursing home clients received a score of three or greater on the PIB ADL scale. This finding corresponds fairly well with the findings of Barney (1977) and Miller (1965). Both reported that 60 percent of the nursing home residents surveyed by them needed ADL assistance. Among the elderly community clients in this study, 22 percent recelved a PIB ADL score of three or greater indicating the need for some assistance with ADL. Only eight percent recelved a score of four or greater indicating the need for regular assistance. These findings correspond closely with those reported in the literature. The estimated percent of elderly community clients needing ADL assistance ranged from 16 percent (U.S. National Center for Health Statistics 1974) to 21 percent (Pfeiffer 1975). Both elderly community and nursing home clients in this study appear less functional than the clients reported in the literature in the area of mental functioning. In this study 85 percent of all elderly 
nursing home residents have a score of three or greater on the Mental scale, indicating moderate dysfunction. This is much higher than the 46 percent who were judged to need intermittent supervision for mental impairment (Monroe County Health Care of the Aged Study 1968), 56 percent who were judged by nursing home administrators to be senile (U.S. National Center for Health Statistics 1973c) and the 59 percent judged to be forgetful or confused by Zimmer (1975). In this study 39 percent of the elderly community residents have a score of three or greater on the Mental scale, indicating a moderate level of dysfunction. In contrast, Blenkner (1967) in a review of isolated studies found estimates of mental impalrment among the elderly residing in the community to range from 10 to 14 percent. The Monroe County Health Care of the Aged Study (1968) reported that 10 percent of the community elderly studied by them needed intermittent supervision for mental impairment. It is difficult to evaluate the extent to which these differences are due to factors other than inter-rater reliability. It is not known, for example, how comparable the samples are with regard to age or diagnosis. Operational definitions of confusion and senility are not provided and may not be comparable to those implied in the PIB scale.

The elderly nursing home clients in this study appear to need much more assistance with eating and medication administration than the elderly nursing home clients reported in the literature. In this study 94.9 percent of all nursing home clients received a score of three or greater on either PIB 21 (Medication Management) or PIB 11 (Eating). This is considerably higher than the 76 percent needing dietary or medication assistance reported by the 1976 Survey of Institutionalized 
Persons (U.S. Bureal of Census 1978). This finding tends to support the concern for inter-rater reliability for PIB 21. Further testing is certainly warranted.

Other characteristics of the elderly in this study cannot be compared due to a lack of reported studies in the literature.

\section{Functional Similarity Across Location}

Functional similarity was evaluated by comparing PIB scale scores for elderly nursing home cllents living in 20 of the 51 locations indicated on the DHR-280. Thirty one locations were not evaluated due to frequencies of less than fifteen. Using ANOVA, random effects, significant differences were found between location on all of the scales. Although the $F$ ratios were small (2.85 to 4.68$)$, location does seem to make a difference and should be explored in greater detail. It is not known whether the differences between locations is a reflection of functional differences in the elderly population, variation in the enforcement of the use of the a priorl decision rules, poor inter-rater reliability, or other factors such as cultural differences between the populations, or the availability of nursing home beds and community resources.

The relationship between bed supply and placement for example, has been discussed in the review of 1iterature. It was not possible, however, to pursue this relationship within the scope of this study. The location indicators avaflable to this researcher do not directly correspond with the boundaries used to report the avallability to nursing home beds. 
SUMMARY OF IMPORTANT RESULTS

The measurement capabilities of the PIB were evaluated with a sample of 2287 elderly clients residing in the community, substitute homes, nursing homes, and selected non-nursing home institutions. All items were found to have varfability across the five point response range. Some items, however, have bimodal or skewed distributions. Items appear to measure the dimensions of physical, mental, and social functioning.

Multi-item scales were developed from twenty of the PIB items on the basis of theoretical considerations, Pearson product-moment correlations, and factor analysis. Four scaies evolved which measure Activities of Daily Living (ADL), Instrumental Activities of Daily Living (IADL), Mental, and Social dimensions. These scales are highly reliable and have alphs coefficlents of $.90, .88, .87$, and .75 , respectively. Two summary scales, Physical and Mental-Social, were also developed. Their alpha coefficients are .91 and .88 , respectively. In addition, an alternative Mental scale which included PIB 21 (Medication Management) was developed. Its alpha coefficient is .88 and Increases to .89 when combined with the Social scale to form the Mental-Social, scale. All but one of the developed scales have distributions of scores that are more normal than the score distributions of PIB items. The IADL scale has a skew of -2.01 and may warrant further study.

Tests of selected hypotheses using the newly constructed scales tend to support construct validity of the scales. One set of findings supporting construct validity of the scales is that within-scale 
correlations are higher than between-scale correlations. In addition, PIB scales measuring physical functioning are significantly correlated with age as hypothesized. Although the findings for two other hypotheses failed to support construct validity of the scales, a re-examination of the literature suggests that the hypothesized relationships lack the theoretical clarity desirable for construct validity.

The criterion-related validity of PIB items and scales was evaluated with a sample of 1772 elderly community and nursing home clients. Approximately half of this sample was randomly selected to form a derivation group and the remaining half was assigned to a cross-validation group. Using various combinations of PIB items and scales as predictors, ten discriminant function equations were developed to predict nursing home vs. community placement.

For each of the functions, predictive accuracy was at least 79.2 percent with the derivation group and even higher with the cross-validation group. The function having the highest overall predictive accuracy with the cross-validation group correctly classified 87.6 percent of all elderly community clients and 91.8 percent of all elderly nursing home clients. The function having the lowest overall predictive accuracy correctly classified 82.9 percent of all elderly communtty clients and 88.1 percent of all elderly nursing home clients. Functions omftting PIB 21 (Medication Management) had predictive accuracy equivalent to those functions containing PIB 21. Functions containing only single items, predicted as well or better than functions 
containing scales. This latter finding appears to be a reflection of the high predictive accuracy of several of the individual items.

Predictive accuracy of three of the a priori decision rules was also evaluated using PIB items as predictors. The very high probability decision rule has the highest overall predictive accuracy and correctly classified 87 percent of all elderly community residents and 85 percent of all elderly nursing home residents. The moderate probability decision rule has the lowest overall predictive accuracy and correctly classified 46 percent of all elderly community clients and 94 percent of al1 elderly nursing home clients. When PIB 21 (Medication Management) is removed from the equations, the predictive accuracy of the very high probability decision rule drops dramatically.

A comparison between the a priori decision rules and the discriminant function equations indicates that each of the ten discriminant function equations is predictively equal to or superior to any of the a priori decision rules.

Inter-rater reliability was evaluated indirectly using three approaches. Findings from hypothesis one were compared with expected findings, functional characteristics of the elderly in this study were compared with those reported in the literature, and the functional characteristics of elderly from different geographic locations within Oregon were compared. Al.though the construct validity hypotheses tend to support inter-rater reliability, the literature comparison was inconclusive due to differing methodologies. The comparison across geographic locations within the state indicates that location does affect the scores of the elderly nursing home clients. Whether this 
effect is due to poor inter-rater reliability or other factors such as bed avallability is not known and needs further examination. It should be noted that PIB 21 (Medication Management), the 1tem with the most questionable inter-rater reliability (Reed 1982) was not found to be necessary for high levels of predictive accuracy and is omitted from six of the discriminant functions. Cognitive items identified as having questionable inter-rater reliability by Dingman (1983) were either not entered into functions during the discriminant function analyses or are included in the form of a scale, reducing their influence. 


\section{CHAPTER V}

\section{POLICY RECOMMENDATIONS AND SUGGESTIONS FOR}

FUTURE RESEARCH

\section{Policy Recommendations}

The policy recommendations of this study are based on three findings. First, nursing home placement in Oregon can be predicted with high levels of accuracy using selected items from the Placement Information Base PIB. Second, the very high a priori decision rule and the ten discriminant functions derived from PIB items and scales are predictively equivalent but vary in their measurement qualities. Third, the Natural Support item (PIB 17) is clearly related to nursing home placement.

The Desirability of Using PIB as a Nursing Home Screening Instrument. It is apparent from the findings presented in the previous chapter that the very high probability decision rule and each of the ten discriminant functions derived from PIB Items and scales can predict nursing home placement with high levels of accuracy. The accuracy of three of these functions was further evaluated and found to be generalizable to subsets of the elderly population, i.e., both men and women, and both the young-old and the old-old. As discussed in the introduction of this study, a screening instrument which is brief, has the potential to be administered by nonprofessionals, and has a high level of predictive accuracy, is very attractive to Oregon and to other states seeking an economical and equitable method 
of determining nursing home placement for the elderly. Such an instrument can be administered at a low per unit cost and can be implemented in areas of low population density where highly trained professionals are either not avallable or not cost effective to employ. A screening instrument used for placement decisions should bring about a greater standardization of practice and an over-all reduction in the proportion of elderly placed in nursing homes. This standardization of practice is particularly important in a statewide program where practice standards are varied and where large numbers of raters are employed.

As a screening instrument, PIB can also be used to identify elderly at risk of institutionalization. This would enable the state to delay or reduce nursing home admissions by the timely provision of critical services. PIB would be particularly attractive to states who wish to participate in the federal Medicald waiver program, since a systematic program of screening is one of the requirements.

While this discussion of policy considerations is not intended to be comprehensive, it does serve to highlight major areas in which the adoption of PIB as a screening instrument for nursing home placement can make a difference.

This researcher recommends that one of the discriminant functions derived from PIB items and scales be selected for program implementation and that $P I B$ be revised to include only those items contained in the selected discriminant function. The discriminant function equation can then be used to create a total score for Medicaid cllents based on their responses to the items or scales within the function. 
This revised $\mathrm{PIB}$ should be administered to the elderly prior to and separately from the PAS process. Since a screening instrument is, by definition, not expected to be error free, the revised PIB can be used to Identify the elderly clients who obviously need nursing home placement and elderly clients who obviously do not need placement. Elderly for whom placement is questionable or elderly whose score is close to the critical score for placement can then be evaluated with a more comprehensive analysis conducted by the PAS team.

In practice, this recomendation calls for establishing both an upper and lower threshold which create a net or catch area. Clients whose discriminant function screening scores fall within these two thresholds would be eligible for the comprehensive PAS assessment. One procedure for creating upper and lower thresholds is illustrated in Figure 14, Appendix $C$. In this illustration the thresholds have been placed at the discriminant function score levels which allow a predetermined percent of clients to be inappropriately placed. A comparison between the two sets of thresholds in Flgure 14 provides some Indication of the relationship between the destred level of accuracy and the number of clients who must be assessed in order to attain that level of accuracy.

While the selection of a particular set of thresholds is beyond the scope of this study, one constraint could be the cost of providing screening and assessment as it compares with the cost of inappropriate placement to both the client and the state.

Which Combination of PIB Items and Scales Should be Used for the Screening Instrument? While the very high probability a priori decision 
rule and each of the ten discriminant functions are very similar in their predictive accuracy, they vary in their measurement qualities. In addition, the a priori decision rule varies from the discriminant function in that it creates a profile based on five items rather than a single total sccre based upon a weighted sum of PIB scales and/or items. The recommendations of this researcher are based, therefore, not upon the predictive accuracy, but upon the measurement and scoring characteristics of the various combinations of PIB items.

This researcher recommends that the very high probability decision rule not be used for nursing home placement screening. Because of its maximum need decision format, this rule does not lend itself easily to the establishment of thresholds. In addition, all of the items contained in the decision rule have score distributions which are either bimodal, skewed, or both. One of these items is PIB 21 (Medication Management) whose reliability has been seriously questioned.

Functions 5, 6, 7, and 8 are not recomended for use at this time. Each of these functions contain PIB 21 elther as a single item or within a scale. With further study, the concerns surrounding PIB 21 may be resolved. These four functions could then be considered for implementation.

While function 9 does not contain the medication item, it does contain other items whose measurement qualities have been questioned. Two of the four PIB items in function 9 have score distributions which appear bimodal. One PIB item has a score distribution which is severely skewed. Until these items can be adequately studied, this researcher 
does not recommend that they be used in a function in which their individual influence is so strong.

The five remaining functions, $1,2,3,4$, and 10 , do not contain the medication item but do contain other skewed or bimodal items. Most of these items are, however, contained within a scale where their individual influence is diminished.

of these five remaining functions, two are clearly more comprehensive than the others. Both functions 3 and 4 contain the Mental-Social scale and the Physical scale which in turn is composed of the ADL and IADL scales. Functions 1 and 2 do not contain the IADL or Social scale and function 10 does not contain the Mental or Social scale.

Because of the increased sensitivity which is possible with scales representing multiple dimensions and because of the statistical advantages associated with scales, this researcher recommends the use of either function 3 or 4 for the nursing home placement screening instrument. In addition to having superior measurement qualities, these two functions have practical advantages. While discriminant function scores are somewhat cumbersome to compute with these functions, the scores are also difficult to alter inappropriately. The relationship between the item score and thresholds for nursing home placement is not obvious. Functions 3 and 4 also have the advantage of providing the state with a broad data base for use with other policy decisions. Function 3 contains 21 of the 25 original PIB 1tems; function 4 contains 20 . The two functions are identical except for the presence of PIB 10 (Nutritional Habits) in function 3. 
The selection of one of these functions over the other might be guided by an evaluation of the number of elderly who would need followup assessment at various thresholds. As the distance between the upper and lower threshold is widened, the percent of elderly whose placement is accurately predicted by the screening instrument is increased. Unfortunately, a widened distance also catches an increased number of elderly clients who then require the more costly follow-up assessment. An examination of Table $x x$ indicates that the percent of elderly clients who would require follow-up assessment at several levels of predictive accuracy is consistently lower with function 3 than with function 4. Since function 3's advantage is quite small at some levels, the two functions may be comparable at the particular thresholds selected by the state.

In summary, either function 3 or 4 appear to be well suited for use as a screening instrument for nursing home placement dectsions. While function 3 appears to have slightly higher predictive accuracy and generates the need for fewer follow-up assessments at specific threshold levels, those differences are very small and may be of little practical Importance. This researcher, therefore, recommends that both functions be considered by the state and that the final selection be determined aiter a pilot study is conducted.

The pilot study is advisable because it provides an opportunity to refine the instrument instructions and the type of inservice and rater follow-up which is necessary. It would be falrly easy to compute two 
TABLE XX

PERCENT OF ELDERLY CLIENTS NEEDING POST-PIB SCREENING

ASSESSMENT BY TYPE OF PLACEMENT, BY LEVEL OF

PLACEMENT ACCURACY, AND BY FUNCTION

\begin{tabular}{|c|c|c|c|}
\hline $\begin{array}{l}\text { Type of } \\
\text { Placement }\end{array}$ & $\begin{array}{c}\text { Leve } \\
95 \text { percent place- } \\
\text { ment accuracy for } \\
\text { both community } \\
\text { and nursing } \\
\text { homes }\end{array}$ & $\begin{array}{l}1 \text { of Placement Accl } \\
90 \text { percent place- } \\
\text { ment accuracy for } \\
\text { both community } \\
\text { and nursing } \\
\text { homes }\end{array}$ & $\begin{array}{l}\text { uracy } \\
90 \text { percent place- } \\
\text { ment for com- } \\
\text { munity; } 95 \% \text { place- } \\
\text { ment accuracy for } \\
\text { nursing homes }\end{array}$ \\
\hline \multicolumn{4}{|c|}{ Function 3} \\
\hline $\begin{array}{l}\text { Community } \\
\text { Nursing Home }\end{array}$ & $\begin{array}{l}17 \\
26\end{array}$ & $\begin{array}{l}3 \\
4\end{array}$ & $\begin{array}{r}8 \\
21\end{array}$ \\
\hline \multicolumn{4}{|c|}{ Function 4} \\
\hline $\begin{array}{l}\text { Community } \\
\text { Nursing Home }\end{array}$ & $\begin{array}{l}20 \\
31\end{array}$ & $\begin{array}{l}5 \\
7\end{array}$ & $\begin{array}{l}10 \\
25\end{array}$ \\
\hline
\end{tabular}

NOTE: Percentages derived from community and nursing home crossvalidation groups; $N=420$ and 488 , respectively.

different sets of function scores at that time. A comparison of client characteristics for those misclassified by each function might provide data which would be useful in favoring one function over another.

Regardless of which function is selected, the number of elderly who would require follow-up assessment is substantially smaller than the number currently being assessed by the PAS teams. Of the 1772 elderly community and nursing home clients In this study, 7 percent of the community clients and 62 percent of the nursing home clients (36 percent of the combined clients) had been evaluated by a PAS team. If the PAS program becomes completely operational the percent of nursing home clients who will receive assessment will increase to 100 . In contrast, the 
discriminant function requiring the largest number of assessments at the 95 percent accuracy level would identify 20 percent of the commity clients and 31 percent of the nursing home clients $(24$ percent of the combined clients) as needing assessment (see Table XX). In practice, the percent of community clients needing follow-up assessment can be expected to be much lower. Many community clients are as functionally disabled as nursing home clients but do not seek nursing home placement. At an estimated cost of $\$ 140$ per PAS assessment (Hinkle 1982), the reduction in the number of assessments which must be conducted creates a potential for substantial savings.

Natural Support and Nursing Home Placement. The findings of this study indicate that the availability of a natural support system plays a key role in allowing elderly clients to stay in the community. While PIB 17 (Natural Support) is not the most predictive 1tem or scale in the screening instrument, it seems to tip the balance for elderly clients who appear functionally similar. This finding suggests that nursing home placement can be delayed or avoided through the development of programs which bolster existing natural support systems or create support systems through community services.

In light of the findings regarding the Importance of Social Support systems, this researcher recommends that the state give a higher financial priority to programs which try to develop or provide social support for the elderly. In addition this researcher recommends that the state examine how its existing policies encourage or discourage networking and the strengthening of social support systems for the elderly. A recent study conducted by the Regional Research Institute for Human Services at 
Portland State University (1983) reported that many of the state's trends in planning for the delivery of in-home care are in the opposite direction of those recommended by the Institute for improving the elderly's informal networks. While these trends undoubtedly reflect the state's effort to economize, such trends may prove costly in the long run. Elderly clients who cannot function in the community due to a lack of natural (social) support will end up being placed in nursing homes at a substantially higher cost to the state.

\section{Suggestion for Future Research}

This researcher recommends that a pilot study be conducted prior to the implementation of PIB as a screening instrument. This researcher also recommends a further exploration of the measurement qualities of the PIB ftems having bimodal or skewed score distributions.

Pilot Study. This researcher recommends that a pilot study be conducted with community and nursing home residents using functions 3 and 4. The areas of particular interest are: (1) the extent to which the functions identify the same clients as needing nursing home or community placement, (2) the characteristics of the clients for whom the recommended placement is not the same for both functions, and (3) the characteristics of the clients who are misclassifled by both functions. These findings would be useful for making a cholce between the functions for evaluating the clarity of the Instructions which accompany the function. More importantly, however, the findings would provide additional insight into the sensitivity of the functions and the type of factors which Influence placement. It may be, for example, that there are clusters of 
elderly with similar characteristics who need nursing home placement based on theoretical standards but are not being identified by the functions. Likewise, there may be clusters of elderly nursing home residents with similar characteristics who do not appear to need nursing home placement based on either theoretical or empirical standards. These types of findings could be used to further refine the screening instruments or to hypothesize relationships between other variables and nursing home placement.

Measurement Concerns. This researcher recommends that the PIB items with bimodal or skewed score distributions receive further evaluation for content and construct validity, and for inter-rater reliability.

As discussed in relation to the findings of this study, items which appear to have bimodal score distributions need to be examined for sensitfvity in the middle ranges. The Social scale also needs to be evaluated for possible inclusion of social measures such as subjective well-being and environmental fit (Kane and Kane 1981). It is possible that social functioning plays a greater role in nursing home placement decisions than is indicated by elderly scores on the Social scale in this study.

To provide a better understanding of the nature of the predictive items and scales, construct validity should be addressed in greater depth than was possible in this study. Items with bimodal score distributions, for example, may be measuring more than one dimension. PIB 21 (Medication Management) appears to be measuring the client's physical ability to manage medications, his cognitive ability to manage 
medications, and the nature of the medication itself. Nursing home clients, for example, are not allowed to manage some medications such as Injections and transfusions because of the legal implications. Items with skewed score distributions also need to be examined. While items such as PIB 4 (Trave1) may be measuring the actual functional status of the client, it is possible that they measure the opportunity of the client to perform the task or some other factor.

As discussed in previous chapters, inter-rater reliabllity could only be addressed indirectly in this study and warrants further examination. Highly predictive items which have skewed or bimodal score distributions should be evaluated. Inter-rater rellability across geographic locations and between PAS teams and caseworkers should also be examined.

It is quite possible that the items in question are being used appropriately and are accurately representing the functional status of the clients. If reliability or validity is found to be a problem, steps can be taken to improve the items. Depending upon the source of the problem, PIB items or descriptor statements can be revised or additional rater training and supervision can be provided.

\section{Post Script}

This researcher acknowledges that the criterion employed in this study (actual placement) is not understood as well as might be desfred, and that the basis for placement decisions may need to be altered in the future. This researcher contends, however, that the employment of discriminant functions 3 or 4 (coupled with follow-up assessment) would 
provide an equitable and more economic screening process than the PAS program which is now being implemented. A discriminant function used as a screening instrument has the added advantage of being easily modified when change in practice does occur. Thresholds can be raised or lowered, or the equation itself can be wodified to correspond to the desired practice. 
BIBLIOGRAPHY

BOOKS

Anastasi, Anne. Psychological Testing. London: The MacMillan Company, 1970.

Brown, Frederick. Principles of Educational and Psychological Testing, 2nd ed. New York: Holt, Rinehart \& Winston, 1976.

Colorado Foundation for Medical Care. Long Term Care Department. Guidelines for Functional Score Assessments. Denver: Colorado Foundation for Medical Care, March 8, 1982.

Colorado Foundation for Medical Care. Long Term Care Department. LTC-101. PSRO Certification and Patient Transfer Form. Denver: Colorado Foundation for Medical Care, January 1980.

Cronbach, Lee Joseph. Essentials of Psychological Testing, 3rd ed. New York: Harper \& Row, 1970.

Delury, George, ed. The World Almanac and Book of Facts. New York: Newspaper Enterprise Association, 1977.

Dingman, Patricia. "Assessing Cognitive Impairment and Its Impact on Nursing Home Placement of Frail Elderly." M.N. dissertation, Oregon Health Sciences University, 1983.

Garnett, Janice. Algorithm Description of Level of Care Survey. Centra Care St. John Inc. Saint John, New Brunswick, July 30, 1980.

Health Care of the Aged Study (Part I of Two Parts). A Study of the Physical and Mental Needs of Older People in Monroe County, New York. Published by University of Rochester, Health Council of Monroe County, Inc., and the Council of Soclal Agencies of Rochester and Monroe County, Inc., 1968..

Kane, Rosalie A. \& Robert L. Kane. Assessing the Elderly: A Practical Guide to Measurement. Lexington, Massachusetts: Lexington Books, 1981 .

Kerlinger, Fred N. Foundations of Behavioral Research, 2nd ed. New York: Holt, Rinehart and Winston, Inc., 1973. 
Klecka, William R. "Discriminant Analysis." In SPSS: Statistical Package for the Social Sciences, 2nd ed. Norman H. Nie, ed. New York: McGraw-H111 Book Co., 1975.

Ladd, Richard C. Testimony for Oregon Ways and Means Committee. Manager of Special Projects, State Department of Human Resources, July 27, 1981. Cited by Michael Saslow, Opportunities for the Portland/Multnomah Area Agency on Aging under Senate Bill 955 (Senior Service Division): Background and Recommendations. Philomath, Oregon, August 1981.

Meeh1, Paul E. Clinical vs Statistical Prediction: A Theoretical Analysis and a Review of Evidence. Minnesota: University of Minnesota Press, 1954.

Nunnally, Jum. Psychometric Theory. New York: McGraw Hill Book Company, 1967.

Nunnally, Jum. Psychometric Theory. 2nd ed. New York: McGraw Hill Book Company, 1978.

Oregon Medical Assoclation. Senfor Health Improvement Project. FIGWaiver Project Manual No. 2: The Placement Information Base (PIB), by Michael Saslow and Jan Yamodis. Portland, Oregon: Oregon Medical Association, 1980.

Pfeiffer, Eric. "Multidimensional Functional Assessment: Why and How" in Multidimensional Functional Assessment: The OARS Methodology, A manua1. North Carolina: Duke University, Eric Pfeiffer, ed. 1975, pp. 1-21..

Pfeiffer, Eric \& Connie Service. "Survey of Community Resident Elderly" in Multidimensional Function Assessment: The OARS Methodology, A Manual. North Carolina: Duke University. Eric Pfeiffer, ed. 1975, pp. 23-37.

Regional Research Institute for Human Services. Supporting Care Givers of the Elderly: Final Report. Oregon: Portland State Unfversity, June $30,1983$.

Riley, Matilda W. Aging and Society. Vo1. I: An Inventory of Research Findings. New York: Russell Sage, 1968.

Saslow, Michael G. Opportunities for the Portland/Multnomah Area Agency on Aging under Senate B111 955 (Senior Services Division): Background and Recommendations. By the author, Route 1, Box 414, Philomath, Oregon, August, 1981 .

Somers, Anne R. \& Herman M. Somers. Health and Health Care: Policies in Perspective. Maryland: Aspen Systems Corporation, 1977. 
Stewart, Barbara, ed. Methods of Assessing Well-Being and Change in the Retirement History Study, 2 vols. Portland, Oregon: Institute on Aging. Portland State University, November 1982.

Thorndike, Robert. Personnel Selection Test and Measurement Techniques. New York: John Wiley \& Sons, 1961.

Thorndtke, Robert \& E. Hagen. Measurement and Evaluation in Psychology and Education, 3rd ed. New York: Wiley, 1969.

World Health Organization. The First Ten Years of the World Health Organization. Geneva: WHO, 1958:459.

\section{ARTICLES}

Applebaum, Robert, Frederick W. Seidl, Carol D. Austin. "The Wisconsin Community Care Organization: Preliminary Findings from the Milwaukee Experiment." The Gerontologist, Vol. 20, No. 3, June 1980 , pp. 350-355.

Barney, Jane L. "The Perogative of Choice in Long Term Care." The Gerontologist, Vo1. 17, No. 4, August 1977, pp. 309-314.

Bergner, Marilyn, Ruth Bobbitt, with Willtam Carter \& Betty Gilson. "The Sickness Impact Profile: Development and Final Revision of a Health Status Mezsure." Medical Care, Vo1. 19, No. 9, August 1981, pp. 787-805.

Blenkner, Margaret. "Impact on Soctal Work." The Gerontologist, Vol. 7, No. 1, March 1967, pp. 28-30.

Brook, Robert H., John E. Ware, Davies, Allyson Davies-Avery, et al. "Overview of Health Status Measures Fielded in Rand's Health Insurance Study." Medical Care, July Suppl, Vol. 17, 1979, pp. $1-54$.

Cape, Ronald D., Christopher Shorrock, \& Robert Tree. "Square Pegs in Round Holes: A Study of Institutions in London, Ont. Canadian Medical Assoc. Journal, Vol. 117, No. 11, December 1977, pp. 1284-87.

Carnes, Charlotte \& Ann Cook. "Nursing Home Preadmission Screening in Virginia." Journal Medicaid Management, Vol. 1, No. 4, Winter 1977, pp. 1-8.

Fillenbaum, Gerda, Michael A. Smyer. "The Development, Validity, and Reliability of the OARS Multidimensional Functional Assessment Questionnaire." Journal of Gerontology, Vol. 36, No. 4, July 1981, pp. 428-434. 
Foley, William J. \& Donald P. Sneider. "A Comparison of the Level of Care Predictions of Six Long Term Care Patient Assessment Systems." American Journal of Public Health, Vol. 70, No. 11,

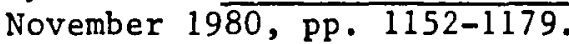

Furman, Walter M. \& Donald A. Lund. "The Assessment of Patient Needs: Description of the Level of Care Survey." Journal of Psychiatric Treatment and Evaluation, Vol. 1, No. 2, February 1979, pp. 29-37.

Goga, John A. \& William 0. Hambacher. "Psychslogical and Behavioral Assessment of Geriatric Patients: A Review." Journal of The American Geriatrics Society, Vo1. 25, No. 5, May 1977, pp. 232-237.

Grauer, Harry \& Frances Birnbom. "A Geriatric Functional Rating Scale to Determine the Need for Institutional Care." Journal of The American Geriatrics Society, Vol. 23, No. 10, October 1975, pp. $472-476$.

Greene, Vernon L. \& Monahan, Deborah. "Inconsistency in Level of Care Assignment Decisions in Skilled Nursing Facilities." American Journal of Public Health, Vol. 71, No. 9, September 1981, pp. 1036-39.

Guion, R. M. "Content Validity in Moderation." Personnel Psychology. Vo1. 31, No. 2, Summer 1978, 205-218. Cited by Samuel Messick, "Test Validity and the Ethics of Assessment. American Psychologist, Vo1. 35, No. 11, December 1980, pp. 1012-1027.

Gulliksen, Harold. "Intrinsic Validity." American Psychologist, Vol. 5, No. 10, October 1950, cited by Samuel Messick, "Test Validity and the Ethics of Assessment," American Psychologist, Vol. 35, No. 11, November 1980, pp. 1012-1027.

Gurel, Lee, Margaret Linn, Bernard Linn. "Physical and Mental Impairment of Function Evaluation in the Aged: The Pamie Scale." Journal of Gerontology, Vol. 27, No. 1, January 1972, pp. 83-90.

Gurland, Barry, Judith Kuriansky, Lawrence Sharpe, Robert Simon, Pamela Stillier \& Peter Birkett. "The Comprehensive Assessment and Referral Evaluation (Care): Rationale, Development and Reliability." International Journal of Aging and Human Development, Vo1. 8, No. 1, August 1977-78, pp. 9-42.

Guttman, Louis A. "A Basis for Scaling Qualitative Data." American Sociology Review, Vol. 9, No. 1, February 1944, pp. 139-150.

Haddad, Laurence B. "Utilizing Rating Instruments for Evaluating Behavioral Characteristics Differentiating Elderly Patients Selected for Skilled Nursing, Intermediate and Psychlatric Care." Journal of Gerontology, Vol. 36, No. 5, September 1981, pp. 583-585. 
Holt, Robert. "Yet Another Look at Clinical and Statistical Prediction: Or is Clinical Psychology Worthwhile?" American Psychologist, Vol. 25, March 1970, pp. 337-349.

James, Lawrence R. "Criterion Models and Construct Validity for Criterla." Psychological Bulletin, Vol. 80, No. I, July 1973, pp. 75-83. Cited by Sammual Messick, "Test Validity and the Ethics of Assessment." American Psychologist, Vol. 35, No. 11, November 1980, pp. 1012-1027.

Kahn, R. L., A. I. Goldfarb, M. Pollack \& I. E. Gerber. "The Relationship of Mental and Physical Status in Institutionalized Aged Persons." American Journal of Psychiatry, Vol. 117, August 1960, pp. 120-124.

Kamerman, Shelia B. "Community Services for the Aged: The View from Eight Countires." The Gerontologist, Vol. 16, No. 6, December 1976, pp. 529-537.

Kane, Robert L., Lawrence Z. Rubenstein, Robert H. Brook, Edyth Schoenrich, Bert Harrell, John Van Ryzin, Patricia Masthay. "Utilization Review in Nursing Homes: Making Implicit Level-of-Care Judgments Explicit. Medical Care, Vol. 19, No. 1, January 1981 , pp. 3-13.

Katz, Sidney, Thomas D. Downs, Helen R. Cash, Robert Gorotz. "Progress in Development of the Index of ADC." The Gerontologist, Vol. 10, No. I (Part I), Spring 1970, pp. 20-30.

Kraus, Arthur S., Robert A. Spasoff, Ellen J. Beattie, David E. W. Holden, J. Stuart Lawson, Martin Rodenburg, Gwen M. Woodcock. "Elderly Applicants to Long Term Care Institutions. I. Their Characteristics, Health Problems, and State of Mind." Journal of the American Geriatrics Society, Vo1. 24, No. 3, March 1976, pp. 117-125.

Lawton, M. Powell, Miriam Moss, Mark Fulcomer, Morton Kleben. "A Research and Service Oriented Multilevel Assessment Instrument." Journal of Gerontology, Vol. 37, No. 1, January 1982, pp. 91-99.

Lawton, M. Powell \& Elaine M. Brody. "Assessment of Older People: Self Maintaining and Instrumental Activities of Daily Living." The Gerontologist, Vol. 9, No. 3, Autumn 1969, Part I of 2 Parts, pp. 179-186.

Meer, Bernard, \& Janet A. Baker. "The Stockton Geriatric Rating Scale." Journal of Gerontology, Vol. 3, No. 21, July 1966, pp. 392-403. 
Messick, Samuel. "The Standard Problem: Meaning and Value in Measurement and Evaluation." American Psychologist, Vol. 30, No. 10, October 1975, pp. 955-966. Cited by Messick, Samuel in "Test Validity and the Ethics of Assessment." American Psychologist, Vol. 35, No. 11, November 1980, pp. 1012-27.

Messick, Samuel. "Test Validity and the Ethics of Assessment." American Psychologist, Vol. 35, No. 11, November 1980, pp. 1012-1027.

Miller, Eva Ruth \& Joanne Frazier Parachek. "Validation and Standardization of a Goal 0:iented, Quick Screening Geriatric Scale." Journal of tise simerican Geriatrics Society, Vol. 22, No. 6, June 1974, pp. 278-283.

Miller, Michael B. "Physical, Emotional, and Social Rehabilitation in Nursing Home Population." Journal of the American Geriatrics Soclety, Vol. 13, No. 2, February 1965, pp. 176-185.

Palmore, Erdman. "Varlables Related to Needs Among the Aged Poor." Journal of Gerontology, Vo1. 26, No. 4, October 1971, pp. 524-31.

Palmore, Erdman. "Total Chance of Institutionalization Among the Ages." The Gerontologist, VoI. 16, No. 6, December 1976, pp. 504-507.

Parkerson, George R. Stephen Gehlbach, Edward Wagner, Sherman James, Nancy Clapp, Lawrence Muhlbaier. "The Duke-UHC Health Profile: An Adult Health Status Instrument for Primary Care." Medical Care, August 81, Vo1. 19, No. 8, pp. 806-823.

Parkerson, George R., Stephen Gehlbach, Edward Wagner, Sherman James, Nancy Clapp, Lawrence Muhlbaier. "The Duke-UNC Health Profile: An Adult Health Status Instrument for Primary Care." Medical Care, Vol. 19, No. 8, August 1981, pp. 806-823.

Pattee, James J. "The Family Physictan and Nursing Home Care." American Physician, Vol. 5, No. 11, November 1980, pp. 137-141.

Pfeiffer, Eric. "A Short Portable Mental Status Questionnalre for the Assessment of Organic Brain Deficit in Elderly Patients." Journal of the American Geriatrics Society, Vol. 23, No. 10, October 1975, pp. 433-441.

Pfeiffer, Eric, Thomas Johnson \& R. C. Chiofolo. "Functional Assessment of Elderly Subjects in Four Service Settings." Journal of The American Geriatrics Society, Vol. 29, No. 10, October 1981, pp. 433-437.

Sawyer, Jack. "Measurement and Prediction, Clinical and Statistical." Psychological Bulletin, Vol. 66, No. 3, September 1966, pp. 178-200. 
Shanas, Ethel. "Health Status of Older People. American Journal of Public Health, Vol. 64, No. 3, March 1974, pp. 261-264.

Sherwood, Sylvia \& Feldman, Claire. "The Use of Easily Obtained Precoded Data in Screening Applicants to a Long Term Care Facility." The Gerontologist, Vol. 10, No. 3, Part I of 2 Parts, Autumn 1970, pp. 182-188.

Sherwood, Sylvia, John Morris, Ester Barnhart. "Developing a System of Assigning Individuals into an Appropriate Residential Setting." Journal of Gerontology, Vol. 30, No. 3, May 1975, pp. 331-342.

Smith, James M., Bertha Bright \& John McCloskey. "Factor Analytic Composition of the Geriatric Rating Scale (GRS)." Journal of Gerontology, Vol. 32, No. 1, January 1977, pp. 58-62.

Smyer, Michael A., Brian F. Hofland, Edward A. Jones. "Validity Study of the Short Portable Mental Status Questionnaire for the Elderly." Journal of the Amerlcan Geriatrics Society, Vol. 27, No. 6, June 1979, pp. 263-269.

Taber, Merlin A., Steve Anderson, C. Jean Rogers. "Implementing Community Care in Illinols: Issues of Cost and Targeting in a Statewide Program." The Gerontologist, Vo1. 20, No. 3, June 1980, pp. 380-388.

Taylor, Howard G., Lawrence M. Bloom. "Cross Validation and Methodological Extension of the Stockton Geriatric Rating Scale." Journal of Gerontology, Vol. 29, No. 2, March 1974, pp. 190-193.

Vicente, Leticia, James A. Wiley \& R. Allen Carrington. "The Risk of Institutionalization Before Death." The Gerontologist, Vol. 19, No. 4, August 1979, pp. 361-367.

Whanger, Alan \& Patti Lewis. "Survey of Institutionalized Elderly," in Multidimensional Function Assessment: The OARS Methodology, Eric Pfeiffer, ed. North Carolina: Duke University, 1975, pp. 71-74.

Yesavage, Jerome A., Michael A. Dey, \& Paul Werner. "Development of a Geriatric Behavioral Self Assessment Scale." Journal of the American Geriatric Society, Vol. 24, No. 6, June 1981, pp. 285-288.

Zimmer, James. "Characteristics of Patlents and Care Provided in Health Related and Skilled Nursing Facilities." Medical Care, Vol. 13, No. 12, December 1975, pp. 992-1010. 
GOVERNMENT PUBLICATIONS

Georgla. Department of Human Resources. Cost Effective Alternatives to Nursing Home Institutionalization. Atlanta: October 19, 1977.

Illino1s. Department of Aging. Community Care Program. Determination of Need. Form no. IL402-0195. Springfield. September 1981 .

Illinois. Department on Aging. Community Care Program. Instructions for Completion of the Determination of Need Scale (402-0195). Springfield: n.d.

Kansas. Division of Medical Programs. Department of Social and Rehabilitation Services in Conjunction with the University of Kansas, Long-Term Care Gerontology Center. Assessment Instrument: For Use with Persons Not in Adult Care Homes. Topeka: July 1982.

Massachusetts. Department of Public Health. Office of Health Planning and Statistics. The Massachusetts Department of Public Health Long-Term Care Patient Surveys: I. Survey Methodology and Patient Characteristics, by Leonard W. Gruenberg. Boston: November 1975a.

Massachusetts. Department of Public Health. Office of Health Planning and Statistics. The Massachusetts Department of Public Health Long-Term Care Patient Surveys: II. Levels of Care Needed by Patients in Long-Term Care Facilities, by Leonard W. Gruenberg. Boston: November 1975b.

Massachusetts. Department of Public Health. Office of Health Planning and Statistics. The Massachusetts Department of Public Health Long-Term Care Patient Surveys: III. Summary of Results and Implications. Boston: November 1975c.

New York. Department of Comprehensive Health Planning of Western New York. Estimated Need for Nursing Home and Health-Related Facilities and Services in the Six Counties of Western New York. Albany: September 1970 .

New York. Office of Health Systems Management. Bureau of Research and Evaluation. Development of Numerical Standards for Patient Placement in New York State Long-Term Care Facilities, by Mart in Orr. Albany: April 18, 1978.

Oregon. Department of Human Resources. FIG/Waiver Continuum of Care Project for the Elderly: A Long-Term Care Demonstration Project. Salem: June 1979 . 
Oregon. Department of Human Resources. Oregon Systems Development Project for Long-Term Care: A Study of Long-Term Care in Oregon with Emphasis on the Elderly. Salem: 1981a.

Oregon. Department of Human Resources. Long-Term Care Unit, HSS. Comparative Time Study, Multnomah and Marion Regions PAS. Inter-office Memo from Richard Schneider. Salem: July 28, $1981 \mathrm{~b}$.

Oregon. Department of Human Resources. Senfor Services Division. PreAdmission Screening Statistical Report. January-December 1981. Salem: 1982a.

Oregon. Department of Human Resources. Adult and Family Services Division. Pre-Admission Screening Statistical Report, May 1982. Salem: $1982 \mathrm{~b}$.

Oregon. Office of Elderly Affairs. Common Service Definitions and Units of Comprehensive Planning of Services for Seniors. Final Project Report. DHEW Order No. RX-1685-78. Salem: January 15, 1979 .

Oregon. State Health Planning and Development Agency. State of Oregon State Health Plan 1981, by Ralph Crawford and Richard H. Grant. Salem: 1981 .

U.S. Bureau of the Census. Some Demographic Aspects of Aging in the United States. Current Population Reports, Special Studies, Series P-23, no. 43. Washington: February, 1973.

U.S. Bureau of the Census. Demographic Aspects of Aging and the Older Population in the United States, by Jacob S. Siegel. Current Population Reports, Special Studies, Series P-23, no. 59 (rev). Washington: May 1976.

U.S. Bureau of the Census. 1979 Survey of Institutionalized Persons Receiving Long-Term Care. Current Population Reports, Special Studles, Serles P-23, no. 69. Washington: August, 1978 .

U.S. Bureau of the Census. Prospective Trends in the Size and Structure of the Elderly Population, Impact of Mortality Trends, and Some Implications, by Jacob S. Siegel. Current Population Reports, Special Studies, Series P-23, no. 78. Washington: January 1979a.

U.S. Bureau of the Census. Social and Economic Characteristics of the older Population: 1978. Current Population Reports, Special Studies, Series P-23, no. 85. Washington: August, $1979 \mathrm{~b}$.

U.S. Bureau of the Census. Population Profile of the United States: 1980. Current Population Reports, Special Studies, Series P-20, no. 363. Washington: June, 1981a. 
U.S. Bureau of the Census. 1980 Census of Population Supplementary Reports: Age, Sex, Race and Spanish Origin of the Population by Region, Division, States. Washington: $1981 \mathrm{~b}$.

U.S. Dept. of Health, Education, and Welfare. Patient Classification for Long-Term Care: Users Manual, by Ellen Jones, Barbara McNitt, and Eleanor M. McKnight. Publication no. HRA 75-3107. Washington: 1974.

U.S. General Accounting Office. Home Health--The Need for a National Policy to Better Provide for the Elderly. Washington: 1977.

U.S. General Accounting 0ffice. Profiles of Older People. Publication no. 0-352-510: OL3. Washington: 1981.

U.S. National Center for Health Statistics. Chronic Conditions and Limitations of Activity and Mobility: United States, July 1965June 1967. Vital and Health Statistics, Series 10, no. 61. PHS Publication no. 1000. Washington: January, 1971.

U.S. National Center for Health Statistics. Characteristics of Residents of Nursing and Personal Care Homes: United States, June to August, 1969. Vital and Health Statistics, Series 12, no. 19. DHEW Publication no. (HSM) 73-01704. Washington: February, 1973a.

U.S. National Center for Health Statistics. Limitation of Activity Due to Chronic Conditions, United States, 1969 and 1970 . Vital and Health Statistics, Series 10, no. 80. DHEW Publication no. (HSM) 73-1516. Washington: April, 1973b.

U.S. National Center for Health Statistics. Chronic Conditions and Impairments of Nursing Home Residents: United States, 1969. Vital and Health Statistics, Series 12, no. 22. DHEW Publication no. (HRA) 74-1707. Washington: December 1973c.

U.S. National Center for Health Statistics. Measures of Chronic IIlness Among Residents of Nursing and Personal Care Homes, United States, June to August 1969. Vital and Health Statistics, Series 12, no. 24. DHEW Publication no. (HRA) 74-1709. Washington: 1974.

Vermont. Department of Mental Health. Agency of Human Services. Request to Provide Home and Community-Based Services Under Section 1715 (C) of the Social Security Act. Appendix D. Waterbury: January 1982 .

Virginia. Office of Medical Assistance. Waiver Request. Richmond: n.d. 
4 U.S. Code (1974), pp. 7842-8001. "National Health Planning and Resources Development Act of 1974."

95 U.S. Code (1981). sec. 2176. "The Omnibus Budget Reconciliation Act of 1981."

Oregon Rev1sed Statutes (1973), chapter 442.400. "Health Planning."

\section{INTERVIEWS}

Dyer, Melissa. State of Nevada Department of Human Resources, Medicaid Division. Carson City, Nevada, August 14, 1982.

Essner, Robert. Sandoz Pharmaceuticals. Hanover, New Jersey, August 17, 1982.

Fecht, Arthur. South Dakota Department of Social Services. South Dakota, Division of Medical Services, Pierre, South Dakota, August 13, 1982.

Feltman, Nancy. Minnesota State Department of Public Welfare. Office of Medicald Pollcy. St. Paul, Minnesota, August 12, 1982.

Furman, William. New York Department of Mental Hygiene, Bureau of Program EValuation. Albany, New York, April 23, 1982.

Goldman, Allen. Georgia State Health Planning Department, Iong Term Care Task Force. Atlanta, Georgla, July 29, 1982.

Gumb, Jack. The Department of Soclal and Rehabilitation Services, Division of Medical Programs. Topeka, Kansas, August 12, 1982.

Hinkle, Charles. Department of Human Resources, Senfor Services Division, Salem, Oregon, September 22, 1982.

Howe, Chris. Division of Provider Service Coverage, Policy and Program Financing, Health Care Financing Administration, Washington, D.C., August 11, 1982 .

Landrum, Marg. Florida State Department of Health and Rehabilitative Services. Medicare Office, Tallahassee, Florida, August 12, 1982.

Melzer, Ronald. Department of Mental Health, Agency of Human Services. Waterbury, Vermont, August 19, 1982. 
Mitche11, Andrea. Colorado Foundation for Medical Care, Criterion Department. Denver, Colorado, November 11, 1982.

Oliver, Mary. Iowa State Department of Social Services and State Department of Health. Division of Health Planning, De Moines, Iowa, August 12, 1982.

Orr, Martin. New York State Office of Health Systems Management, Bureau of Research and Evaluation. Albany, New York, April 23, 1982.

Reed, Daisy. Oregon Department of Human Resources, Senior Services Division, Salem, Oregon, May 6, 1982.

Saslow, Michael G. State Health Planning and Development Agency, Health Planning Section. Salem, Oregon, June 11, 1982.

Sims, John. Office of Family Security and Long Term Care. Department of Health and Human Resources. Baton Rouge, Louisiana, December 2, 1982 .

Triestman, Louis. Social and Rehabilitative Service, Division of Medical Assistance. Providence, Rhode Island, August 17, 1982.

Uda, Lowell. State of Montana Bureau of Economic Assistance. Division of Medicaid Services. Helena, Montana, August 12, 1982.

Welch, Pam. Illinois Department of Aging, Division of Long Term Care, Springfield, Illinois, June 11, 1982.

UNPUBLISHED LETTER

Mitche11, Andrea. Program Planning and Criteria Coordinator, Colorado Foundation for Medical Care. Denver, Colorado. Letter to author. November $12,1982 b$. 
APPENDIX A

INTERVIEW SCHEDULE AND INSTRUMENTS CITED

IN THE LITERATURE 


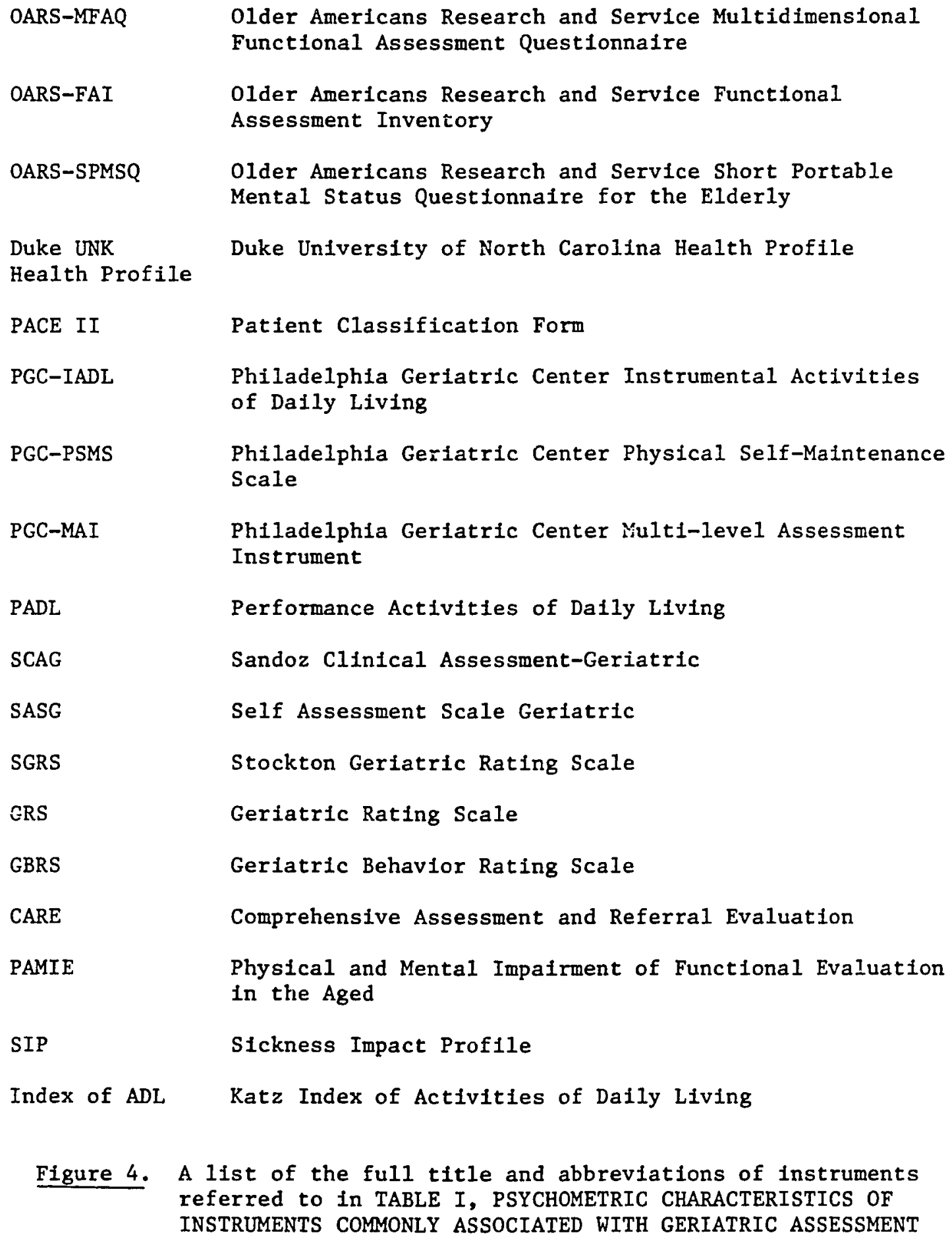




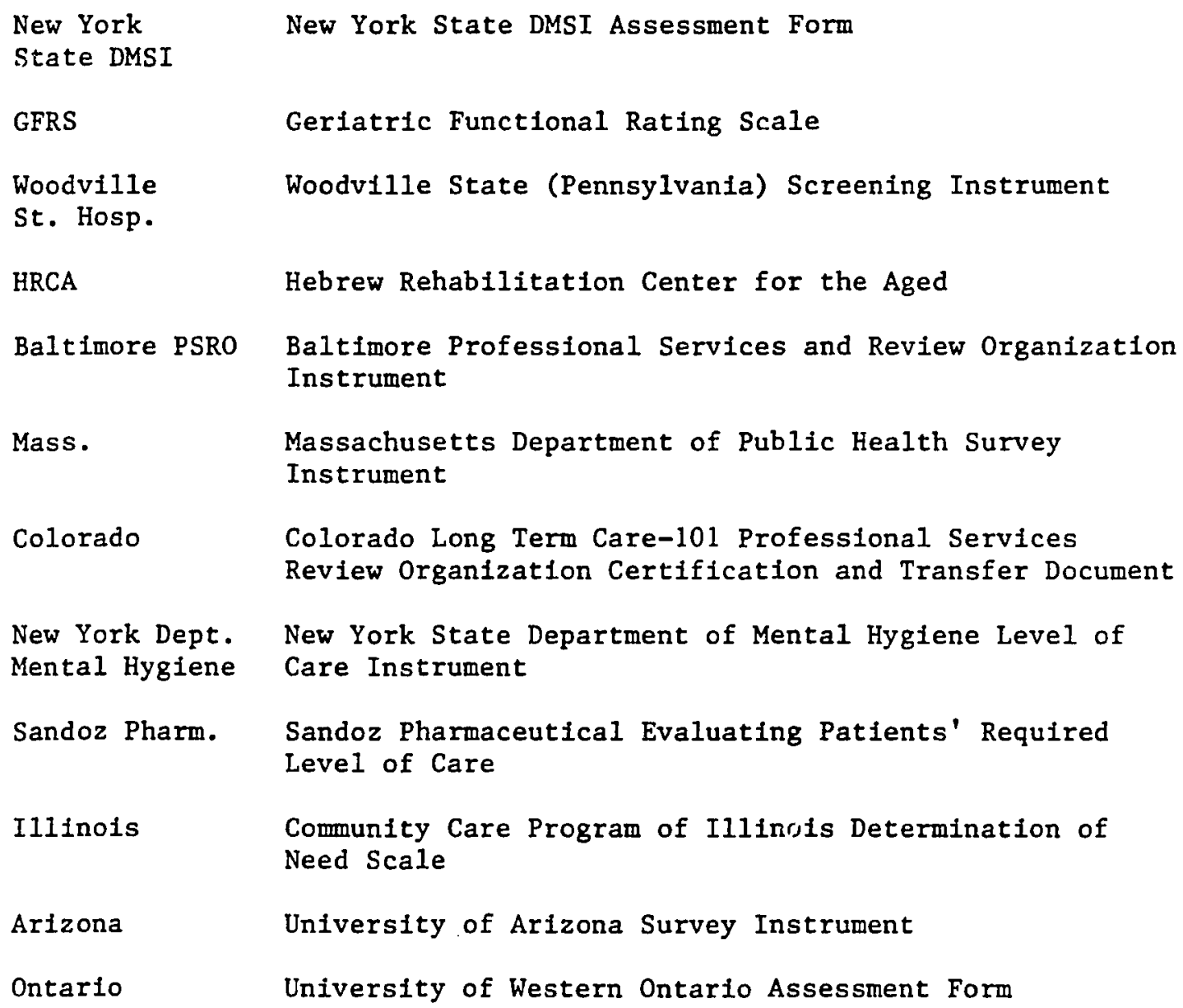

Figure 5. A list of the abbreviations and full titles of instruments referred to in TABLE II, PSYCHOMETRIC CHARACTERISTICS OF INSTRUMENTS DEVELOPED SPECIFICALLY FOR LEVEL OF CARE DECISIONS 
1. What is the process used by your state to determine who will be placed in a nursing home?

2. Could you describe the instruments which are used in the screening process? (content, type of questions, methods of scoring)

3. How is the data obtained? (method, source)

4. Who obtains the data? (educational background, training, reliability)

5. What is the relationship between the data and the placement decision? (supportive, direct)

6. If direct, how were placement decisions established and validated?

Figure 6. Open-ended interview schedule used to obtain information on pre-admission screening instruments used by states with a federal Medicaid walver. 
APPENDIX B

INSTRUMENTS 


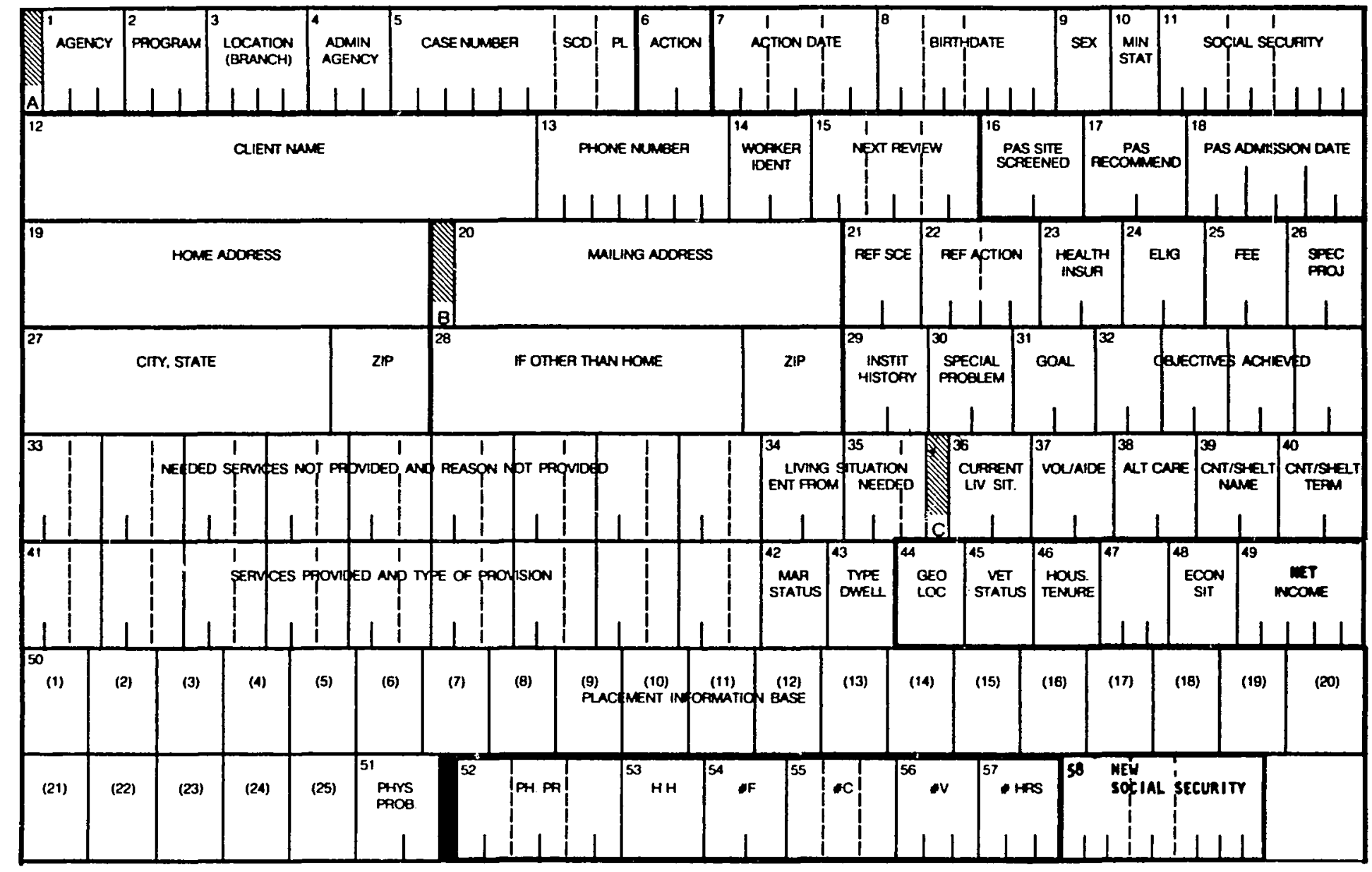

Figure 7. That portion of the DHR-280 Service Activity Report which was used to record secondary data employed in this study. 


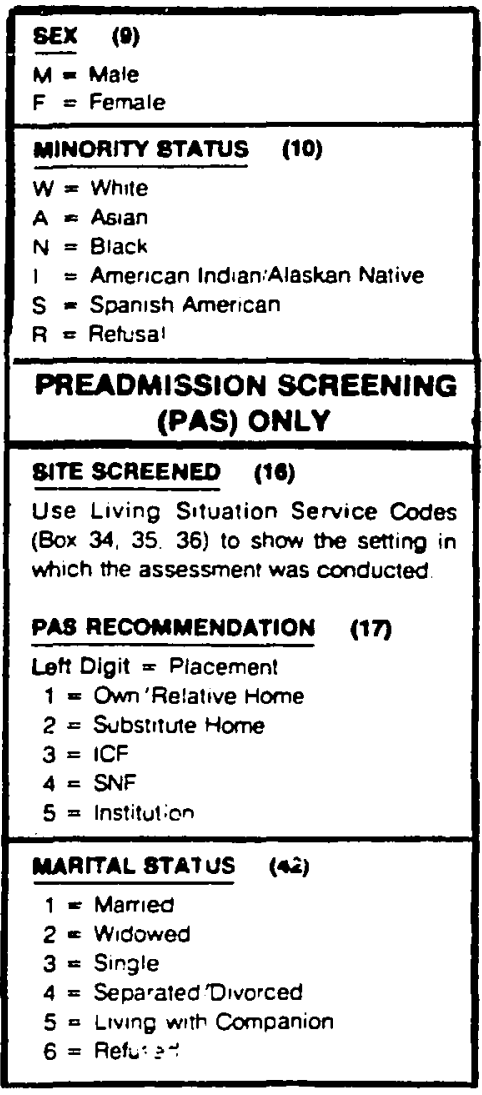

\begin{tabular}{|c|}
\hline $\begin{array}{l}\text { UVING SITUATION SERVICE } \\
\text { CODES }(34,35,36)\end{array}$ \\
\hline 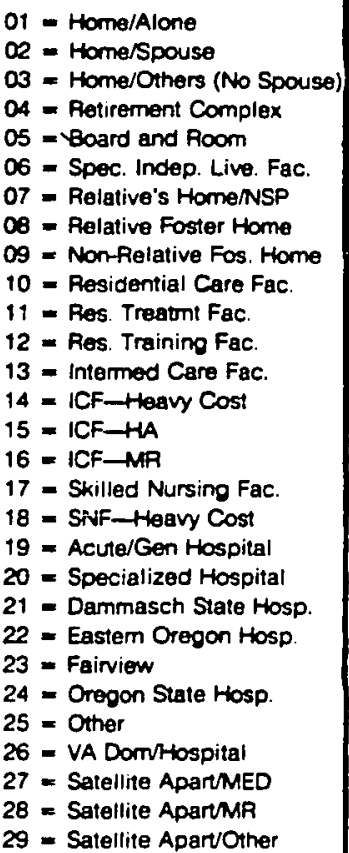 \\
\hline
\end{tabular}

\begin{tabular}{|l|}
\hline $\begin{array}{c}\text { PLACEMENT INFORMATION } \\
\text { BuSE-PIB (50) }\end{array}$ \\
\hline (01) Self Identification \\
(02) Vision \\
(03) Hearing \\
(04) Travel \\
(05) Mobility w/o Aids \\
(06) Mobility with Aids \\
(07) Housekteping \\
(08) Porsonal Shopping \\
(09) Shop/Prepare Food \\
(10) Nutritional Habits \\
(11) Eating \\
(12) Social Activities \\
(13) Pers. Independence \\
(14) Emotional Control \\
(15) Telephone \\
(16) Orientation-Living \\
Alone \\
(17) Natural Suppont \\
(18) Porsonal Activities \\
(19) Money Management \\
(20) Health Condition \\
(21) Managing Medication \\
(22) GroomingDressing \\
(23) Bathing/Showering \\
(24) Using Toilet \\
(25) Continence \\
\end{tabular}

Figure 8. Selected service activity codes for
DHR-280 Service Activity Report 
TABLE XXI

RELATIONSHIP BETWEEN LEVELS OF FUNCTIONING (ACROSS) AND PROBABIIITY THAT NURSING HOME PLACEMENT IS NECESSARY (SHADING)

\begin{tabular}{|c|c|c|}
\hline $\begin{array}{l}\text { Personal and Soc1al Functions Relevant } \\
\text { to Long-Tern Care Placement Dec1sions }\end{array}$ & $\begin{array}{l}\text { Levels of } \\
\text { Punctioning }\end{array}$ & $\begin{array}{l}\text { Key to Levels } \\
\text { of Functioning }\end{array}$ \\
\hline & 1234 & \\
\hline 1. Can 1dentify self (or use I.D.) & & \Level 1: Functions \\
\hline 2. Vision (with glasses, if used) & & \\
\hline 3. Heartng (with hearing ald, if used) & & have some problems with \\
\hline 4. Travel (by public or private means) & & \\
\hline 5. Moblilty (without walker, cane, wheelchair) & & $\begin{array}{l}\text { Level 3: Midd but con- } \\
\text { inuing problems with the }\end{array}$ \\
\hline $\begin{array}{l}\text { 6. Mobllity, with aids (walker, cane, wheelchair, } \\
\text { does not respond if alds not needed) }\end{array}$ & & \#Level 4: Moderate prob- \\
\hline 7. Housekeeping (vacuums, dusts, dishes, chores) & & \\
\hline $\begin{array}{l}\text { 8. Personal shopping (newspapers, tollet articles, } \\
\text { snack foods) }\end{array}$ & & with the function \\
\hline 9. Shopping for and prepar1ng food & & \\
\hline 10. Nutritional habits (Eood selection, balance, amount) & : & \\
\hline 11. Eating (with special equipment if regularly used) & & \\
\hline $\begin{array}{l}\text { 12. Social activities (family, neighbors, church/ } \\
\text { fraternal/occupational/social/political groups) }\end{array}$ & & Key to Shading \\
\hline $\begin{array}{l}\text { 13. Personal independence (acceptance of changes, } \\
\text { handling crises and decisions positively }\end{array}$ & & $\begin{array}{l}\text { (probability that } \\
\text { nursing home placement }\end{array}$ \\
\hline $\begin{array}{l}\text { 14. Emotional control (personal problems, disturbances, } \\
\text { emotlonal states do not restrict living arrangements } \\
\text { and relationships with others; not dangerous to } \\
\text { self oz others) }\end{array}$ & & Not likely \\
\hline 15. Use of telephone (making and tak1ng cal1s) & & Low probability \\
\hline $\begin{array}{l}\text { 16. Orientation for living alone (can explain detalis } \\
\text { of self-case needed, reasons, duration; and is } \\
\text { responsible for following regime without } \\
\text { resinding) }\end{array}$ & & Zo Moderate probability \\
\hline $\begin{array}{l}\text { 17. Natural support (regular avallability of rellable } \\
\text { help from family, friende, nelghbors or volunteers) }\end{array}$ & & \\
\hline $\begin{array}{l}\text { 18. Personal activities (spends substantial part of } \\
\text { each day on reading, hobbies, crafts, occupations, } \\
\text { etc. not fncluding passive entertainment }\end{array}$ & & probab111ty \\
\hline
\end{tabular}


TABLE XXI continued

19. Money management (writing checks, paying $b 1218$, keeping expenses within income)

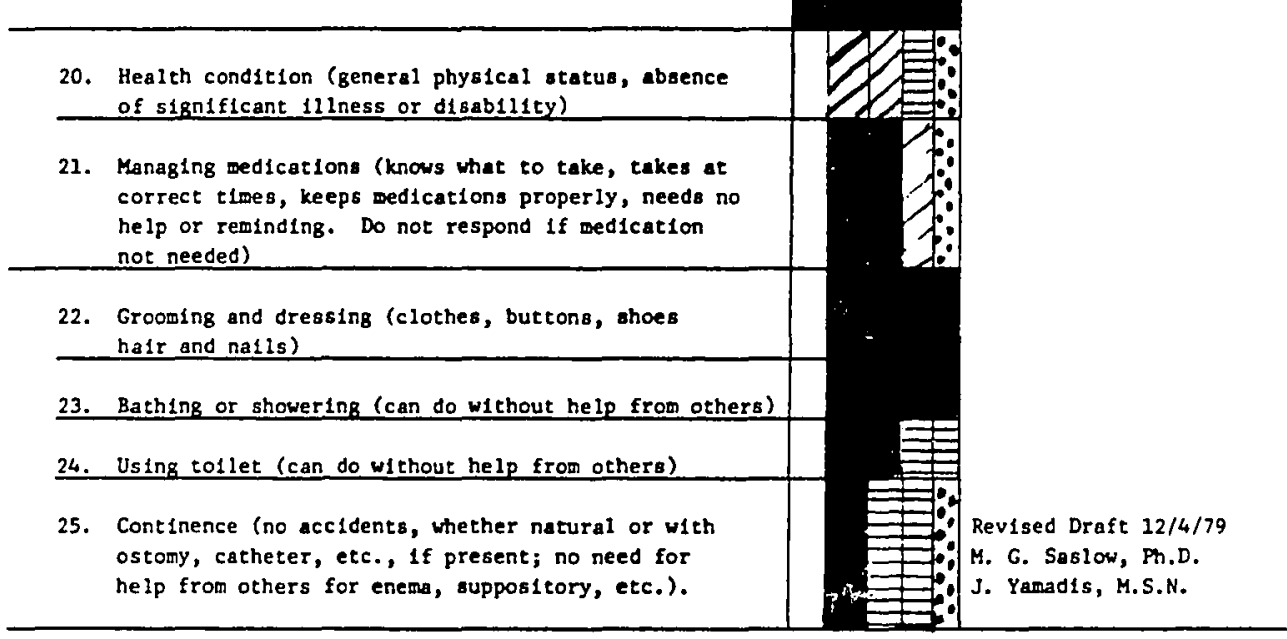


1. "Key to Levels of Functioning" refers to the five levels on each PIB scale. The key gives the general meaning of each level. For accurate results, you should refer to the exact wording of each PIB scale.

2. "Key to Shading" refers to the probabllity that nursing home placement is necessary. The key gives only a general idea of what each degree of shading means. For accurate results, you should refer to the following discussion.

A. "Not likely" means that, with 1ittle or no help, the person can function in a normal home environment, if all PIB scales come out in the "not likely" shading.

B. "Low probability" means that the person needs some non-medical help from family, filends, or from community services in order to stay at home, if the person's "worst" PIB scale or scales come out in the "low probability" shading.

C. "Moderate probability" means that the person needs part-time or full time medical help in order to stay at home, if the person's "worst" PIB scale or scales come out in the "moderate probability" shading, unless unusual help from family, friends, or from community services is avallable.

D. "High probability" means that, if the person's "worst" PIB scale or scales comes out in the "high probability" shading, the person needs to be in a nursing home unless a substitute home (foster home, home for aged) alternative is available, or if unusual help from family, friends, or community is available (as indicated by levels 1 or 2 on scale $\left.\right|_{17}$ ) or if the individual has strong desire and capacity for living alone (levels

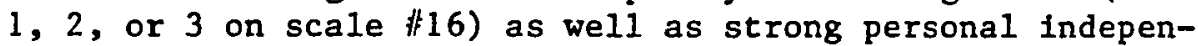
dence (levels 1 or 2 on scale \#13).

E. "Very high probability" means that, if the person's "worst" PIB scale or scales come out in the "very high probability" shading, the person must be in a nursing home (intermediate care facility or skilled nursing facility, depending on need for round the clock registered nurse attention), a community hospital, or a specialty hospital or institution, unless very unusual and reliable help from family, friends, or community is available.

Figure 9. An explanation of the key to the levels of functioning which appears in Table XXI. 
Oregon Department of thuman Resources Senfor Services Division PLACEMENT INFORMATION BASE (PIB) 4/82 Person Code: Observer Code: Date: INSTRUCTIONS: For each scale, choose and write in the anower apace that one level uhich, from your observation and knowledge of the person, and/or conversation with him or her, best describes how the person is usually functioning these days. When you are not oure wich of several levels to choose, because the wordings of two or more levels seem to fit the person's usual function about equally vell, or because the person regularly varies among levels, select the lower numbered level. If you cannot moke a reasonable choice after attempting to get the inforation, write zero $(0)$ in the answer apace.

Cluster one: comonication

1. ( ) SELF-IDENTIFTCATION

1. Individual states name, address, phone number, time, and place accurately and appropriately, and comounicates information fluently and with detall appropriate to the situation.

2. States, name, address, phone number, accurately and appropriately, but without adjustment to the situation, or uses I.D. for these purposes.

3. Identifles self only sometimes or only partly.

4. Hardly ever Identifies self, even with 1.D., or does so Inaccurately at least some of the tine.

5. Does not state name/address/phone number information accurately and appropriately, does not use I.D. for these purposes.

2. () VISION (with glasses, if used--if the person is confused, make the best estimate you (an)

1. Norpal or Dinimal loss, without glasses, or with old prescription. Sees adequately in most situations; can see newsprint, public notices, television, wedication labels.

2. Normal or ninimal loss, with glasses prescribed within the last year.

3. Hoderate loss, can read large print, see simple pictures, and see obstacles, but not detalls, usually can count fingers at arw' a length.

4. Severe loss, cannot find way around without feeling or using cane, cannot locate objects without hear1ng or touch Ing them; can tell 11ght from dark.

5. Total blindness. No vision at all. Cannot tell 11 ght frow dark.

3. ( ) HEARING (with hearing ald, if used--if the person 1s confused, aske the best estimate you can.

1. Normal or minimal loss, without hearing ald or with old prescription. Hears adequately in most situations, can carry on an unrestricted conversation or otherwise responds approprlately to being addressed without epesice ralsing volce or altering normal pace and style of diction in groups as well as one-to-one; TV or radio; addressed from behind; etc.

2. Normal or minimal loss, with hearing ald prescribed or with correction rechecked within the last three years.

3. Moderate loss, hears edequately only in special situations, 1.e., one-to-one, with firw, clear diction, ralsed volume of radio, etc.

4. Severe loss, hears with difficulty even in special situations, 1.e. conversation restricted, many ol sunderstandings, or frequently falls to respond, etc.

5. Total deafness, no hearing at all useful for communication.

Cluster Two: Mobility

4. ( ) TRAVEL (by those weans which are avallable and accessible)

1. Uses private and public transportation properly and appropriately, on own. Can drive safely.

2. Uses public transportation properly and approprlately, with a little help. Cannot or should not drive.

3. Uses public transportation for both short and long trips with a moderate amount of help.

4. Manages short trips with moderate essistance, but totally dependent on others for long or unusual trips.

5. Totally dependent on help from others then any travel 18 necessary.

5. ( ) MOBILITY, WITHOUT AIDS (the extent to wich the Individual gets around alone, without aids; walker, cane, wheelchair).

1. Has no difficulty and takes regular outside walks for exercise.

2. Walks or gets around without difficulty both inside and outside.

3. Walks or gets around easily inalde, can get to various rooms alone, but needs help outside.

5. Does not get around, even in room, without continuous assistance by another person. 
6. ( ) MOBILITY WIIH ADS (the extent to which the Individual gets around alone, using whatever alds (walker, cane, wheelchalr) he/she has).

1. Walks or gets around without difficulty both inside and outside.

2. Walks or gets around essily Inside, can get to various rooms alone, but needs some help.

3. Cets around in an roow, but needs assistance beyond that.

4. Gets around in room, but unes theelchair and needs help to transfer; may or may not need assistance to go further.

5. Does not get around, even in roow, without contlnuous assistance by another peraon.

Cluster three: Household and Food Management

7. ( ) HOUSEREEPINC

1. Takes coeplete care of his/her living spuce and that of others in living altuation.

2. Takes care of h1s/her ow living space, both 11ght and heavy work.

3. Consistently saneges own l1ght houvekeeping, but not heavy work.

4. Does light housekeeping, but inconslatently or inadequately.

5. Does not take care of own living apace.

8. ( ) PERSONAL SHOPPING (gets such 1tens as newspapers, tollet articles, mack foods, with1n physical 110itations and any other restrictions)

1. Does personal shopping regularly and properly without assistance or reminding.

2. Does personal shopping without help, but wust be reminded frow time to time.

3. Does personal shopping without help, but wust always be reminded.

4. Heeds assiatance frow another person to get nose 1tems.

5. Another person geto all items.

9. ( ) SHOPPING FOR AND PREPARING FOOD

1. Does food shopping and preparation of meals.

2. Shops with help; usually prepares seals.

3. Does not shop, but usually prepares meals.

4. Does not shop; prepares meals about half the tide.

5. Does not thop or prepare weals, or needs special diet, does not prepare it.

10. ( ) NUTRITIONAL HABITS

1. Eats three wess a day; dally, eats at least two servings of each of (a) frults, (b) vegetables, (c) whole grain products, (d) Elsh, poultry, or meat, and (e) dalty products.

2. Eats three meals a day; dally, eate at least one serving of each of (a) fruits, (b) vegetables, (c) whole grain products, (d) fiah, poultry, or deat, each day, and (e) dalry products.

3. Eats three meals a day; but ususlly oolts at least one of (a) fruits, (b) vegetables, (c) whole grain products, (d) fish, poultry or weat, each day, and (e) dairy products.

4. Eats two meals a day, but does eat at least one cerving of (a) frults, (b) vegetables, (c) whole grain products, (d) fish, poultry or meat, and (e) dsiry products.

5. Eats oporadically, primarily carbohydrates and soft foods; or doesn't remember to eat, so needs resinding and/or aupervision; or coesn't stop eating without reminding or supervision.

11. () EATINC (with special equipment if regularly used)

1. Feeds self, chews and swallows solld foods without difficulty.

2. Feeds self, chews and swallows solld foods which have been cut or pureed.

3. Necjs assistance with feeding, but chews and awallows solid foods (which way have to be cut or pureed)

4. Needs asalstance with feeding and has difficulty vith chewing or swallowing, even with food cut or pureed. May need to be fed by tube.

5. Must be fed intravenously.

Cluster Four: Soc1al and Emotional

12. () SOCLAL ACTIVITIES

1. Involved regularly in activities with (a) famlly, (b) nelghbors, and (c) church/fraternal/occupational/soclal/political organization(B). Extenofve and satisfying social relationships.

2. Involved regularly in activities with at least one of these three kinds of grcups.

3. Will particlpate in activities with at least one of these three kinds of groups 1 reminded and/or assisted to do so; only sowe of the relationships may be satisfying.

4. Will go to or be present at activities of at least one of these three kinds of groups if reminded and/or assiated to, but needo prompting and encouragement to actually participate; or is responsive when visited by one of only a limited number of people.

5. Not willing to go to activities of any of these kinds of groups, nor to be involved 1 present at them. Is not responsive to visitors, no social relationships. 
13. ( ) PERSOMLL INDEPENDENCE

1. Accepte change: actively adapts, sakes plans, hendles crises vell, is consident.

2. Accepting, but needs sowe help in adapting and aaking plans and decigions.

3. Actively resistive; refuses to make deciolons; consistently negative or hostile.

4. Neutral or passive. Requires regular assurance and/or guidance.

5. Withdrawn, afrald, or insecure; needs near constant eupport.

14. () EHTIONAL CONTROL

1. Personal problems, disturbances, emotional atates do not particularly restrict the individual's type of living arrangement and companions.

2. Personal probleas, disturbances, emotional states reatrict Individual's type of living arrangement and compantons, but things work out $\mathbf{O} . K$. In present set-up.

3. Personal problems, disturbances, emotlonal states restrict the type of living arrangement and companions, and things are not vorking out 0.K. In preaent set-up.

4. Person is dangerous or violently abusive to self or others, but is controllable with medications.

5. Person is dangerous or violently abusive to self or others, not controllable with medications, requires physical restrainto.

15. () TELEPHONE

1. Makes and takes calls appropriately, fluently, with normal frequency.

2. Makes and takes calls appropriately, but infrequently.

3. Makes few calls, but takes calls and handles most of them appropriately.

4. Makes few or no calls, but takes some calls and handles at least sode appropriately.

5. Ne1ther makes nor takes calls appropriately.

16. ( ) ORIENTAIION FOR LIVING ALONE (Oriented means: explains detalls of care, if any;

reasons for 1t; how long $1 t$ will be needed. Responsible deans actually does the tasks he or she 1s supposed to do es part of the care).

1. Fully orfented and responsible for care of aelf, if needed.

2. Fully oriented but needs to be checked up on once or twice a day.

3. Fully oriented but needs help with activities of cally living.

4. Is sometimes confused, need reminders and/or help for activities of dally living, but does not physicality wander of $f$.

5. Is sometimes or frequently confused, needs reminders andor help for activities of dally living, and physically vanders off regularly.

17. ( ) Natural support (friends/family/neighbors/volunteers)

1. One or more persons avallable to give care indefinitely.

2. One or more persons avaliable to give care regularly for several months.

3. One or more persons available to give care from time to tide for several wonths.

4. Several persons avallable to help out, one at. time or in rotation, fron time to time, but there is no one to take overall responsibility for helping on a regular basis.

5. No person avellable to help except perhaps under extreme circumstances.

18. (, PERSONAL ACIIVIIIIES

t. Spends most of the tide each day in a variety of personal activitles, including reading, hobbles, crafts, occupations (not including pessive entertalnment).

2. Spends most of the tibe each day in a limited set of personal activities (other than passive entertalnment).

3. Spends mornings, afternoons, or evenings each day in personal activities (other than passive entertainment).

4. Spends 1 to 2 hours a day in personal activitles (other than passive entertainment).

5. Spends less than an hour a day in personal activities (other than passive entertainment).

Cluster Five: Finances

19. ( ) MONEY MANAGEMENT

1. Writes checks, pays bills without any help. Keeps expenses within incowe.

2. Writes checks, pays b111s without any help, but needs some advice or help each month to balance checkbook or perform almilar tasks.

3. Manages day-to-day buying, but needs help with writing checks and/or paylng bills.

4. Can handle purchasing of sode personal items, but cannot handle all day-to-day buying.

5. Completely unable to handie money. 
Cluster Six: Health

20. ( ) HEALTH CONDITION

1. Excellent or good physical hesith; no significant llinesses or disablities; only routine health care such a annual checkups.

2. Mild healch problems needing short-ters attention or corrective wesaures (wounds requiring dressing changes, bed sores, etc.).

3. Has one or more moderate medical problems which may be painful or thich require medical attention periodically (gets dizzy on movesent, etc.).

4. Highly 1mpalred, confined to bed, requires full tibe medical assistance or nursing care to maintain certain vital bodily functions (for example, turning for pressure relief and repositioning because of stroke, paralysis, reakness, or other reason).

5. Unconsclous, unable to respond, needs total care for all bodlly functions.

21. ( ) MaNaging medicarions (Consider the person's currently prescribed oral, topical, and injectable wedications. Select the one category which fits best.)

1. Needs no medications, or if needs then, manages medications alone. Knows what to take, takes them at correct times, keeps them properly.

2. Medications must be laid out for him/her each veek, but no problems taking correct ones at correct times.

3. Wust be given direct dally reminders, but follows then.

4. Does not manage own medications, needs to have sode medication administered to him/her by someone else regulariy but less than dally.

5. Does not manage am wedications, needs to take some medication administered to him/her by someone else regularly, and dally or wore frequently.

Cluster Seven: Self-Care

22. ( ) GROOMING AND DRESSING

1. Grooms and dresses self without ony help. Combs hair, does nails, manages buttons, ties shoes, etc.

2. Grooms and oresses self without any help, but wast be reminded to do so on some days.

3. Grooms and dresses self without any help, but must always be reminded to.

4. Needs help from another person to do some parts of grooming, or sowe parts of dressing, buch as managing buttons or tying shoes; way or may not need reminding.

5. Needs help from another person to do all of grooming, or all of dressing, or both, and or may not need reminding.

23. ( ) BATHINC OR SHOWERING

1. Bathes or showers self regularly, without resinders and without help for any task including tuming the water on and off.

2. Bathes or showers self without any help, but must be reminded at least some of the time.

3. Bathes or showers self, but arst have help for turning the water on and off.

4. Bathes or showers self, but aust have help for nore than cuming the water on and of $f$.

5. Does not do any part of bathing or showering, reguires another person to do everything.

24. ( ) USING TOILET

1. Gets to and from tollet, adjusts clothes, cleans self, etc., without help.

2. Needs help getting to tollet, but needs no other help.

3. Gets to tollet, but needs some help once there.

4. Gets to tollet, but needs total help.

5. Does not use tollet. Nelther gets there, nor handles function without at lesst some help.

25. 1 ) CONIINENCE (To what extent are the individual's natural excretory functions under personal control, day and night, whether naturally or with ostour, catheter, etc.; ald weans having another person give an enera, Insert a suppository, clean an appliance, etc.).

1. No accidents, or Infrequent accidents; no problems, needs no help or ald.

2. Accidents once or twice a week, or needs help or ald once or twice a veek.

3. Accidents three to five times a veek, or needs help or ald three to five tlwes a week.

4. Needs astistance regularly (dally or more frequently) with specifle parts of activity.

5. Needs moderate to great salstance. Soweone must be present every tioe to assist with all, or nearly all, parts of the activity. 
APPENDIX C

NORMATIVE DATA ON PIB ITEMS AND SCALES 

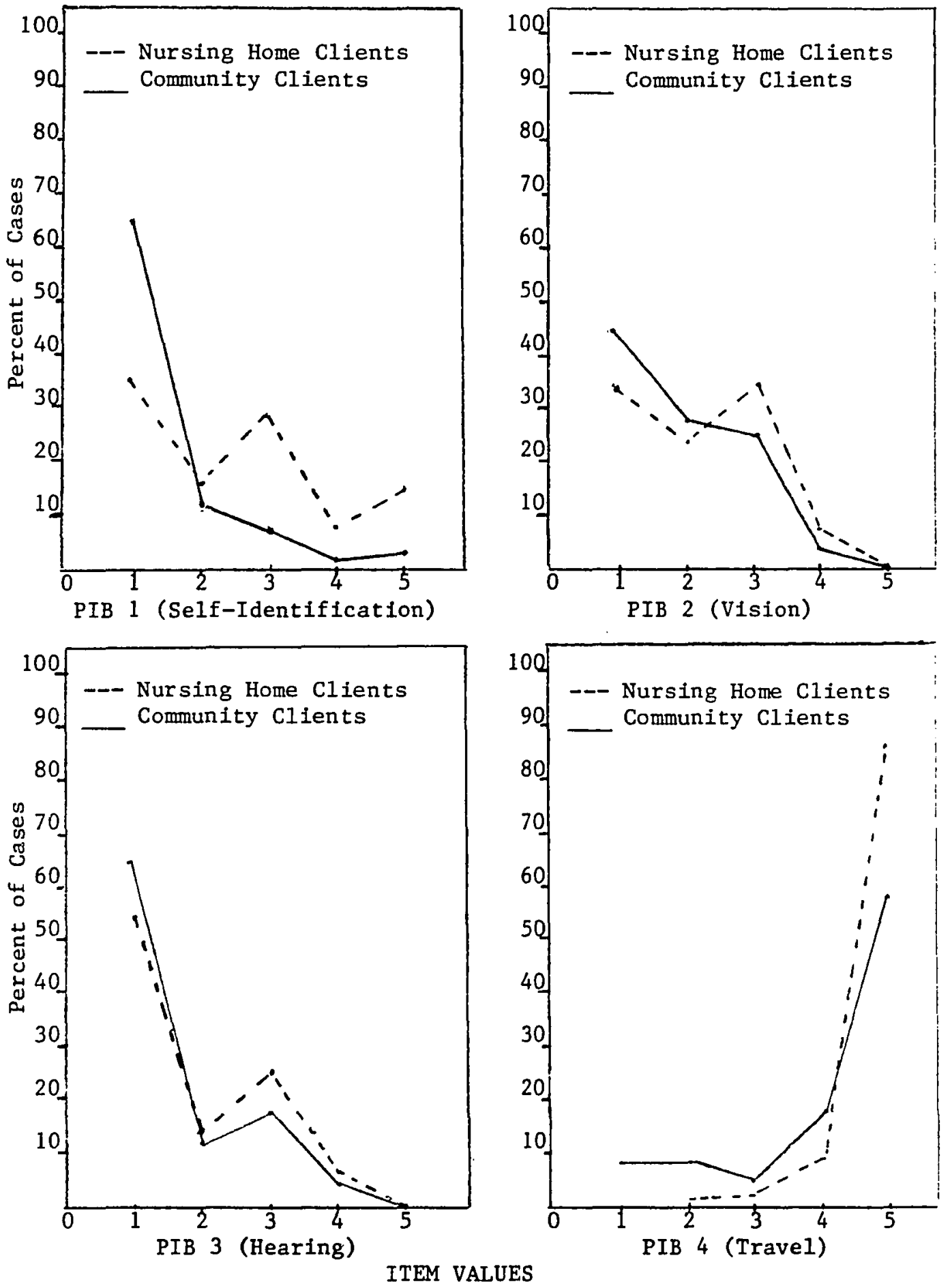

Figure 11. Relative fiequency polygons comparing PIB item scores of elderly nursing home clients with PIB item scores of elderly community clients. With the exception of PIB 11, all scores are significantly different at the .001 level. 

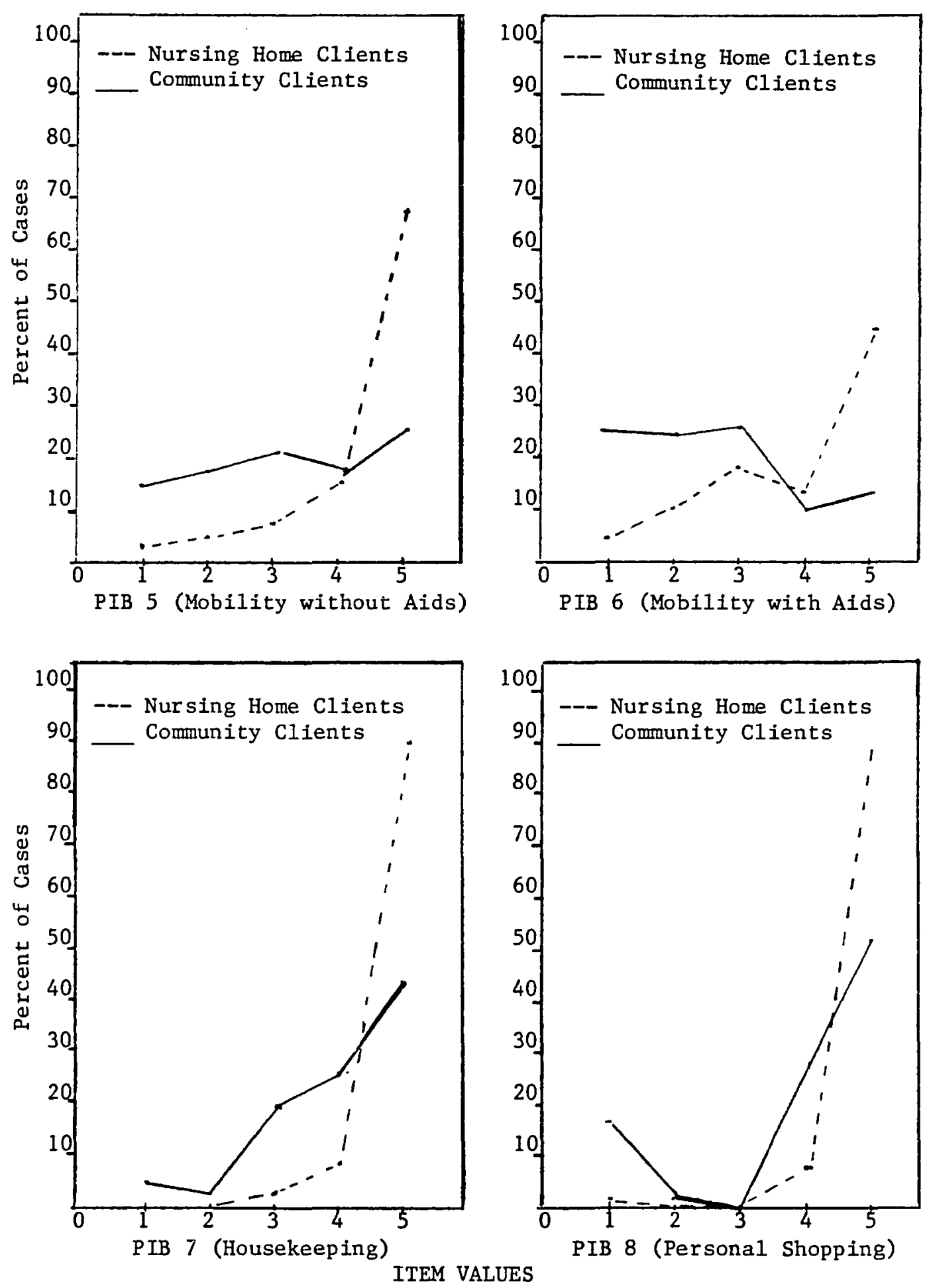

Figure 11 continued 

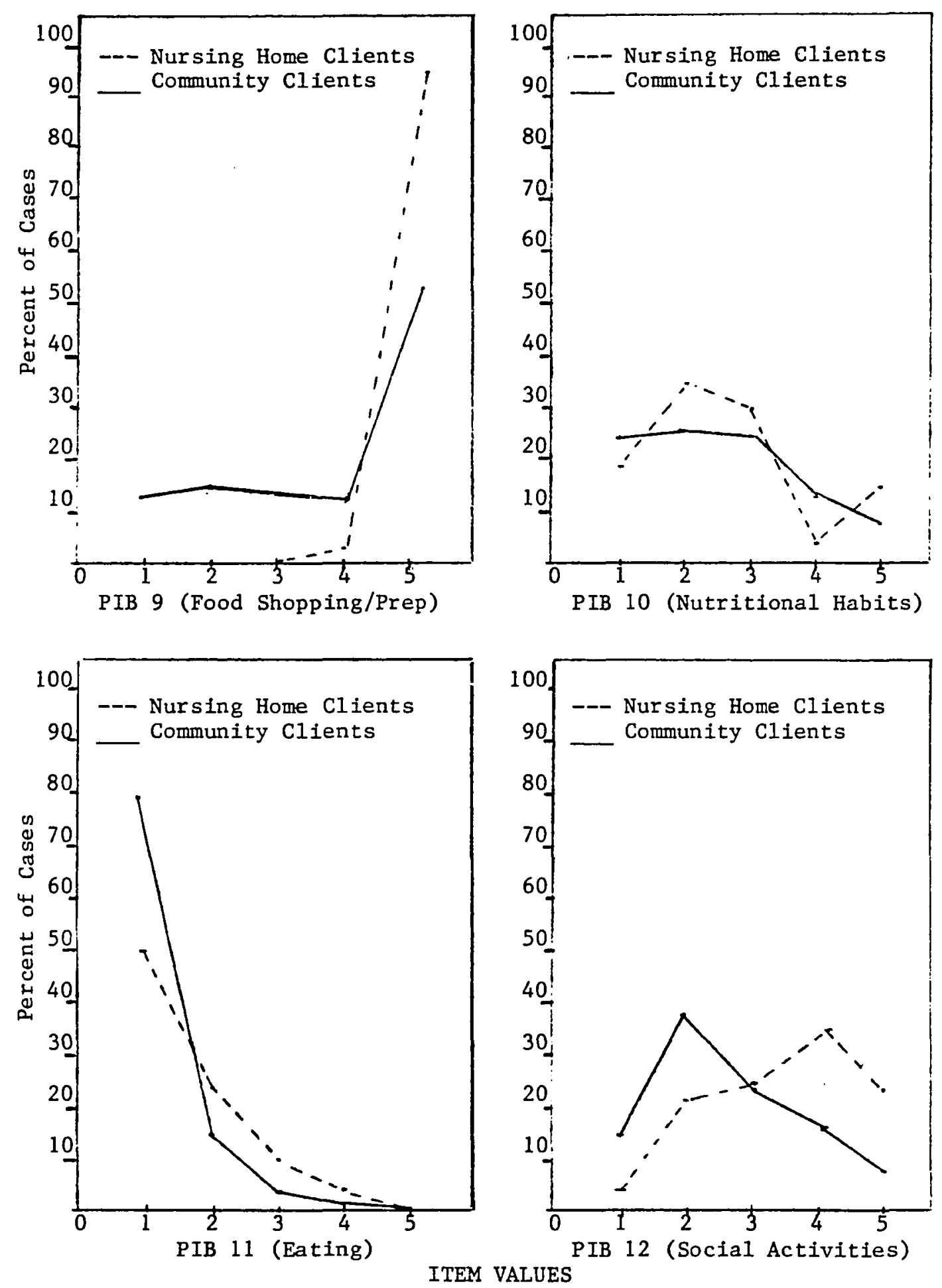

Figure 11 continued 

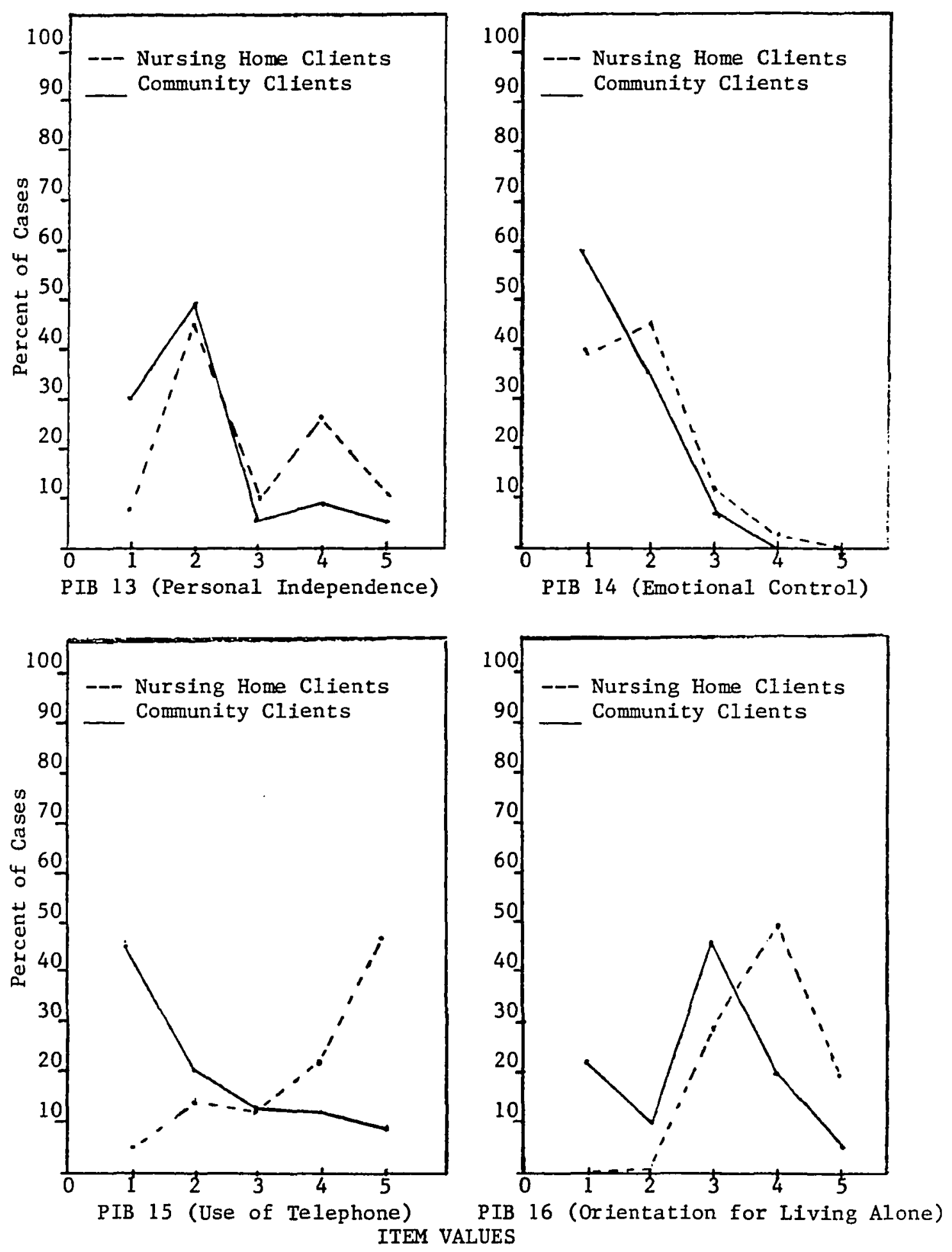

Figure 11 continued 

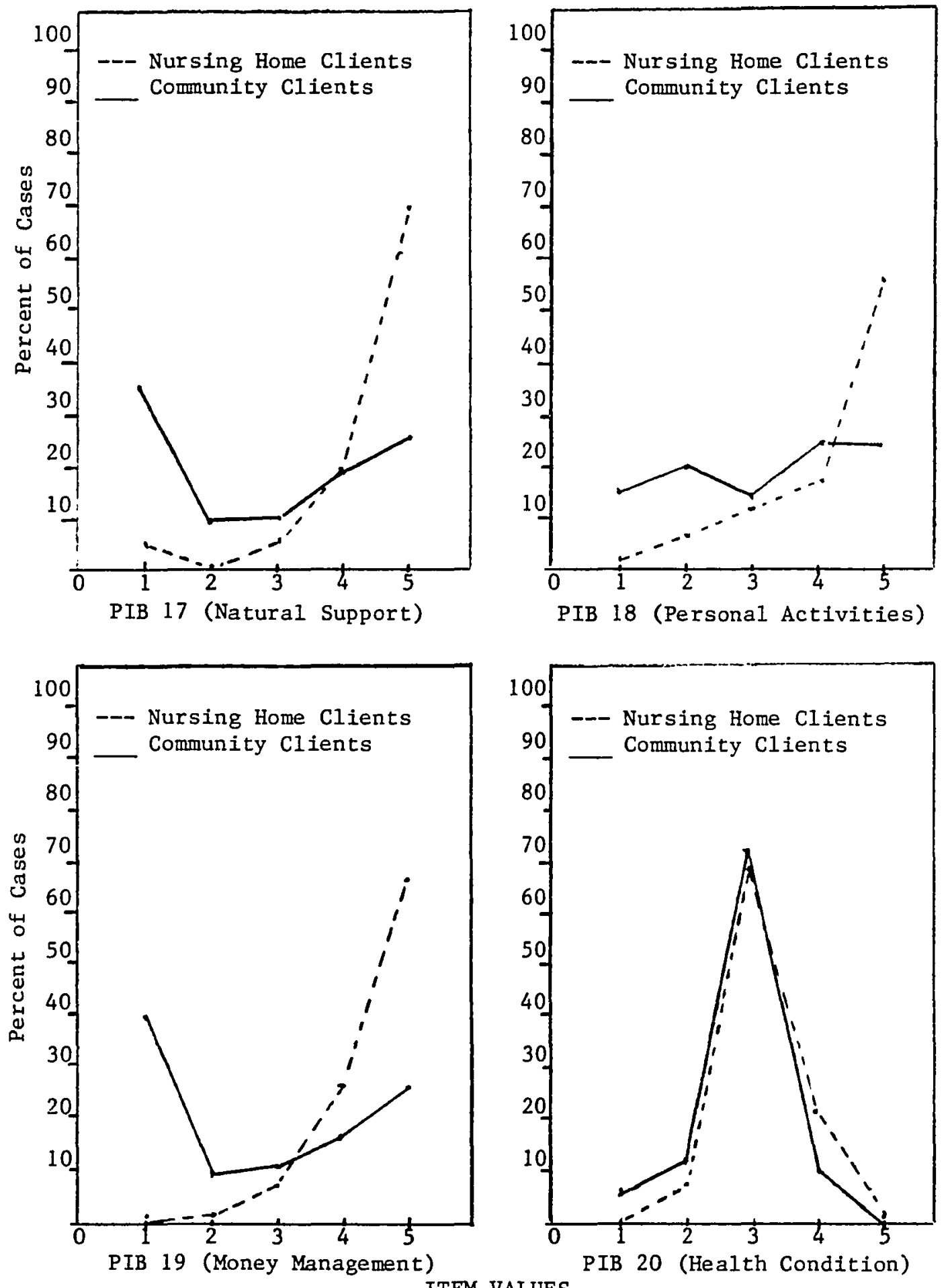

ITEM VALUES

Figure 11 continued 

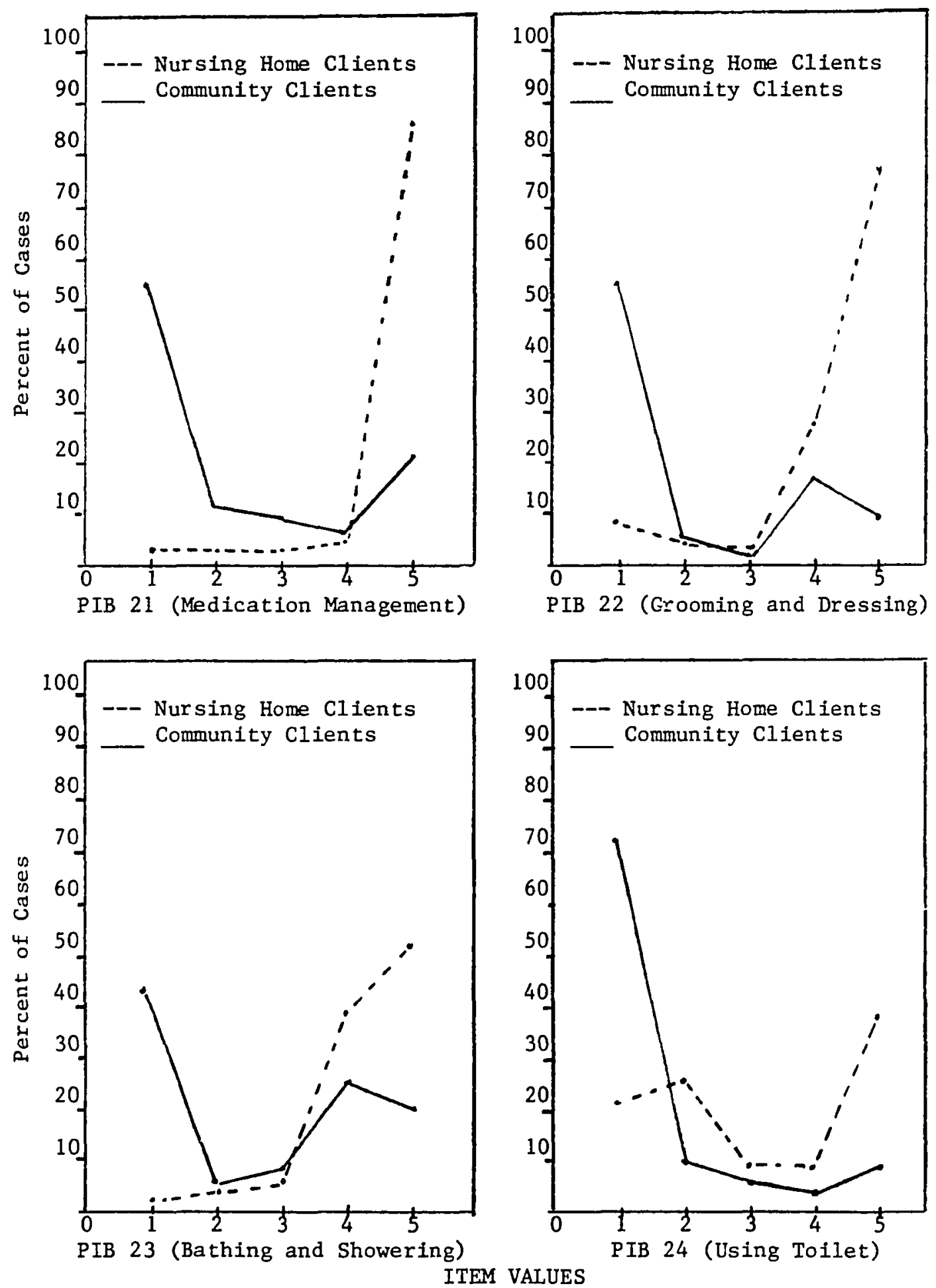

Figure 11 continued 


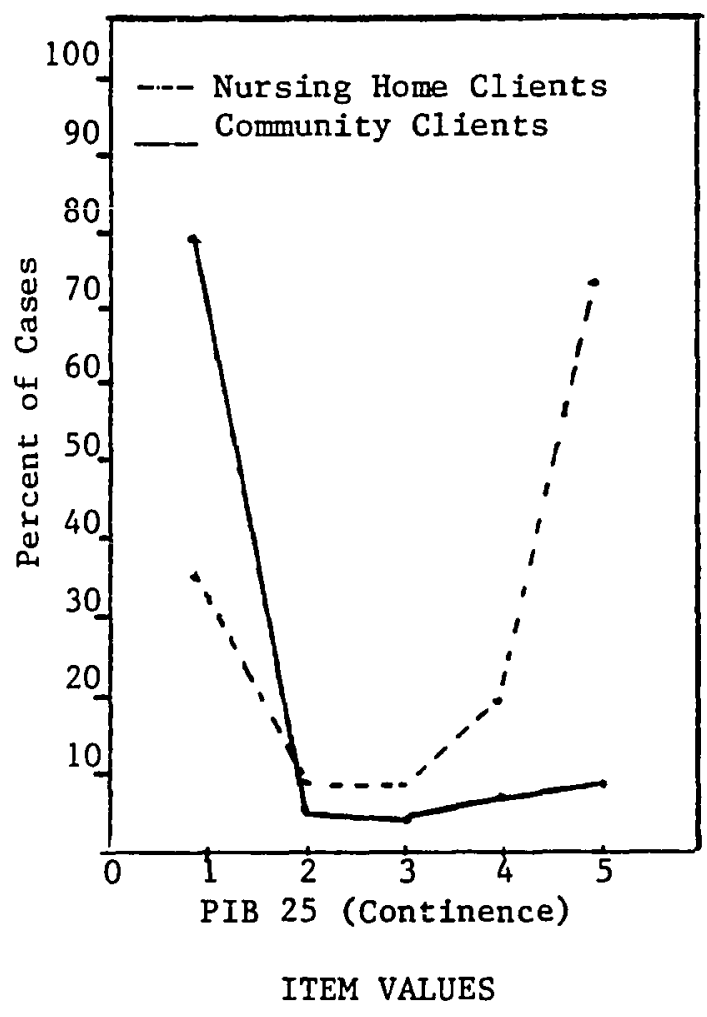

Figure 11 continued 

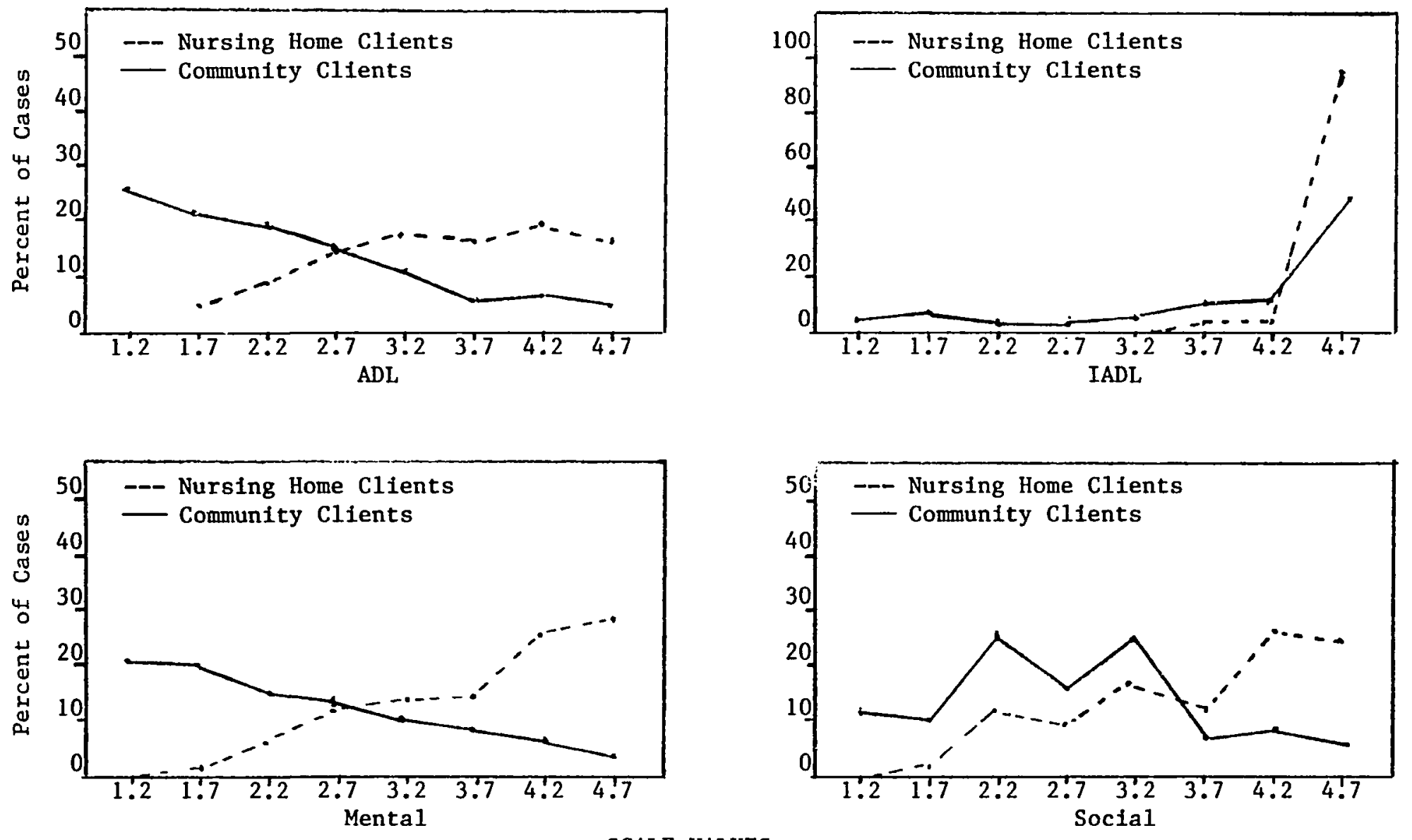

Figure 12. Relative frequency polygons comparirg PIB scale scores of elderly nursing home clients with PIB scale scores of elderly community residents. Based on ANOVA, all are significantly different at the .00 level. 

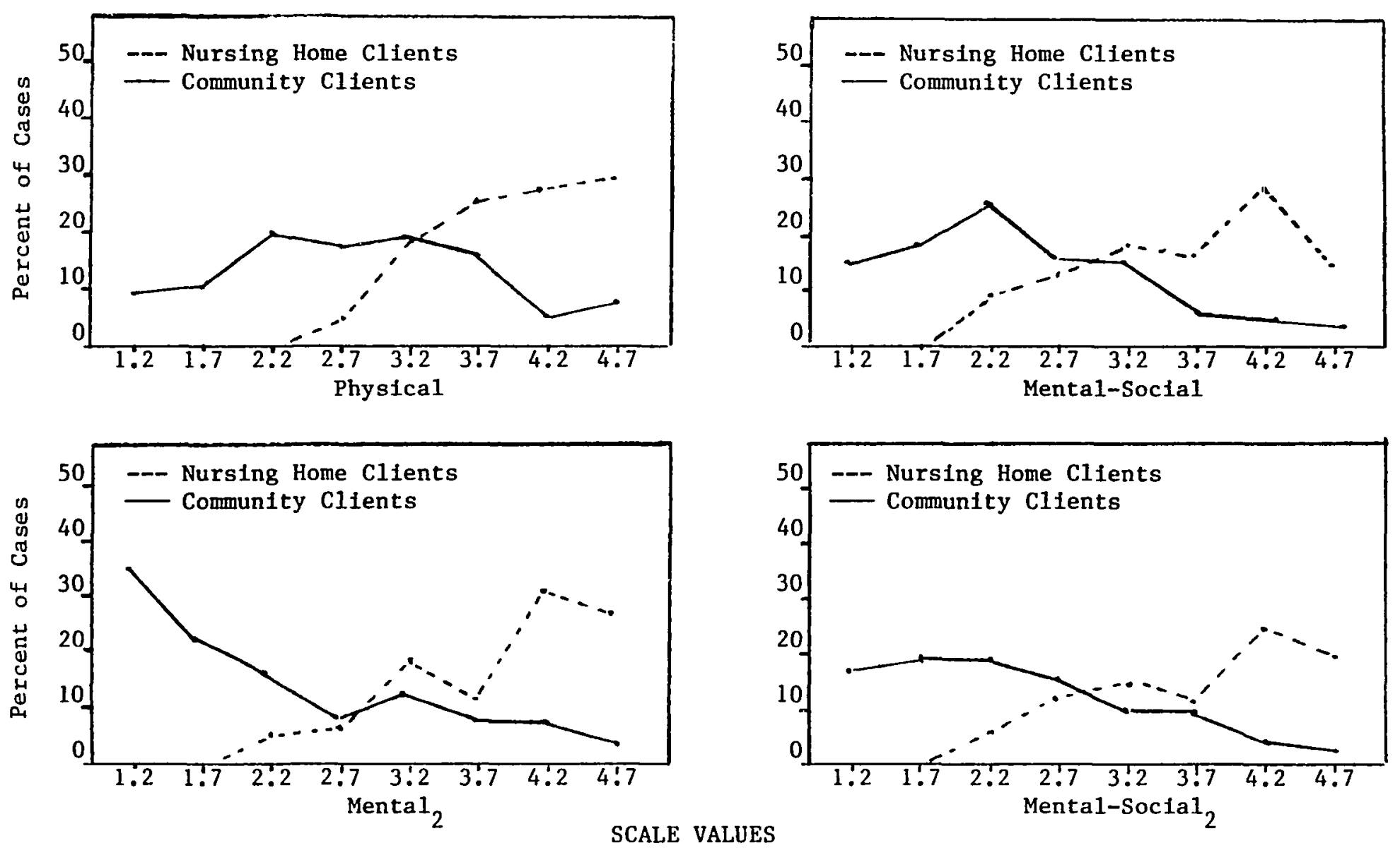

Figure 12 continued 


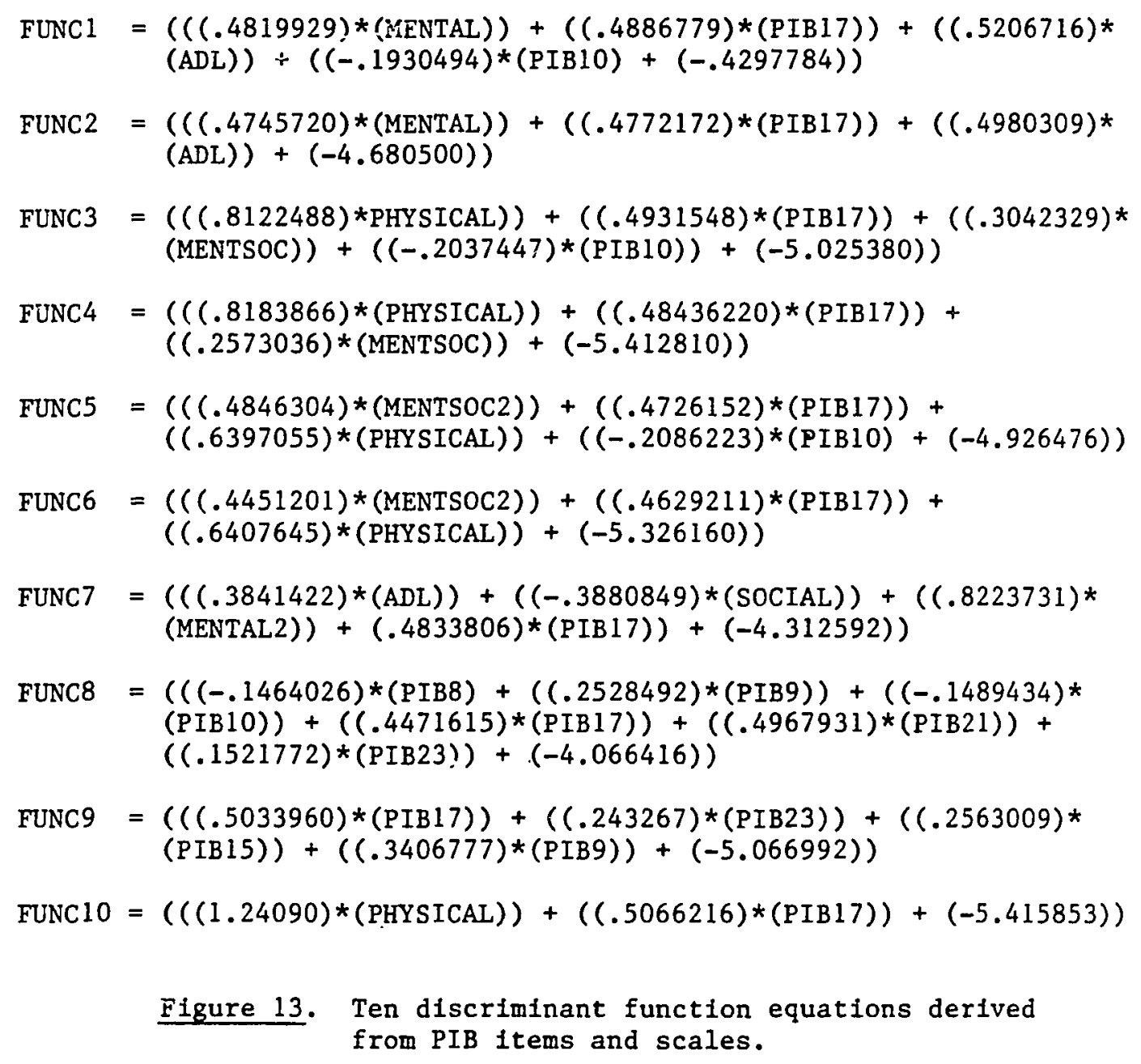


--A community clients validation group

-- nursing home clients validation group

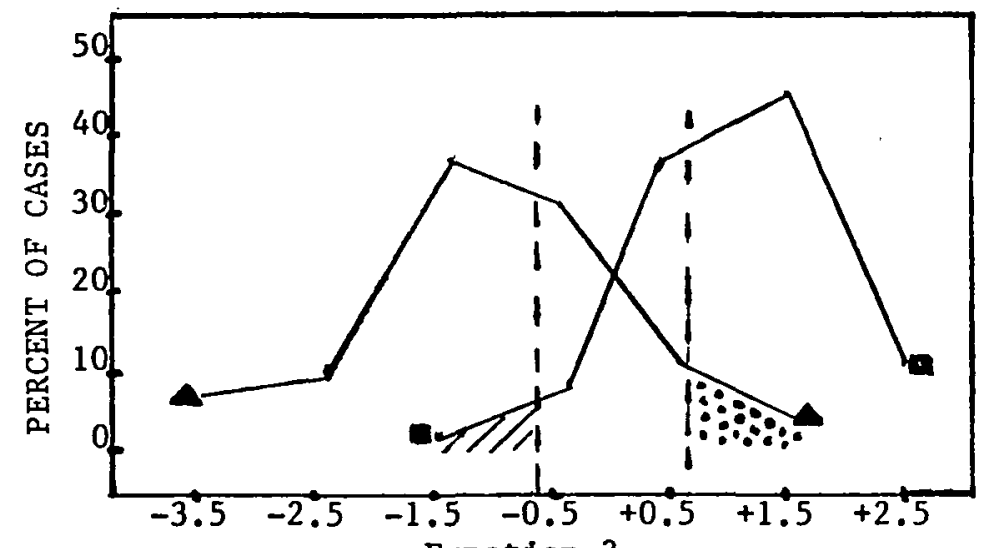

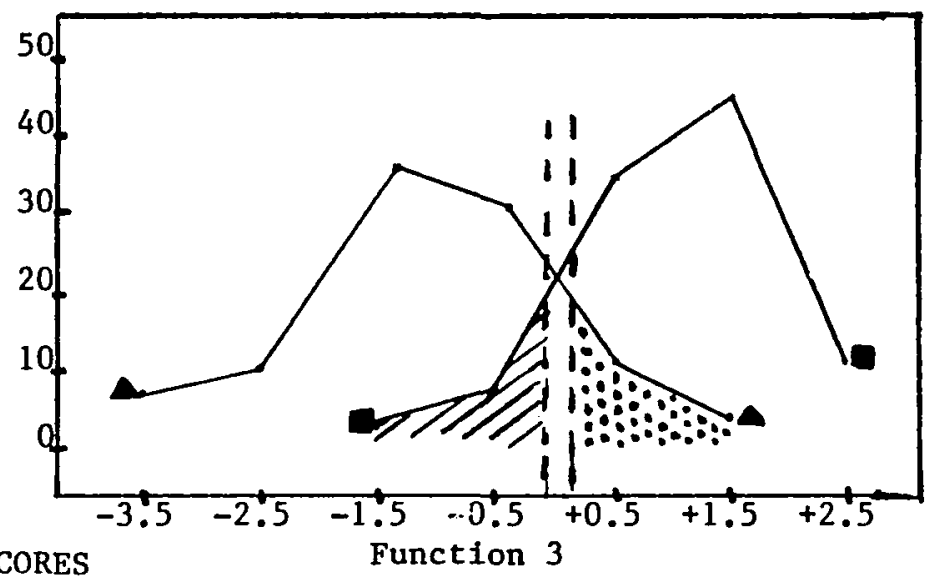

Figure 14. Relative frequency polygons illustrating the relationship of two sets of thresholds to levels of predictive accuracy.

NOTE: The set of thresholds on the left allows 5 percent of both nursing home and community clients to be misplaced. The set of thresholds on the right allows 10 percent of both nursing home and community clients to be misplaced. 